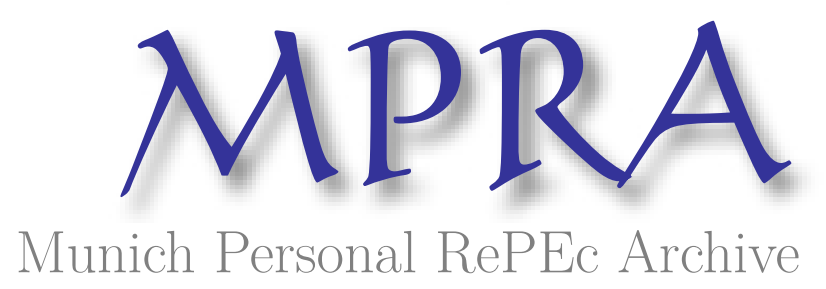

Got Hurt for What You Paid? Revisiting Government Subsidy in the U.S. Mortgage Market

Zhao, Yunhui

International Monetary Fund

22 December 2016

Online at https://mpra.ub.uni-muenchen.de/81083/

MPRA Paper No. 81083, posted 06 Sep 2017 15:34 UTC 


\title{
Got Hurt for What You Paid? Revisiting Government Subsidy in the U.S. Mortgage Market
}

\author{
Yunhui Zhao ${ }^{a *}$ \\ ${ }^{a}$ International Monetary Fund (IMF), Monetary and Capital Markets Department, F. S. Division, \\ 700 19th Street NW, Washington, DC 20431, USA
}

August 1, 2017

\begin{abstract}
I evaluate the subsidized default insurance policy (implemented through the guarantee for Government-Sponsored Enterprises, GSEs) in the U.S. mortgage market both empirically and theoretically. Empirically, I find that the subsidy has raised mortgage interest rates for all loans strictly eligible for the subsidy (conforming loans), which is contrary to conventional wisdom. I do so by applying regression discontinuity designs and using the exogenous variation in mortgage rates generated by a mandate of U.S. Congress. My empirical strategy circumvents the endogeneity problem in conventional studies. Then I set up a screening model with asymmetric information, which explains my empirical results. Moreover, the model implies that the subsidy has hurt borrowers it was intended to help, even without considering the higher tax burden imposed on borrowers to finance the subsidy. The observed positive jumbo-conforming spread can also be explained by the model through incentive compatibility constraints associated with asymmetric information. My paper cautions regulators against interpreting the observed jumbo-conforming spread as an indication that the subsidy necessarily decreases mortgage rates and benefits conforming borrowers. Moreover, the paper shows that the subsidy raises household leverage, increases mortgage default rate, and ultimately undermines financial stability, calling for deeper housing finance reforms in the U.S. beyond the Dodd-Frank Act.
\end{abstract}

${ }^{*}$ Corresponding author. Email: yzhao@imf.org. The paper is based on Chapter 1 of my PhD dissertation at New York University in May 2016. I am deeply indebted to my dissertation committee members Viral Acharya, Hunt Allcott, Tim Christensen, Kris Gerardi, William Greene, and Ennio Stachetti. I am also extremely grateful for the helpful discussions with Deepal Basak, Alessandro Bonatti, Yeon-Koo Che, Eduardo Davila, Joyee Deb, Anthony DeFusco, Kfir Eliaz, Eduardo Faingold, Chris Flinn, Scott Frame, Dan Greenwald, Joseph Gyourko, Martin Hackmann, Thomas Holmes, Przemek Jeziorski, Anastasios Karantounias, Sam Kruger, Alessandro Lizzeri, Federico Mandelman, Niko Matouschek, James Morsink, Alex Murray, Isabelle Perrigne, Paul Scott, Bowen Shi, Bruno Strulovici, Miguel Urquiola, Stijn Van Nieuwerburgh, Quang Vuong, Lawrence White, Tao Zha, and Jidong Zhou. All remaining errors are my own. The views expressed here are those of the author and do not necessarily represent the views of the IMF. This research did not receive any specific grant from funding agencies in the public, commercial, or not-for-profit sectors. 


\section{Contents}

1 Introduction $\quad 3$

2 Empirical evidence $\quad 12$

2.1 Data and summary statistics . . . . . . . . . . . . . . . . . . . 12

2.2 Empirical results from RD designs . . . . . . . . . . . . . . . . . . . . . . . . . . . . . . . . . . . . . . 15

2.3 Validity testings of the RD designs . . . . . . . . . . . . . . . . . . . . 18

2.4 Robustness check . . . . . . . . . . . . . . . . . . . . . . . 19

2.5 Auxiliary evidence on mortgage default . . . . . . . . . . . . . . . . . 21

3 Benchmark model 23

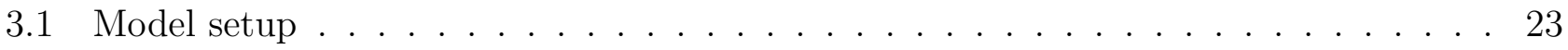

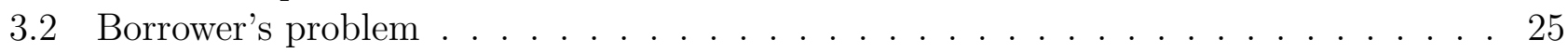

3.2.1 Borrower's problem: period $1 \ldots \ldots \ldots \ldots$

3.2.2 Borrower's problem: period $0 \ldots \ldots \ldots \ldots$

3.3 Bank's problem without subsidy . . . . . . . . . . . . . . . . . 27

3.4 Characterization of the optimal contracts . . . . . . . . . . . . . . . . . . . . 28

3.4.1 Single-Crossing Property (SCP) . . . . . . . . . . . . . . . 28

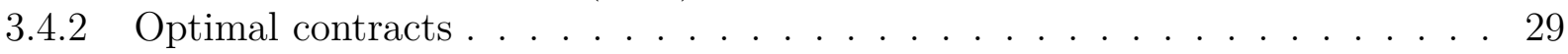

3.4.3 Properties of the optimal contracts . . . . . . . . . . . . . 31

4 Model with subsidy 33

4.1 Setup and solution procedure for optimal contracts . . . . . . . . . . . . . 33

4.2 Positive analysis of subsidy for the strictly conforming group . . . . . . . . . . . . 35

4.3 Normative analysis of subsidy for the strictly conforming group . . . . . . . . . . 37

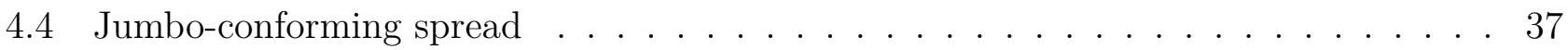

4.5 Effects of subsidy on interest rate: summary . . . . . . . . . . . . . . . 38

$\begin{array}{llr}5 & \text { Conclusion } & 40\end{array}$ 


\section{Introduction}

It is widely believed that the subsidy through Government-Sponsored Enterprises' (GSEs) mortgage default insurance has decreased mortgage interest rates and benefited homebuyers in the U.S. The evidence frequently cited to support this conventional wisdom is the observed "jumboconforming spread:" mortgage loans which are just below the specified loan size limit and eligible for the subsidy (conforming loans) have a discontinuously lower interest rate than those just above (jumbo loans).

In this paper, I examine two questions surrounding this conventional wisdom. First, does the observed jumbo-conforming spread necessarily imply that the subsidy has decreased the interest rates of conforming loans, as policy makers intended when creating Fannie Mae in 1938? Applying regression discontinuity designs to loan-level data, I find that the opposite result actually holds, and I set up an asymmetric information theoretical model to interpret my empirical result. The model illustrates that my result is driven by the mortgage lender's strategic responses to the subsidy policy, including the lender's moral hazard and rent-extraction motive.

Second, does the subsidy improve the welfare of borrowers who qualify for the subsidy? I show that it does not. To the contrary, my model predicts that the subsidy decreases the welfare of these borrowers, even without taking into account the increased tax burden needed to finance the subsidy or the negative externality imposed by the increased mortgage defaults. The reason is that the subsidy, by providing the lender with a "safety net," induces the lender to behave opportunistically and to more aggressively "exploit" borrowers.

The contribution of my paper is twofold. My main empirical contribution is: I show that the supporting evidence for the conventional wisdom is subject to an endogeneity problem. This is because the subsidy policy is implemented in terms of the loan size, which is endogenously chosen by the borrower and thus is affected by the subsidy policy. Hence, it is possible that the subsidy has increased the interest rates of both the conforming and jumbo loans, but increased the jumbo loans by a larger amount so that we can still observe the jumbo-conforming interest rate spread (see Figure 1). To circumvent this problem, I instead use the exogenous variation in interest rates generated by a mandate issued by U.S. Congress in 1992, which is the "special affordable goal" (SAG) targeted at relatively poor borrowers. Since this mandate is implemented in terms of borrowers' incomes, which are unlikely to be manipulated by borrowers of GSE-insured loans, my empirical strategy provides a relatively clean way to identify the causal effect of the subsidy on interest rates. Using various time-to-default models, I also find that the subsidy raises mortgage default rates, which serves as auxiliary supporting evidence for my model's predictions.

My theoretical contribution is: I highlight the importance of accounting for the lender's strategic responses while designing the mortgage subsidy policy. I do so by introducing a model with asymmetric information to the literature on the GSEs' subsidized default insurance. Indeed, my model shows that due to the mortgage lender's moral hazard and rent extraction motive, the subsidy has raised mortgage interest rates and lowered the welfare of eligible borrowers, both in contrast to policy makers' intention. Moreover, the observed jumbo-conforming spread is simply a result of the incentive compatibility constraints associated with asymmetric information, rather than an indication that the subsidy has lowered the interest rates of conforming loans. A standalone prediction of my model is that the subsidy poses a threat to financial stability. Specifically, the subsidy raises household leverage, makes the household more susceptible to adverse macroeconomic shocks and thus increases the aggregate default rate, ultimately undermining financial stability.

The paper has two policy implications. First, on financial regultion and financial stability, the 


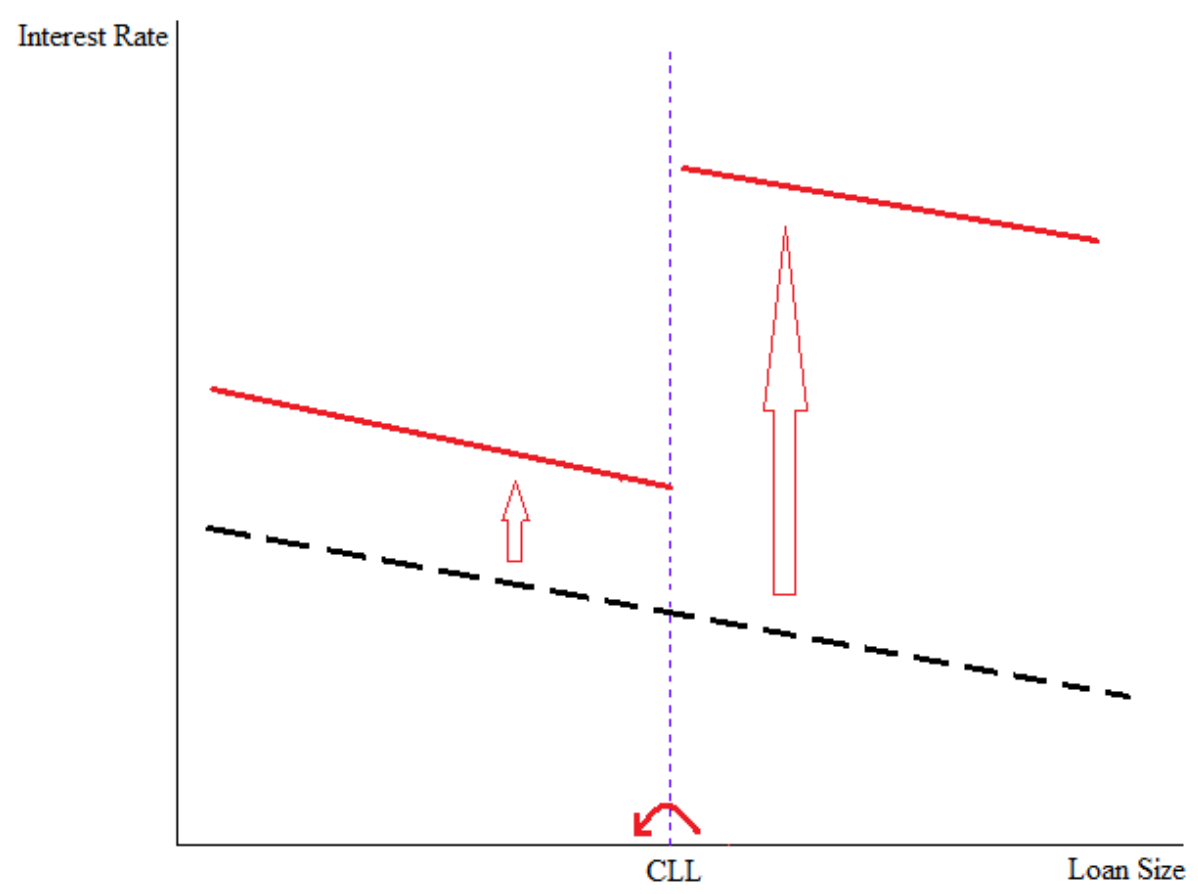

Figure 1: Illustration of Endogeneity

The dotted line represents the counterfactual schedule of the equilibrium interest rate and loan size without the subsidy/intervention. The introduction of the subsidy may have increased the interest rates both to the left and to the right of the subsidy eligibility cutoff (conforming loan limit, CLL), but increased the right by a larger amount. The red arrow on the horizontal axis represents the potential self-selection by borrowers. Note that the slopes of the lines in this figure are for illustration purpose; for more precise representations of the actual equilibrium, see Figure 9.

Editorial comment: Color should be used for any figures in print.

paper cautions against interpreting the observed jumbo-conforming spread as an indication that the subsidy has decreased interest rates, benefited conforming borrowers, and enhanced financial stability. It also calls for deeper housing finance reforms in the U.S. because Dodd-Frank Act still maintains the substantial government support as in the pre-crisis period. Second, on macrofinancial surveillance, the paper highlights the importance of replacing the existing governmentbacked mortgage insurance system with a well-regulated private system, because the existing system imposes a fiscal burden on the government, increases financial fragility, and even hurts borrowers it was intended to help. This is in a similar spirit to the policy recommendation made in the 2014 Financial Sector Assessment Program by the IMF. It is also consistent with Australia's privatization experience in 1998. Plausible policy measures to transmit to such a private system include the lender risk sharing program as in Hong Kong (Canada is also actively considering such a program).

Motivation and institutional background. On September 6, 2008, the U.S. federal government committed to invest as much as $\$ 188$ billion through 2009 to keep the GSEs solvent. This amounted to about $1.3 \%$ of U.S. GDP in 2008. Indeed, as the New York Times (09/08/2008) wrote, it was "the biggest and costliest government bailout ever." As summarized by Frame, Wall, and White (2013), this bailout has sparked many debates about the role of the federal government in the housing finance system, with opinions ranging from no role at all to insuring against all credit 
losses. To shed light on these debates, it is important to understand the positive and normative effects of the subsidy to the housing finance system introduced through the government's backing of the housing GSEs.

In simple terms, the subsidy works as follows. Banks as a whole (consolidated to a single entity, referred to as "bank") provide loans to borrowers in the primary mortgage market. ${ }^{1}$ If the loan amount is below the pre-specified conforming loan limit (CLL) (being a "conforming loan"), ${ }^{2}$ then it is eligible to receive the GSEs' default insurance, so that in the event the borrower defaults, the GSEs will fully compensate the bank for any credit loss (although not all eligible loans actually receive the default insurance, every conforming loan has a positive probability of being insured by the GSEs ex ante). For example, in 2006 and 2007, this limit was $\$ 417,000$ in almost all states in the U.S. ${ }^{3}$ If the loan amount is above the CLL (being a "jumbo loan"), then it is ineligible for the insurance. ${ }^{4}$ Hence, the subsidy is effectively a default insurance program provided by the GSEs to the bank, but only for smaller loans.

This default insurance is subsidized (underpriced) for two reasons. On the one hand, the GSEs enjoy an implicit government guarantee: should the GSEs become insolvent due to mortgage credit losses, the federal government will step in and bail them out, which is exactly what happened in 2008. This implicit government guarantee increases investors' confidence in the GSEs and enables the GSEs to borrow at a lower cost from the financial market, which constitutes a benefit to the GSEs. On the other hand, the competition between the two major GSEs (Fannie Mae and Freddie Mac) implies that they will undercut each other when pricing the default insurance, passing through some of the subsidy benefit to the bank in the form of underpriced default insurance. ${ }^{5}$ The focus of my paper is on the primary mortgage market between the borrowers and the bank, with the understanding that the bank receives a subsidy in the form of underpriced default insurance.

This subsidized default insurance is likely to have important effects on the equilibrium contract terms offered by the bank to borrowers. In particular, it is likely to have differential effects on conforming loans and jumbo loans. Panel (a) of Figure 2, extracted from Figure 1 in DeFusco and Paciorek (2014), plots the observed interest rate schedule with respect to loan size for fixed-rate loans originated in 2006. Panel (a) shows that the interest rate schedule displays a clear discontinuity at the CLL, with average interest rates on loans just above the CLL being approximately 20 basis points higher than those on loans just below. Panel (b) plots the histogram of the loan size, which shows that the frequency of the loan size bunches exactly at the CLL, and drops substantially just above the CLL. It is the discontinuity in Panel (a) that is cited as supportive empirical evidence for the conventional wisdom that the subsidized default insurance has decreased interest rates of conforming loans.

Moreover, with an underpriced default insurance scheme, the bank will optimally choose to over

1 Throughout the paper, the word "bank" also includes other non-bank mortgage originators.

${ }^{2}$ For simplicity, I do not consider other criteria for conforming loans, e.g., the credit score. Fortunately, in reality, the size limit criterion is enforced much more strictly than other criteria.

3 Exceptions were Alaska, Hawaii, Guam and the U.S. Virgin Islands, where the CLLs were $50 \%$ higher. Moreover, since 2008, more "high-cost areas" are allowed to establish their own higher CLLs.

${ }^{4}$ Some researchers regard jumbo loans as a strict subset of non-conforming loans, and understand loans which are below the CLL but fail to satisfy other criteria of GSE's insurance are "non-jumbo and non-conforming loans." I do not consider these loans, because I do not consider the conforming criteria other than the size limit.

${ }^{5}$ In practice, GSEs' subsidized default insurance is more complicated, and it is done through GSEs' securitization. That is, GSEs purchase mortgages loans from the bank in the secondary market, issue mortgage-backed securities (MBS) against a pool of mortgages, and provide default insurance on these MBS instead. For details, see Acharya et al. (2011, Page 13 and Page 187) and Guttentag (2010, Page 138). 


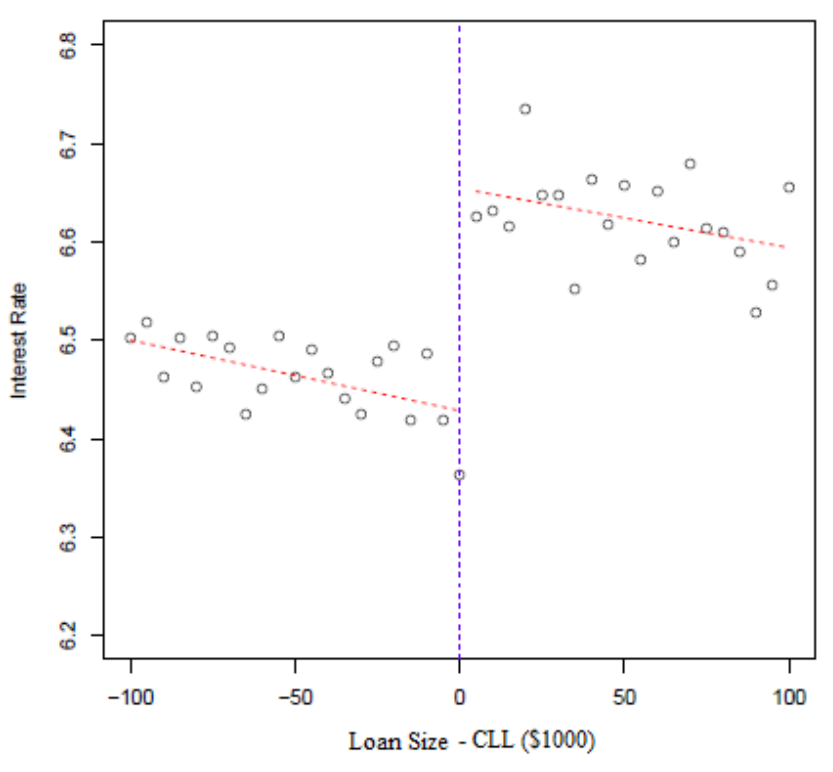

(a) Mean Interest Rate by Loan Size (2006)

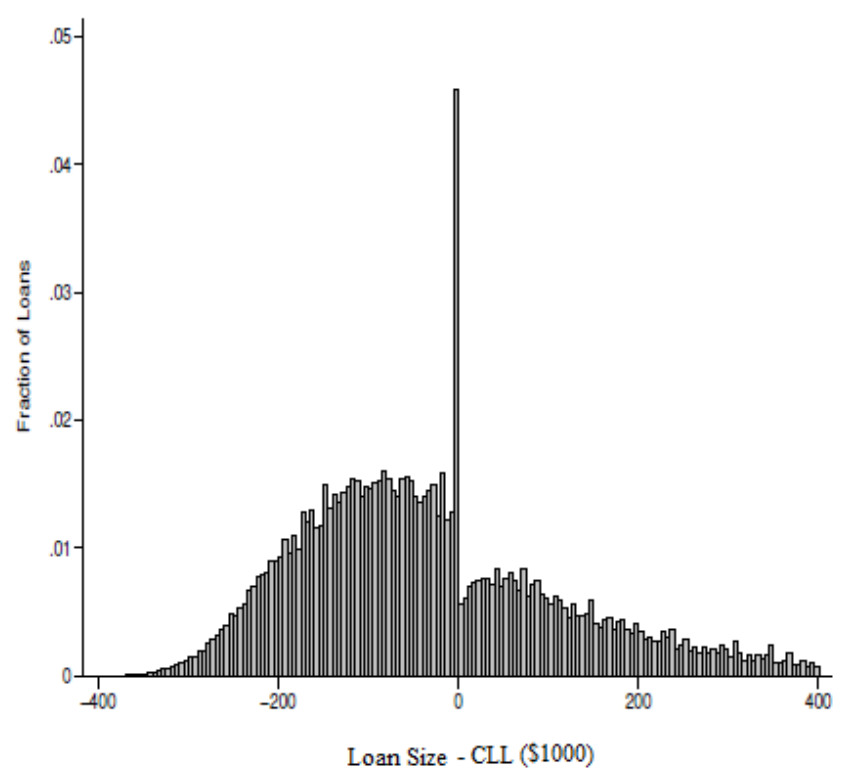

(b) Loan Size Density

Figure 2: Interest rate-loan size plot (2006) and loan size histogram.

In Panel (a), each dot represents the mean interest rate in 2006 within a given $\$ 5,000$ bin relative to the CLL $(\$ 417,000)$. The dashed lines are predicted values from a regression on the binned data. Panel (b) plots the fraction of all loans that are in any given $\$ 5,000$ bin relative to the conforming limit. Data in Panel (b) are pooled across years and the sample includes all transactions in the primary DataQuick sample that fall within $\$ 400,000$ of the conforming limit.

insure by taking excessive risk. There are two ways to do so. Firstly, the bank can take excessive risk through an extensive margin, i.e., by relaxing the lending criteria and extending mortgage loans to more borrowers. This is the margin studied by Keys et al. (2010). Secondly, the bank can take excessive risk through an intensive margin, i.e., by raising the interest rate and/or leverage ratio of the same borrower (for the same borrower, a higher interest rate and/or a higher leverage ratio means a larger repayment burden and thus a higher default risk). It is the intensive margin that is the focus of this paper.

Summary of the empirical strategy. The main empirical contribution of this paper is to apply regression discontinuity designs to estimate the causal effect of GSEs' subsidized default insurance on mortgage interest rates. Doing so can correct for the endogeneity problem in conventional studies, as explained above.

The main data set I use consists of the 30-year fixed-rate mortgage loan-level data collected by U.S. mortgage lenders under the Home Mortgage Disclosure Act (HMDA). My identification strategy exploits the variation in interest rates generated by the GSEs' SAG mandated by Congress. ${ }^{6}$ Specifically, the SAG requires that at least a certain percentage of mortgage loans insured by GSEs ${ }^{7}$ should be taken by borrowers with incomes below $60 \%$ of the median income of its metropolitan

6 This is one of the three "affordable housing goals" or "mission goals." The other two are "underserved areas goal" (UAG) and "low- and moderate-income goal" (LMIG).

7 The percentage specified by the goal varies over time: it is $20 \%, 22 \%, 23 \%$ and $25 \%$ from 2004 to 2007 . 
statistical area (or nonmetropolitan county). ${ }^{8}$

My identification strategy can be summarized as follows. On the one hand, even if a mortgage loan falls below the loan size limit and is eligible to receive the subsidized default insurance (being a conforming loan), it does not necessarily get insured ex post. In fact, data show that only about $15 \%$ of the conforming loans actually get insured and receive the subsidy. On the other hand, the SAG implies that among the conforming loans, those taken by borrowers with incomes just below $60 \%$ of their MSA's median income will have a discontinuously higher ex ante probability to receive the subsidized default insurance than those with incomes just above. It is this higher ex ante subsidy probability that is the treatment in my empirical study. Since borrowers are unlikely to be able to manipulate their incomes and since the $60 \%$ income cutoff is arguably an exogenous rule, ${ }^{9}$ borrowers just above and just below the $60 \%$ income cutoff are comparable (even in terms of the unobservable quality) except for the discontinuity in the ex ante probability of receiving the subsidized default insurance. Hence, any discontinuity in the interest rate at the $60 \%$ cutoff can be attributed to the discontinuity in the ex ante subsidy probability, and thus to the subsidy itself.

Using this strategy, I find that loans with a discontinuously higher ex ante subsidy probability also have a discontinuously higher interest rate than those with a lower probability, even after controlling for borrower characteristics such as income and lien status. The difference is about 14 basis points on average, which amounts to about $4 \%$ of the sample average (17 basis points using data with income ratios between $59 \%$ and $61 \%$ ). These effects seem to be economically small, but since the SAG eligibility is far from capturing the full effect of the GSEs' subsidized default insurance itself (it only measures the ex ante probability to receive that subsidy), the actual effect of the subsidy may still be economically large. These empirical findings imply that the subsidized default insurance has raised mortgage interest rates of conforming loans, which is contrary to conventional wisdom.

To better understand the empirical strategy, consider two borrowers from the same area. Suppose both borrowers take conforming loans, so both of them are eligible to receive the subsidy. Furthermore, suppose the first borrower has an income equal to $59.9 \%$ of the area's median income, and the second borrower has an income equal to $60.1 \%$. These two borrowers are so similar to each other that their fundamental characteristics such as the credit scores and all other unobservable characteristics are also very similar. The only significant difference is that the $59.9 \%$ borrower has a discontinuously higher ex ante probability to receive the default insurance subsidy than the $60.1 \%$ borrower. If we find that the $59.9 \%$ borrower also has a discontinuously higher interest rate, then it must be caused by the discontinuously higher subsidy probability. This is the main idea of regression discontinuity designs.

As auxiliary supporting evidence to the theoretical model discussed below, I also show that the subsidy raises mortgage default rates of all conforming loans. I do so by applying various timeto-default models (including Exponential, Weibull, and Lognormal models) to the single-family loan-level data released in 2013. I find that all else being equal, being more likely to receive the government's mortgage subsidy shortens the conforming mortgage's time to default, i.e., raises the mortgage's default risk.

${ }^{8}$ In practice, there is another criterion for the SAG, which is based on the census-tract income. To get cleaner results, I restrict my sample to loans which have satisfied the borrower-income-based criterion.

${ }^{9}$ Some recent studies show evidence of mortgage borrowers misreporting incomes, but mainly in the non-GSE insured mortgages and low-documentation mortgages. See Subsection 2.3 for more discussions. 
Summary of the theoretical section. The empirical section of my paper implies that the subsidy has raised mortgage interest rates of conforming loans, which is contrary to conventional wisdom. How to interpret this seemingly counterintuitive empirical result? Why does the bank charge the borrower more after receiving a subsidy? The theoretical section attempts to explain these via a two-period monopolistic screening model with asymmetric information. Moreover, it also sheds light on the welfare implications of the subsidy.

In the model, the monopolistic bank is unable to observe the true qualities of a continuum of borrowers. Thus, the bank has to design pairs of loan size and interest rate in period 0 , subject to borrowers' participation and incentive compatibility constraints. In period 1, the stochastic housing price is realized. If the borrower defaults, the bank forecloses on the house and seizes the collateral value; if the borrower repays, the model ends. In the equilibrium without the subsidy, a higher-quality borrower is strictly less leveraged (taking a smaller loan size), and also pays a strictly lower interest rate. These results are consistent with the finance literature.

The introduction of subsidized default insurance fundamentally alters the equilibrium contracts. In particular, the subsidy causes a moral hazard problem on the part of the bank. It is this moral hazard problem that plays a key role in raising the mortgage interest rate. The intuition is as follows: the subsidized default insurance actually provides the bank with a safety net, and induces the bank to behave opportunistically. Specifically, suppose the bank raises the mortgage interest rate after the subsidy policy is implemented. If the borrower does not default at the higher interest rate, then the bank can receive a larger interest payment and get a higher profit; but even if the borrower does default at the higher interest rate, the bank can still recover the loss from Fannie Mae and Freddie Mac. That is, the subsidy induces an asymmetric payoff structure to the bank (receiving all the benefits on the upside, but being protected on the downside). As a result, the bank will optimally choose to raise the interest rate under the subsidy.

One may wonder if the result is solely driven by the assumption of a monopolistic banking industry. Four responses can be made:

Firstly, as discussed above, the "bank" in my model is actually the entire consolidated mortgage lending system in the US. This includes all banks and other mortgage lenders. Therefore, the results in my model capture the intrinsic problem faced by the entire mortgage lending industry as a whole rather than an individual mortgage lender. Hence, the competition among different mortgage lenders is unlikely to qualitatively change the results.

Secondly, a vast literature on relationship banking, such as Sharpe (1990) and Kim, Kliger, and Vale (2003), suggests that the incumbent bank has monopoly power due to its informational advantage over competitors, or due to the borrower's large switching cost. For example, Kim, Kliger, and Vale (2003) estimate the switching cost to be roughly one-third of the average interest rate on loans in the Norwegian market. Indeed, a sizable number of borrowers do take mortgages from the banks with which they have already established a relationship.

Thirdly, the presence of asymmetric information acts as a countervailing force to the usual undercutting force associated with competition among banks. Specifically, when a bank undercuts the interest rate for a particular customer in an attempt to steal customers from other banks, it will also induce other customers of the undercutting bank to mimick and take the contract of this customer. Moreover, the undercutting bank cannot prevent such mimicking from happening because it cannot observe the true types of customers due to information asymmetry. Such mimicking will decrease the undercutting bank's total profit and may prevent the bank from undercutting in the first place. 
Lastly, the mortgage origination business in the U.S. is relatively concentrated. ${ }^{10}$ The limited number of dominant banks in the market makes it possible for them to collude and split the monopoly profit. ${ }^{11}$ Some recent papers such as Anzoategui, Chivakul, and Maliszewski (2015) also allow for market power by the bank and a positive profit in equilibrium (although they do not study the mortgage lending industry in the U.S.). Hence, all arguments made in the monopolistic case are likely to apply to an oligopolistic case. As such, I study the monopoly case for simplicity.

Another important prediction of the model is that the subsidy has increased the default probabilities of all conforming borrowers. By the Law of Large Numbers, it has also increased the aggregate default rate in the entire mortgage market. This result implies that the subsidy mechanism via Fannie Mae and Freddie Mac's default insurance has increased the systematic risk in the housing finance system, posing a threat to financial stability. This result is consistent with that in Acharya et al. (2011), which provides another robustness check of my model.

To be consistent with the data, the model also needs to explain the observed positive jumboconforming spread. This can be explained by incentive compatibility constraints associated with asymmetric information. Specifically, if the bank designed a lower interest rate for a loan just above the CLL, then the borrower taking the contract at the CLL would want to deviate to that contract because he can obtain a larger loan size at a lower interest rate. Therefore, in equilibrium, the interest rates for loans just above the CLL must have strictly higher interest rates than loans equal to the CLL. ${ }^{12}$ Hence, the observed positive jumbo-conforming spread is simply a result of the incentive compatibility constraints associated with asymmetric information, rather than an indication that the subsidy policy has lowered interest rates of conforming loans.

The second research question this paper attempts to answer is the welfare effect of the subsidy. When creating Fannie Mae in 1938 and Freddie Mac in 1970, one important intention of the federal government was to improve consumer welfare through promoting mortgage lending. Indeed, this is one of the most frequently used arguments to support GSEs. However, under the set-up of this paper, I find that the subsidy decreases consumer welfare, which is also contrary to conventional wisdom. The intuition follows from the bank's moral hazard problem and rent extraction motive: exactly because the subsidy allows the bank to more aggressively "exploit" borrowers by charging higher interest rates, the welfare of borrowers will be lower after the subsidy is introduced. This is true even if we do not consider the increased tax burden needed to finance the subsidy or the negative externality imposed by increased mortgage defaults.

To better understand this welfare result, consider one particular borrower. Suppose this borrower took a mortgage contract with the bank before the subsidy was introduced, and suppose he got 10 units of consumer surplus from this contract relative to his outside option (i.e., not borrowing). After the subsidy is introduced, the bank raises the interest rate in the new contract offered to this borrower. Suppose he can only get 8 units of surplus instead of 10 from the new contract. However, he will still want to accept this new contract because he will get 0 if he drops out of the mortgage market, and he will get an even lower surplus if he takes the contract designed for another borrower. This, in turn, is because the bank has raised the interest rates of all other borrowers in the new contract menu; and the bank has done so in such a way that each borrower

${ }^{10}$ From Q1 2012 to Q1 2014, the top 5 mortgage lenders account for about $40 \%$ of the market. These lenders are Wells Fargo, JPMorgan, Bank of America, U.S. Bancorp, and Citigroup. Data source: Forbes.

${ }^{11}$ The collusive equilibrium can be sustained by a dynamic game with infinite horizon, where the equilibrium strategy is such that the deviating bank will be punished by all other banks if it "cheats" and undercuts the interest rate.

${ }^{12}$ Moreover, the bank will optimally shift all loans slightly above the CLL to be just equal to the CLL so that it can receive the subsidy for these loans. Therefore, the equilibrium loan size will jump discontinuously from the CLL to a higher level, and thus the interest rate will also jump discontinuously. 
will be worse off by deviating. By uniformly raising the interest rates for all borrowers, the bank can force the borrowers to "choose the lesser of two evils" and thus extract more consumer surplus while still satisfying all borrowers' participation and incentive compatibility constraints.

Related literature. My paper is related to the vast literature on estimating the size of the jumbo-conforming spread and the interpretation of the spread. This includes Cotterman and Pearce (1996), Ambrose, Buttimer, and Thibodeau (2001), Naranjo and Toevs (2002), Passmore, Sparks, and Ingpen (2002), and Ambrose, LaCour-Little, and Sanders (2004). McKenzie (2002) provides a summary. The estimates in these studies vary substantially, from as low as a few basis points to as high as 60 basis points. These studies generally regress the interest rate on a "jumbo" dummy under a particular parametric form, and interpret the coefficient of the jumbo dummy as the jumbo-conforming spread. Exceptions include Sherlund (2008), who non-parametrically estimates the effect of loan size and loan-to-value ratio on interest rate while assuming the jumbo dummy enters linearly.

Moreover, most of these studies interpret the estimated jumbo-conforming spread as a proxy for the reduction in mortgage interest rates due to the GSE subsidy. One of the few exceptions is Passmore (2005), who points out that GSE shareholders and/or mortgage originators may capture some or all of the subsidy and not pass it on to homeowners. The result of my paper is in line with that of Passmore (2005), but goes one step further: the subsidy not only fails to be passed on to homeowners, but also hurts them due to its very presence.

As shown theoretically by Burgess, Passmore, and Sherlund (2005), the estimated jumboconforming spread is only a coarse measure of the GSEs' influence on mortgage rates. The reason emphasized by the authors is that mortgage rates depend on many factors other than the GSEs' subsidized default insurance, including the funding cost and the spreads needed to compensate for the credit, prepayment, and maturity mismatch risks of the mortgage. Each of these factors could be priced differently for jumbo versus conforming mortgages, thereby affecting the jumboconforming spread. Therefore, the authors conduct a second-step regression, which is to regress the jumbo-conforming spread (estimated using the traditional regression approach) on a measure of GSEs' funding advantage and the aforementioned factors. The authors then interpret the coefficient of the GSEs' funding advantage in the second-step regression as a more precise measure of GSEs' (causal) effect on mortgage rates.

As Kaufman (2014) points out, these studies are vulnerable to selection bias and sorting bias by borrowers, i.e., borrowers of higher quality (who would receive lower interest rates anyway) may have sorted into conforming loans, which causes bias in the estimate of the jumbo-conforming spread in the aforementioned studies. Sherlund (2008) attempts to address these biases. He uses geographic location to control for unobserved borrower characteristics, although assuming loans similar to each other in terms of loan size, loan-to-value ratio or geographic location might also be similar in other unobservable borrower characteristics. Kaufman (2014) instruments for a loan's conforming status using a discontinuous function of the home appraisal value, and finds that GSE purchase/insurance has lowered interest rates by about 10 basis points over the period from 2003 to $2007 .{ }^{13}$

Although the instrumental variable approach in Kaufman (2014) can help address the sorting bias and thus identify the effect of the subsidy on the interest rates of conforming loans relative to jumbo loans, it cannot identify the effect of the subsidy on conforming loans relative to the no-subsidy case. To identify that effect using a reduced-form study, we would need the pre-subsidy

${ }^{13}$ Adelino, Schoar, and Severino (2014) and Fuster and Vickery (2015) use similar instruments for conforming status. 
data. Given such data, we could use the variation in the interest rates (of conforming loans) before and after the introduction of the subsidy program. Unfortunately, such pre-subsidy data are not available because the subsidy was introduced in 1938 for Fannie Mae and 1970 for Freddie Mac; therefore, a theoretical model is needed to identify that effect. Of course, variation in the probability of receiving the subsidy generated by the mandate of Congress can be used to provide indirect evidence on the effect of the subsidy on conforming loans. That is the empirical strategy used in this paper, as noted earlier. ${ }^{14}$

In addition to the aforementioned literature, my paper also contributes to the growing literature on more general government interventions in the mortgage market. There are several forms of such interventions, including the mortgage interest tax deductibility, the tax exemption of imputed rental income of owner-occupied housing, and the loan insurance by GSEs. Most existing work focuses on the effects of the first two interventions. Examples include Gervais (2002), Poterba and Sinai (2008), Chambers, Garriga, and Schlagenhauf (2009), Poterba and Sinai (2011), Sommer and Sullivan (2013), and Floetotto, Kirker, and Stroebel (2016). Unlike these studies, this paper instead focuses on the third intervention and the associated mortgage interest rate subsidy.

There are some recent papers that also study the third intervention, using general equilibrium macroeconomic models. Important contributions include Jeske, Krueger, and Mitman (2013) and Elenev, Landvoigt, and Van Nieuwerburgh (2015). Using a model with heterogeneous, infinitelylived households and competitive housing and mortgage markets, Jeske, Krueger, and Mitman (2013) find that eliminating this subsidy leads to a large decline in mortgage origination and increases aggregate welfare by $0.5 \%$ in consumption equivalent variation.

In a related paper that emphasizes the role of the financial sector, Elenev, Landvoigt, and Van Nieuwerburgh (2015) develop a rich new model of the mortgage market in which both borrowers and banks can default on their liabilities. They find that the underpriced GSE mortgage insurance leads to an excessive financial sector leverage and lower mortgage rates, as well as more mortgage defaults, resulting in a welfare loss. It is worth noting that although their paper implies that the mortgage interest rate itself decreases as the subsidy increases, the spread (between the interest rate and the risk-free rate) still increases in their paper since the risk-free rate decreases by a larger amount as the subsidy increases. Since my paper treats the risk-free rate as fixed and does not model this general equilibrium effect, the prediction of a higher interest rate in my paper is still consistent with theirs, with the understanding that the interest rate in my model is actually the spread in theirs. Of course, this also means that my paper cannot capture the systematic impact of GSEs on the macroeconomy manifested in the risk-free rate, as in any partial equilibrium model.

There are several differences between my paper and these papers. First, these papers assume perfect information between the lenders and borrowers, while my paper assumes asymmetric information between them and focuses on the interaction between information asymmetry and government subsidy. Because information asymmetry is a fundamental feature in the mortgage market, my paper provides a complementary understanding to the literature. Second, in these papers, all mortgages are eligible for the subsidy, whereas my paper explicitly models the subsidy eligibility (i.e., only loans below the CLL are eligible). Since the conventional wisdom is based

${ }^{14}$ Bhutta (2012) and Moulton (2014) also use this strategy to study GSEs' affordable housing goals, although they focus on the effect on GSE insurance (purchases) and volume of loan originations, rather than on interest rates. Bhutta (2012) finds that the UAG has a positive but limited effect on GSE purchases and the mortgage origination volume. Moulton (2014) studies all the three mission goals (SAG, UAG, and LMIG). He finds that the SAG increased GSE purchases but had no effect on mortgage lending (loan volumes and fraction of high-price loans), and that the UAG or LMIG did not alter GSE purchases or mortgage lending. These results are consistent with my empirical findings to the extent that the subsidy policy does not benefit consumers as much as intended. 
on the interest rate gap around the CLL, explicitly modeling the CLL provides a direct way to examine the conventional wisdom.

More broadly, my paper is connected to the literature on government bailout of the financial sector, such as Acharya and Yorulmazer (2007), and Farhi and Tirole (2012). This literature studies the direct bailout of the banks, whereas my paper focuses on the indirect subsidy done through the bailout of the GSEs with an explicit modeling of the collateralized lending. Finally, my paper is related to the literature on securitization and mortgage contract design, including Keys et al. (2010), Keys, Seri, and Vig (2010), Bubb and Kaufman (2014), and Piskorski and Tchistyi (2010).

The rest of the paper is organized as follows. Section 2 presents the empirical section. Section 3 presents the benchmark model without subsidy. Section 4 presents the model with subsidy and the discussions on the effects of the subsidy. Section 5 concludes. The appendices collect some proofs.

\section{Empirical evidence}

\subsection{Data and summary statistics}

The primary data source used in this study is the loan application-level data provided by U.S. mortgage lenders under the HMDA. The HMDA requires lenders to disclose information about the geographic location and other characteristics of the mortgage loans to facilitate enforcement of the fair lending laws. The lenders currently covered by the HMDA account for approximately $80 \%$ of all home lending nationwide, so the HMDA data set provides a representative picture of most home lending in the U.S. Since 1990, HMDA has required covered lenders to provide individuallevel mortgage application information instead of the census-tract aggregate information in each calendar year (Avery et al. (2007)). The vast majority of these are 30-year fixed-rate loans.

Before explaining the data cleaning procedure, I would like to make several remarks on the data set. First, although the HMDA data set does not contain information on the contract interest rate, it does report the spread between the annual percentage rate (APR) and the applicable Treasury yield for the high-price loans since 2004..$^{15}$ Since the APR also reflects the "points" and other fees paid by the borrower, ${ }^{16}$ it is a more accurate measure of the borrowing cost than the interest rate itself, and may be more suitable for the study of consumer welfare. Second, the focus of the empirical study is to examine the change (rather than the level) of the interest rate caused by the subsidy. Assuming that the subsidy does not affect the risk-free rate (which seems a plausible assumption given that the risk-free rate is determined by many other macroeconomic factors), the change of the spread is equal to that of the interest rate, so the unavailability of the data on interest rate levels does not affect the identification of the effect of the subsidy. Third, although the HMDA data set does not provide the borrower's credit score, this does not cause a bias in the estimation as long as the regression discontinuity design is valid. The reason is that the credit scores (and

\footnotetext{
${ }^{15}$ More precisely, the spread is reported for first-lien loans with spreads equal to or greater than 3 percentage points, and for second-lien loans with spreads equal to or greater than 5 percentage points. The HMDA high-price loans are generally considered as subprime loans (Mayer and Pence, 2009).

${ }^{16}$ Points, also called "discount points," are a form of prepaid interest. One point equals one percent of the loan amount. Borrowers can offer to pay points as a method to reduce the interest rate on the loan and to obtain a lower monthly payment in exchange for this upfront payment. By charging a borrower points, a lender effectively increases the yield on the loan above the amount of the stated interest rate.
} 
all unobservable characteristics) of borrowers who are sufficiently close to the $60 \%$ income cutoff must change in a smooth way, and thus cannot explain the discontinuous change in interest rates across the $60 \%$ income cutoff (indeed, non-mortgage loans such as credit card lendings and auto loans do not differentially target borrowers based on the same $60 \%$ income limit). ${ }^{17}$ In addition, the HMDA data set does provide information on whether a loan is insured by GSEs. This allows me to restrict the sample to loans that are ex post insured by GSEs, which can make the loans more comparable.

One may wonder how we can identify the effect of the subsidy if we only use the loans that have received the subsidy (i.e., being insured by GSEs). Regarding this, the crucial point is that my identification is achieved by using the ex ante different probabilities of receiving the subsidy (being insured by GSEs). Even though banks generally originate a loan knowing ex ante whether the loan will be eligible for the GSE subsidy (by running the loans through the GSEs' automated underwriting software), it is always uncertain whether that loan will actually be insured by GSEs ex post. Indeed, as explained in the Introduction, only about $15 \%$ of the conforming loans actually get insured and receive the subsidy. This implies that even among the loans that have received the GSE subsidy ex post, the bank understands there are still two distinctive groups at the time of setting the interest rates: one group has a discontinuously higher ex ante probability to receive the subsidy (the group with borrower incomes below the $60 \%$ cutoff), and the other group has a lower ex ante probability. If we can show that the first group also has a discontinuously higher interest rate, then it follows that the GSE subsidy has raised the mortgage interest rate. And by using loans that were actually insured by GSEs ex post, we can better control for the unobservables, while still achieving the identification.

The sample period used in this study is from 2004 to 2007. I choose this period because the U.S. adopted a different definition of MSA in 2004, and because the bailout of GSEs in 2008 may have had a systematic impact on mortgage lending. I also merge the HMDA data set with the MSA median income data released by the U.S. Department of Housing and Urban Development to determine each loan's status of the SAG.

To focus on loans insured by the GSEs, I conduct the following procedure to further clean the data: (1) drop loans larger than the CLL; (2) drop loans insured by the Federal Housing Administration, or guaranteed by the Veterans Administration; (3) drop refinance loans and homeimprovement loans, and keep home-purchase loans only; (4) drop denied and withdrawn applications, and keep originated loans only; (5) following Bhutta (2012), drop loans in Alaska, Hawaii, Guam, and the U.S. Virgin Islands ; (6) drop loans for which the sex, race, ethnicity information is not provided by the borrower; (7) drop loans for which the spread information is not available. ${ }^{18}$ The data cleaning yields a total of 1,712,419 observations.

The summary statistics of the cleaned data is presented in Table 1. From 2004 to 2007, the average interest rate spread of all loans in the sample is about $5.37 \% .{ }^{19}$ This is a relatively high

${ }^{17}$ Other mortgage market features, such as prepayment and the possibility of taking piggyback loans, are unlikely to affect my identification because these features do not display a discontinuity exactly at the $60 \%$ income cutoff.

${ }^{18}$ After going through Steps (1)-(6), there about $17 \%$ of originated loans for which the spread information is available in 2004-2007. Hence, the empirical testing conducted here is based on a relatively small subset of loans (subprime loans), and thus the empirical results support my model's prediction to the extent of the representativeness of the selected sample. However, given the role played by the subprime loans in the recent financial crisis, it is important to study the pricing of these loans.

${ }^{19}$ The 30 -year Treasury annual rates was $4.91 \%$ in 2006 , and $4.84 \%$ in 2007 . Hence, the average interest rates on the mortgage contracts were about $10.2808 \%$ and $10.2108 \%$, respectively. Note that the 30-year Treasury constant maturity series was discontinued on February 18, 2002 and reintroduced on February 9, 2006, so the 
spread, but one reason is that this spread is based on the APR which is higher than the contract interest rate. The average loan size is about $\$ 133,000$, and the average fraction of loans eligible for the SAG is $7.65 \%$.

Table 1 also presents the summary statistics for the GSE-insured and non-insured groups, respectively. As the table makes clear, the means of most variables significantly differ from each other in the two groups. The two-sample t-test also confirms this result. For example, the mean spread of the non-insured group is larger than that of the insured group by about $46 \%(1.72$ percentage points). In addition, almost all of the GSE-insured loans are first-lien loans, whereas only $64.67 \%$ of the non-insured loans are first-lien loans. The average incomes in these two groups also differ substantially, with the GSE-insured group being poorer than the non-insured group. These make economic sense, given that GSEs try to pick less risky loans while still satisfying the mission goal of serving relatively poor borrowers. These substantial differences between the two groups make it necessary to limit the sample to GSE-insured loans only. Doing so can also mitigate the bias due to the omitted variables in the HMDA data.

\begin{tabular}{|c|c|c|c|c|c|c|}
\hline & \multicolumn{2}{|c|}{ (1) } & \multicolumn{2}{|c|}{ (2) } & \multicolumn{2}{|c|}{ (3) } \\
\hline & \multicolumn{2}{|c|}{ All } & \multicolumn{2}{|c|}{ GSE-insured } & \multicolumn{2}{|c|}{ Non-insured } \\
\hline & mean & sd & mean & sd & mean & sd \\
\hline Spread & 5.3708 & $(1.557)$ & 3.7543 & $(0.865)$ & 5.4751 & $(1.534)$ \\
\hline $\mathrm{b}$ & 133.0124 & $(97.690)$ & 151.4767 & (82.838) & 131.8204 & $(98.452)$ \\
\hline SAG & 0.0765 & $(0.266)$ & 0.1636 & $(0.370)$ & 0.0709 & $(0.257)$ \\
\hline Income & 87.4729 & $(54.960)$ & 71.1500 & $(47.948)$ & 88.5252 & $(55.216)$ \\
\hline IncomeRatio & 1.4921 & $(0.921)$ & 1.2271 & $(0.822)$ & 1.5092 & $(0.924)$ \\
\hline FirstLien & 0.6679 & $(0.471)$ & 0.9964 & $(0.060)$ & 0.6467 & $(0.478)$ \\
\hline Male & 0.6448 & $(0.479)$ & 0.6621 & $(0.473)$ & 0.6437 & $(0.479)$ \\
\hline Hispanic & 0.2370 & $(0.425)$ & 0.1618 & $(0.368)$ & 0.2419 & $(0.428)$ \\
\hline Black & 0.1674 & $(0.373)$ & 0.1615 & $(0.368)$ & 0.1678 & $(0.374)$ \\
\hline Tract-to-MSA & 1.1283 & $(0.273)$ & 1.1042 & $(0.259)$ & 1.1299 & $(0.274)$ \\
\hline Observations & & 12,419 & & 758 & 1,60 & 661 \\
\hline
\end{tabular}

Table 1: Summary statistics for both GSE-insured and non-insured loans $\mathrm{b}=$ loan size;

IncomeRatio = borrower's income/MSA's median income;

Tract-to-MSA = census tract's median income/MSA's median income.

The summary statistics for the GSE-insured loans are presented in Table 2. To facilitate the discussions in the statistical analyses to come, I also present the summary statistics of loans around $5 \%, 2 \%$ and $1 \%$ of the $60 \%$ income cutoff. Note that although the average spread around the cutoff is quantitatively similar to that of the entire group of the insured loans, the average loan size and income are much smaller than those of the entire group.

annual interest rates for 2004 and 2005 cannot be backed out. 


\begin{tabular}{|c|c|c|c|c|c|c|c|c|}
\hline & \multicolumn{2}{|c|}{ (1) } & \multicolumn{2}{|c|}{ (2) } & \multicolumn{2}{|c|}{ (3) } & \multicolumn{2}{|c|}{ (4) } \\
\hline & \multicolumn{2}{|c|}{ All } & \multicolumn{2}{|c|}{$\begin{array}{c}0.55 \leq \\
\text { IncomeRatio }\end{array}$} & \multirow{2}{*}{\multicolumn{2}{|c|}{$\begin{array}{c}0.58 \leq \\
\text { IncomeRatio } \\
\leq 0.62\end{array}$}} & \multirow{2}{*}{\multicolumn{2}{|c|}{$\begin{array}{c}0.59 \leq \\
\text { IncomeRatio } \\
\quad \leq 0.61\end{array}$}} \\
\hline & \multirow[b]{2}{*}{ mean } & \multirow[b]{2}{*}{ sd } & \multicolumn{2}{|c|}{$\leq 0.65$} & & & & \\
\hline & & & mean & sd & nean & sd & mean & sd \\
\hline Spread & 3.7543 & $(0.865)$ & 3.7559 & $(0.857)$ & 3.7412 & $(0.828)$ & 3.7215 & $(0.800)$ \\
\hline $\mathrm{b}$ & 151.4767 & $(82.838)$ & 108.8084 & $(44.827)$ & 110.2886 & $(44.605)$ & 108.9057 & $(45.140)$ \\
\hline SAG & 0.1636 & $(0.370)$ & 0.4846 & $(0.500)$ & 0.4987 & $(0.500)$ & 0.5154 & $(0.500)$ \\
\hline Income & 71.1500 & $(47.948)$ & 35.9851 & $(5.892)$ & 36.0299 & $(5.764)$ & 35.8797 & $(5.694)$ \\
\hline IncomeRatio & 1.2271 & $(0.822)$ & 0.6012 & $(0.029)$ & 0.5999 & $(0.011)$ & 0.5996 & $(0.006)$ \\
\hline FirstLien & 0.9964 & $(0.060)$ & 0.9983 & $(0.041)$ & 0.9986 & $(0.038)$ & 0.9989 & $(0.033)$ \\
\hline Male & 0.6621 & $(0.473)$ & 0.5982 & $(0.490)$ & 0.5915 & $(0.492)$ & 0.5962 & $(0.491)$ \\
\hline Hispanic & 0.1618 & $(0.368)$ & 0.1474 & $(0.355)$ & 0.1432 & $(0.350)$ & 0.1480 & $(0.355)$ \\
\hline Black & 0.1615 & $(0.368)$ & 0.1859 & $(0.389)$ & 0.1933 & $(0.395)$ & 0.1854 & $(0.389)$ \\
\hline Tract-to-MSA & 1.1042 & $(0.259)$ & 1.0400 & $(0.194)$ & 1.0414 & $(0.194)$ & 1.0483 & $(0.202)$ \\
\hline Observations & \multicolumn{2}{|c|}{103,758} & \multicolumn{2}{|c|}{8,872} & \multicolumn{2}{|c|}{3,513} & \multicolumn{2}{|c|}{1,845} \\
\hline
\end{tabular}

Table 2: Summary statistics for GSE-insured loans

\subsection{Empirical results from RD designs}

I begin with a graphical analysis of the SAG's effect at the $60 \%$ income ratio cutoff, using 2006 as an example. See Figure 3, which plots the average values of the outcome variable (the interest rate spread) for different values of the assignment variable (the ratio of borrower income to MSA median income). In addition, I fit the data non-parametrically on either side of the cutoff. As illustrated in Figure 3, the discontinuity in the fitted lines at the income ratio cutoff provides initial evidence of an SAG-induced discontinuous increase in the interest rate spread in 2006. The following statistical analysis confirms such a discontinuity.

Specifically, I use regression discontinuity (RD) designs to estimate the effect of being eligible for the SAG on mortgage interest rates. Although unobservable characteristics pose a challenge for the identification in general, a valid RD design can still identify the causal effect of the treatment on the outcome variable, as noted earlier. In particular, for this study, the treatment is having a higher ex ante priority for the subsidized default insurance, the outcome variable is the interest rate spread, and the assignment variable is the ratio of the borrower's income over the MSA's median income.

Following Imbens and Lemieux (2008), I use a local linear regression in the RD design. Specifically, I control for the assignment variable on either side of the cutoff, captured by the interaction term between the assignment variable and the SAG dummy. As discussed later, all other covariates change continuously at the cutoff in my study, so controlling for the assignment variable should be sufficient to identify the causal effect. However, including a set of controls provides a robustness check and also reduces the variance, as noted by Lee and Lemieux (2010).

The regression results with various specifications are presented in Table 3. All specifications 


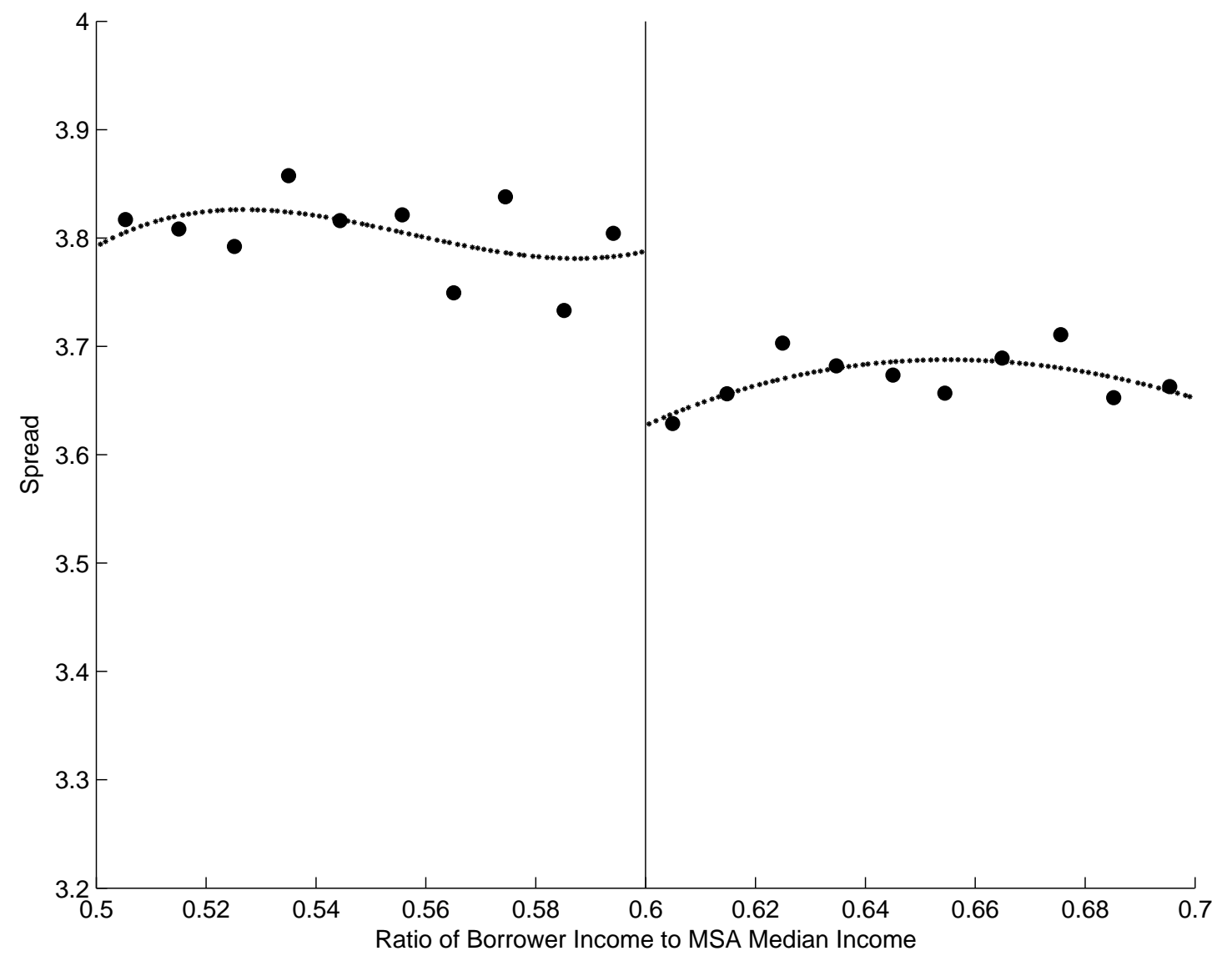

Figure 3: Discontinuity in interest rate spread at the SAG cutoff (2006).

control for year fixed effects. Column (1) is the results of global regressions using all observations, and Columns (3)-(8) are results using observations close to the cutoff. For example, Column (5) uses loans with borrower incomes falling between $58 \%$ and $62 \%$ of their MSA's median income. The closer to the cutoff, the more reliable the RD's result, provided that there are enough observations and that the RD design remains valid. Columns (3)-(8) control for MSA fixed effects, where standard errors are clustered at the MSA-level. All columns control for the income ratio (the assignment variable), and all even-numbered columns also control for the income level (in addition to the income ratio) in order to mitigage the omitted variable bias. As shown in Table 3, the coefficients of the SAG are very similar with and without the income level, confirming the validity of the RD design.

The key variable of interest in Table 3 is the SAG dummy. Columns (5)-(6) show that being eligible for the SAG has a statistically significant effect on the interest rate spread, and it raises the spread (and the interest rate) by 11 basis points, amounting to about $2.9 \%$ of the average spread in the corresponding sample. Using loans that are even closer to the cutoff (for borrowers with incomes between $59 \%$ and $61 \%$ of their MSA median income), Columns (7)-(8) find that the SAG eligibility raises the spread by 17 basis points, amounting to about $4.6 \%$ of the average spread in the corresponding sample. These effects are economically small, but since the SAG eligibility is far from capturing the full effect of the GSEs' subsidized default insurance itself, ${ }^{20}$ the actual effect of the subsidy may still be economically large. These four columns establish the key empirical result

${ }^{20}$ Recall that the SAG eligibility only measures the probability to receive that subsidy. 


\begin{tabular}{|c|c|c|c|c|c|c|c|c|}
\hline Spread & $\begin{array}{l}\text { (1) } \\
\text { global }\end{array}$ & $\begin{array}{c}\text { (2) } \\
\text { global with } \\
\text { income }\end{array}$ & $\begin{array}{c}\text { (3) } \\
5 \% \text { with } \\
\text { MSA }\end{array}$ & $\begin{array}{c}\text { (4) } \\
5 \% \text { with } \\
\text { MSA and } \\
\text { income }\end{array}$ & $\begin{array}{c}\text { (5) } \\
2 \% \text { with } \\
\text { MSA }\end{array}$ & $\begin{array}{c}\text { (6) } \\
2 \% \text { with } \\
\text { MSA and } \\
\text { income }\end{array}$ & $\begin{array}{c}(7) \\
1 \% \text { with } \\
\text { MSA }\end{array}$ & $\begin{array}{c}\text { (8) } \\
1 \% \text { with } \\
\text { MSA and } \\
\text { income }\end{array}$ \\
\hline $\begin{array}{l}\text { SAG } \\
\text { Income }\end{array}$ & $\begin{array}{l}-0.0308^{* *} \\
(0.012)\end{array}$ & $\begin{array}{c}-0.0332^{* * * *} \\
(0.007) \\
-0.0019 * * * \\
(0.000)\end{array}$ & $\begin{array}{l}0.0279 \\
(0.450)\end{array}$ & $\begin{array}{c}0.0271 \\
(0.465) \\
-0.0132 \\
(0.245)\end{array}$ & $\begin{array}{l}0.1078^{*} \\
(0.074)\end{array}$ & $\begin{array}{c}0.1082 * \\
(0.072) \\
0.0038 \\
(0.846)\end{array}$ & $\begin{array}{l}0.1719 * \\
(0.062)\end{array}$ & $\begin{array}{c}0.1659 * \\
(0.077) \\
0.0414 \\
(0.176)\end{array}$ \\
\hline Second-lien & $\begin{array}{l}2.4030 * * * \\
(0.000)\end{array}$ & $\begin{array}{l}2.4140 * * * \\
(0.000)\end{array}$ & $\begin{array}{l}3.5169 * * * \\
(0.000)\end{array}$ & $\begin{array}{l}3.5154 * * * \\
(0.000)\end{array}$ & $\begin{array}{l}3.6244 * * * \\
(0.000)\end{array}$ & $\begin{array}{l}3.6222 * * * \\
(0.000)\end{array}$ & $\begin{array}{l}3.3437^{* * * *} \\
(0.000)\end{array}$ & $\begin{array}{l}3.2749 * * * \\
(0.000)\end{array}$ \\
\hline Female & $\begin{array}{c}-0.0101^{*} \\
(0.070)\end{array}$ & $\begin{array}{c}-0.0106^{*} \\
(0.058)\end{array}$ & $\begin{array}{l}-0.0139 \\
(0.507)\end{array}$ & $\begin{array}{l}-0.0140 \\
(0.505)\end{array}$ & $\begin{array}{l}-0.0372 \\
(0.213)\end{array}$ & $\begin{array}{l}-0.0372 \\
(0.213)\end{array}$ & $\begin{array}{l}-0.0536 \\
(0.257)\end{array}$ & $\begin{array}{l}-0.0535 \\
(0.259)\end{array}$ \\
\hline Not Hispanic or Latino & $\begin{array}{c}0.0826^{* * * *} \\
(0.000)\end{array}$ & $\begin{array}{l}0.0942^{* * * *} \\
(0.000)\end{array}$ & $\begin{array}{l}-0.0100 \\
(0.713)\end{array}$ & $\begin{array}{l}-0.0109 \\
(0.688)\end{array}$ & $\begin{array}{l}0.0314 \\
(0.472)\end{array}$ & $\begin{array}{l}0.0316 \\
(0.468)\end{array}$ & $\begin{array}{l}0.0108 \\
(0.841)\end{array}$ & $\begin{array}{l}0.0144 \\
(0.788)\end{array}$ \\
\hline Asian & $\begin{array}{l}-0.1568 * * * \\
(0.000)\end{array}$ & $\begin{array}{c}-0.1506^{* * * *} \\
(0.000)\end{array}$ & $\begin{array}{r}0.0466 \\
(0.719)\end{array}$ & $\begin{array}{l}0.0454 \\
(0.726)\end{array}$ & $\begin{array}{l}0.0299 \\
(0.839)\end{array}$ & $\begin{array}{l}0.0302 \\
(0.838)\end{array}$ & $\begin{array}{r}-0.1085 \\
(0.672)\end{array}$ & $\begin{array}{l}-0.1038 \\
(0.686)\end{array}$ \\
\hline Black & $\begin{array}{l}0.2011^{* * * *} \\
(0.000)\end{array}$ & $\begin{array}{l}0.2002 * * * \\
(0.000)\end{array}$ & $\begin{array}{l}0.3293 * * * \\
(0.006)\end{array}$ & $\begin{array}{l}0.3289 * * * \\
(0.006)\end{array}$ & $\begin{array}{l}0.3039 * * \\
(0.020)\end{array}$ & $\begin{array}{c}0.3043^{* *} \\
(0.020)\end{array}$ & $\begin{array}{l}0.1032 \\
(0.645)\end{array}$ & $\begin{array}{l}0.1071 \\
(0.633)\end{array}$ \\
\hline $\begin{array}{l}\text { Native Hawaiian or } \\
\text { Other Pacific Islander }\end{array}$ & $\begin{array}{l}-0.0297 \\
(0.533)\end{array}$ & $\begin{array}{l}-0.0305 \\
(0.523)\end{array}$ & $\begin{array}{l}0.2680 \\
(0.239)\end{array}$ & $\begin{array}{l}0.2681 \\
(0.237)\end{array}$ & $\begin{array}{l}-0.1196 \\
(0.620)\end{array}$ & $\begin{array}{r}-0.1191 \\
(0.622)\end{array}$ & $\begin{array}{l}-0.3927 \\
(0.159)\end{array}$ & $\begin{array}{r}-0.3807 \\
(0.173)\end{array}$ \\
\hline White & $\begin{array}{l}-0.0243 \\
(0.424)\end{array}$ & $\begin{array}{c}-0.0268 \\
(0.378)\end{array}$ & $\begin{array}{l}0.0588 \\
(0.582)\end{array}$ & $\begin{array}{l}0.0588 \\
(0.581)\end{array}$ & $\begin{array}{l}-0.0113 \\
(0.922)\end{array}$ & $\begin{array}{c}-0.0109 \\
(0.924)\end{array}$ & $\begin{array}{c}-0.1522 \\
(0.463)\end{array}$ & $\begin{array}{c}-0.1483 \\
(0.475)\end{array}$ \\
\hline IncomeRatioPrim_L & $\begin{array}{c}-0.0196 \\
(0.816)\end{array}$ & $\begin{array}{l}0.0980 \\
(0.248)\end{array}$ & $\begin{array}{r}-0.0861 \\
(0.929)\end{array}$ & $\begin{array}{l}0.6816 \\
(0.542)\end{array}$ & $\begin{array}{l}1.3762 \\
(0.701)\end{array}$ & $\begin{array}{l}1.1703 \\
(0.753)\end{array}$ & $\begin{array}{l}16.5731 \\
(0.278)\end{array}$ & $\begin{array}{l}13.9400 \\
(0.380)\end{array}$ \\
\hline IncomeRatioPrim_R & $\begin{array}{l}0.0057 \\
(0.138)\end{array}$ & $\begin{array}{c}0.1075^{* * *} * \\
(0.000)\end{array}$ & $\begin{array}{l}1.6552^{*} \\
(0.061)\end{array}$ & $\begin{array}{c}2.4353^{* *} \\
(0.025)\end{array}$ & $\begin{array}{l}6.0874^{*} \\
(0.089)\end{array}$ & $\begin{array}{l}5.8920 \\
(0.134)\end{array}$ & $\begin{array}{r}-2.5920 \\
(0.829)\end{array}$ & $\begin{array}{l}-6.7756 \\
(0.583)\end{array}$ \\
\hline Observations & 103,758 & 103,758 & 8,872 & 8,872 & 3,513 & 3,513 & 1,845 & 1,845 \\
\hline R-squared & 0.066 & 0.067 & 0.104 & 0.104 & 0.170 & 0.170 & 0.208 & 0.210 \\
\hline
\end{tabular}

Table 3: RD design results for the SAG

(1) P-values are in parentheses; *** means $\mathrm{p}<0.01, * *$ means $\mathrm{p}<0.05$, and $*$ means $\mathrm{p}<0.1$.

(2) $\mathrm{SAG}=1$ if the loan is eligible for the SAG.

(3) IncomeRatioPrim $=$ IncomeRatio -0.60. IncomeRatioPrim_L $=$ IncomeRatioPrim*SAG. IncomeRatioPrim_R $=$ IncomeRatioPrim* $*(1-\mathrm{SAG})$.

(4) The baseline case of the dummy variable for race is American Indian or Alaska Native.

of the paper: having a higher subsidy probability raises the interest rate spread of conforming loans, as well as the interest rate level itself (assuming the risk-free rate is unaffected). This result contrasts with the conventional wisdom.

Note that although the SAG eligibility decreases the spread in the global regressions and has no effect in the $5 \%$ regressions, these effects are likely driven by the fact that it is hard to correctly identify the economically small effect of the SAG using observations sufficiently far from the cutoff. Thus, we can mainly rely on Columns (5)-(8) when interpreting the results.

Other covariates in the regressions provide a way to double check the empirical strategy used in the paper. As expected, the status of being a second-lien loan significantly increases the spread, both statistically and economically. In addition, the effects of the gender and almost all race dummies are statistically insignificant. This makes economic sense given that the very intention of the HMDA is to prevent from gender and racial discrimination and to enforce fair lending.

The covariate that has an unexpected sign is the dummy variable Black: loans for Black borrowers are found to have a higher spread than those for all other races. However, we can still reconcile this unexpected sign as follows. On the one hand, I have included some variables which are not used by the bank when making the lending decision, such as race and gender. On the other hand, due to data restriction, I have omitted some important variables such as the credit 
score. Since the credit score is likely to be correlated with race and gender, I have effectively used race and gender as a proxy for the omitted variable. Given that Black borrowers may have a lower credit score on average, the positive coefficient of the Black dummy may just reflect the effect of the omitted credit score. Indeed, as we move closer to the cutoff, the omitted variable problem becomes less severe (due to balanced distributions of the omitted variable on both sides of the cutoff), and thus the Black dummy becomes statistically insignificant, as Columns (7)-(8) indicate.

\section{$2.3 \quad$ Validity testings of the RD designs}

Two conditions are needed for the RD designs to be valid. First, the subjects should have an imprecise control over the assignment variable, otherwise the design suffers from a self-selection problem. In our case, this self-selection problem means that borrowers manipulate (i.e., misreport) their incomes to be just below or above the median income of their MSA, depending on whether the offered equilibrium interest rates for loans below the income cutoff are lower or higher than those above. However, such a mis-reporting is unlikely, given that the borrowers of GSE-insured mortgage loans are required to submit verifiable income documents when applying for these loans. Some recent studies show evidence of mortgage borrowers misreporting incomes; examples include LaCour-Little and Yang (2013), Jiang, Nelson, and Vytlacil (2014), Ambrose, Conklin, and Yoshida (2016), and Mian and Sufi (Forthcoming). However, as pointed out by these studies, this phenomenon mainly exists in the non-GSE insured mortgages and low-documentation mortgages. $^{21}$ Given that my paper only considers the loans actually insured by GSEs and that GSEs have strict rules regarding the income documentation, the misreporting is unlikely to be a concern in my case. These arguments support the validity of the RD designs in terms of the first condition.

The second condition is that the baseline covariates other than the assignment variable (such as the income level) should have smooth distributions across the cutoff, so that we can attribute the discontinuity in the outcome variable to that in the treatment status. One way to check this is to simply plot the bin means of baseline covariates and visually check whether the bin mean displays a discontinuity at the cutoff. As Figure 4 makes clear, all covariates are distributed smoothly across the cutoff, including the average income, the fraction of first-lien loans, the fraction of loans to male borrowers, etc.

An alternative and more rigorous way to test the second condition is to do a separate local linear regression for each baseline covariate, replacing the outcome variable by the covariate in the local linear regression. As noted by Lee and Lemieux (2010), with multiple covariates, it is useful to combine the multiple and separate tests into a single test statistic. The authors suggest running a Seemingly Unrelated Regression (SUR) for each covariate, and then performing a $\chi^{2}$ test for all the coefficients of the treatment dummy being zero. I follow the suggestion, and the $\chi^{2}$ statistic in my case turns out to be 2.07 , with a p-value of 0.9132 . Hence, we cannot reject the null hypothesis that all the coefficients of the treatment dummy are zero. In sum, the RD designs conducted in this paper have passed the validity tests.

${ }^{21}$ For example, Mian and Sufi (Forthcoming) find that fraud was most prevalent "among mortgages originated from 2002 to 2005 sold for non-GSE securitization." Ambrose, Conklin, and Yoshida (2016) find that "the majority of adverse selection and income falsification is confined to a specific borrower group", which consists of borrowers who originated low-documentation loans but could have easily originated full-documentation mortgages instead. Moreover, the same study warns against policies that are based on the assumption of income falsification in other borrower groups and that are designed to eliminate activities associated with excesses in mortgage originations. 

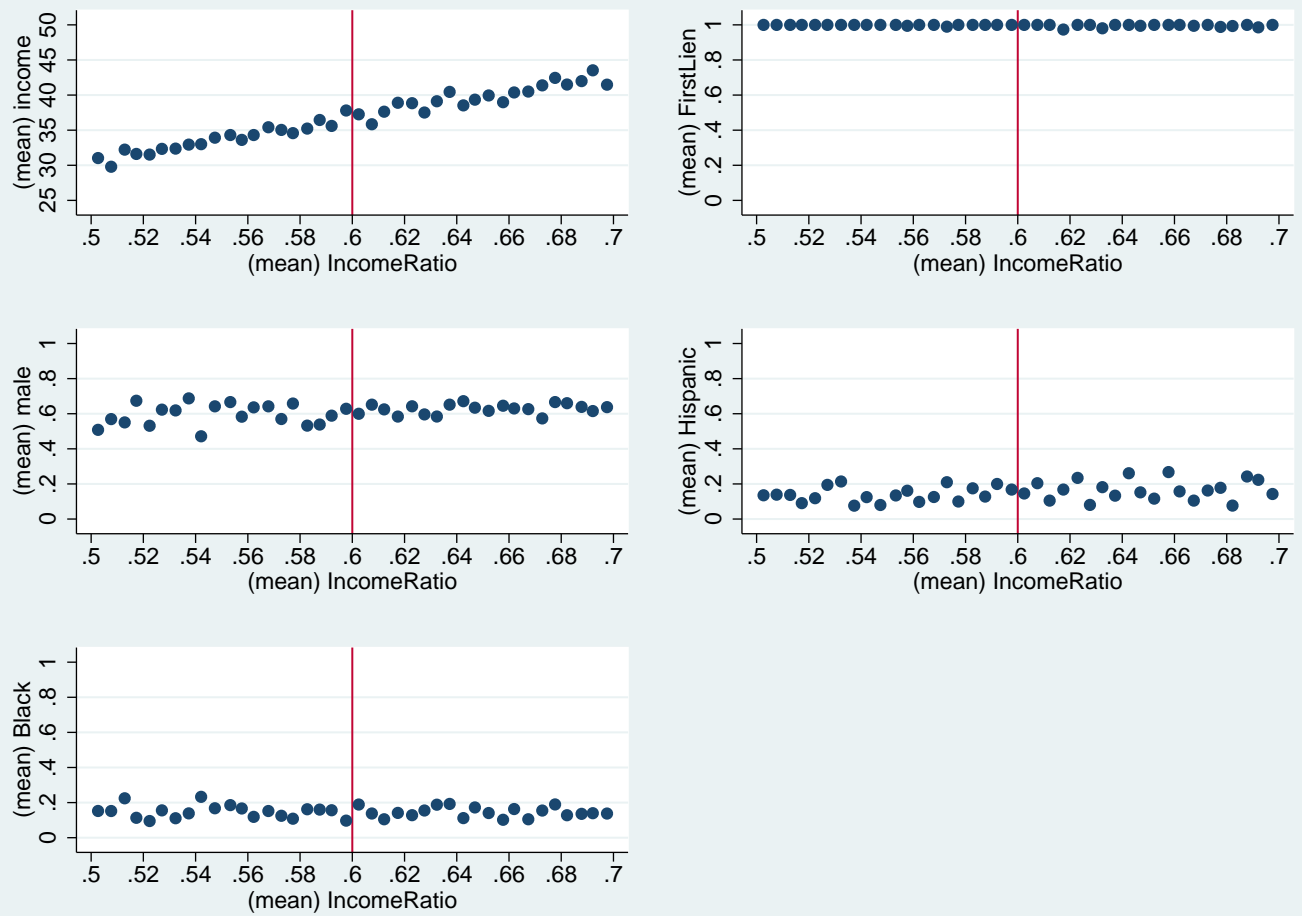

Figure 4: Validity testing for the SAG: balanced distributions of covariates.

\subsection{Robustness check}

This subsection presents a range of robustness checks. First, I conduct some falsification tests to rule out the possibility that the discontinuity results for the SAG are spurious. Specifically, since Figure 3 seems to contain another discontinuity at the income ratio of $57 \%$, I conduct the RD designs at this income ratio, as well as at $63 \%$ to account for the symmetry. The regression results for these falsification tests are presented in Table 4 and Table 5. As the two tables make clear, SAG is insignificant in all local regressions (Columns (3)-(8)), in both the $57 \%$ and $63 \%$ cases). These results confirm that the discontinuous jump of the interest rate at the $60 \%$ cutoff is unlikely to be generated by spurious results, but rather by the underlying subsidy mechanism associated with the $60 \%$ cutoff.

Second, I conduct some robustness checkes using a different data set. Since the HMDA data only contain the spread instead of the interest rate itself, one may wonder if the results with SAG are just driven by this measurement error. To examine this, I use a random sample extracted from another data set, which contains the interest rate information. This is the single-family loan-level (SFLL) data released by Freddie Mac. ${ }^{22}$ I also examine the period from 2004 to 2007, and I follow a similar data cleaning procedure as for the HDMA data where possible. In addition, I keep loans with FICO scores above 620 to make the loans more comparable, since 620 is said to be another conforming criterion used by GSEs. The ultimate sample used in the robustness check contains 47,961 observations.

The SFLL data set does not provide geographic information needed to determine the SAG

${ }^{22}$ I do not use the SFLL data for the main result because it does not have the data for borrower income. Instead, I impute the borrower income information from the "back-end" debt-to-income (DTI) ratio. 


\begin{tabular}{|c|c|c|c|c|c|c|c|c|}
\hline Spread & $\begin{array}{c}\text { (1) } \\
\text { global }\end{array}$ & $\begin{array}{c}(2) \\
\text { global } \\
\text { with } \\
\text { income }\end{array}$ & $\begin{array}{c}\text { (3) } \\
5 \% \text { with } \\
\text { MSA }\end{array}$ & $\begin{array}{c}\text { (4) } \\
5 \% \text { with } \\
\text { MSA and } \\
\text { income }\end{array}$ & $\begin{array}{c}\text { (5) } \\
2 \% \text { with } \\
\text { MSA }\end{array}$ & $\begin{array}{c}(6) \\
2 \% \text { with } \\
\text { MSA and } \\
\text { income }\end{array}$ & $\begin{array}{c}(7) \\
1 \% \text { with } \\
\text { MSA }\end{array}$ & $\begin{array}{c}(8) \\
1 \% \text { with } \\
\text { MSA and } \\
\text { income }\end{array}$ \\
\hline SAG & $\begin{array}{l}-0.0207 \\
(0.114)\end{array}$ & $\begin{array}{c}-0.0233^{*} \\
(0.075)\end{array}$ & $\begin{array}{l}-0.0145 \\
(0.728)\end{array}$ & $\begin{array}{l}-0.0141 \\
(0.734)\end{array}$ & $\begin{array}{l}-0.0069 \\
(0.918)\end{array}$ & $\begin{array}{l}-0.0047 \\
(0.944)\end{array}$ & $\begin{array}{l}-0.0570 \\
(0.605)\end{array}$ & $\begin{array}{l}-0.0546 \\
(0.624)\end{array}$ \\
\hline Income & & $\begin{array}{l}-0.0019 * * * \\
(0.000)\end{array}$ & & $\begin{array}{c}-0.0245^{* *} \\
(0.048)\end{array}$ & & $\begin{array}{l}-0.0318 \\
(0.277)\end{array}$ & & $\begin{array}{l}-0.0202 \\
(0.691)\end{array}$ \\
\hline Second-lien & $\begin{array}{l}2.4035 * * * \\
(0.000)\end{array}$ & $\begin{array}{l}2.4145^{* * *} \\
(0.000)\end{array}$ & $\begin{array}{l}3.8372^{* * *} \\
(0.000)\end{array}$ & $\begin{array}{c}3.8469^{* * *} \\
(0.000)\end{array}$ & $\begin{array}{c}4.2639 * * * \\
(0.001)\end{array}$ & $\begin{array}{l}4.2564^{* * *} \\
(0.001)\end{array}$ & $\begin{array}{c}3.7318^{* *} \\
(0.013)\end{array}$ & $\begin{array}{c}3.7267^{* *} \\
(0.013)\end{array}$ \\
\hline Female & $\begin{array}{c}-0.0104^{*} \\
(0.062)\end{array}$ & $\begin{array}{l}-0.0109^{*} \\
(0.051)\end{array}$ & $\begin{array}{c}-0.0487^{* *} \\
(0.020)\end{array}$ & $\begin{array}{c}-0.0487^{* *} \\
(0.020)\end{array}$ & $\begin{array}{l}-0.0213 \\
(0.544)\end{array}$ & $\begin{array}{l}-0.0213 \\
(0.545)\end{array}$ & $\begin{array}{l}-0.0541 \\
(0.307)\end{array}$ & $\begin{array}{l}-0.0541 \\
(0.308)\end{array}$ \\
\hline Not Hispanic or Latino & $\begin{array}{l}0.0825^{* * *} \\
(0.000)\end{array}$ & $\begin{array}{l}0.0941^{* * *} \\
(0.000)\end{array}$ & $\begin{array}{l}-0.0003 \\
(0.993)\end{array}$ & $\begin{array}{l}-0.0023 \\
(0.949)\end{array}$ & $\begin{array}{l}-0.0104 \\
(0.828)\end{array}$ & $\begin{array}{l}-0.0123 \\
(0.795)\end{array}$ & $\begin{array}{l}-0.0706 \\
(0.302)\end{array}$ & $\begin{array}{l}-0.0700 \\
(0.304)\end{array}$ \\
\hline Asian & $\begin{array}{l}-0.1563^{* * *} \\
(0.000)\end{array}$ & $\begin{array}{l}-0.1501^{* * *} \\
(0.000)\end{array}$ & $\begin{array}{l}0.0429 \\
(0.702)\end{array}$ & $\begin{array}{l}0.0399 \\
(0.723)\end{array}$ & $\begin{array}{l}-0.0035 \\
(0.987)\end{array}$ & $\begin{array}{l}-0.0087 \\
(0.968)\end{array}$ & $\begin{array}{r}-0.0610 \\
(0.849)\end{array}$ & $\begin{array}{l}-0.0641 \\
(0.842)\end{array}$ \\
\hline Black & $\begin{array}{l}0.2012^{* * *} \\
(0.000)\end{array}$ & $\begin{array}{l}0.2004^{* * *} \\
(0.000)\end{array}$ & $\begin{array}{l}0.2812^{* * *} \\
(0.001)\end{array}$ & $\begin{array}{l}0.2779^{* * *} \\
(0.001)\end{array}$ & $\begin{array}{l}0.2790 \\
(0.106)\end{array}$ & $\begin{array}{l}0.2788 \\
(0.105)\end{array}$ & $\begin{array}{l}0.2244 \\
(0.358)\end{array}$ & $\begin{array}{l}0.2288 \\
(0.354)\end{array}$ \\
\hline $\begin{array}{l}\text { Native Hawaiian or } \\
\text { Other Pacific Islander }\end{array}$ & $\begin{array}{l}-0.0295 \\
(0.536)\end{array}$ & $\begin{array}{l}-0.0302 \\
(0.526)\end{array}$ & $\begin{array}{l}0.2278 \\
(0.121)\end{array}$ & $\begin{array}{l}0.2258 \\
(0.124)\end{array}$ & $\begin{array}{l}0.3736 \\
(0.163)\end{array}$ & $\begin{array}{l}0.3775 \\
(0.155)\end{array}$ & $\begin{array}{l}0.4931 \\
(0.222)\end{array}$ & $\begin{array}{l}0.4947 \\
(0.225)\end{array}$ \\
\hline White & $\begin{array}{l}-0.0242 \\
(0.426)\end{array}$ & $\begin{array}{r}-0.0266 \\
(0.381)\end{array}$ & $\begin{array}{l}0.0263 \\
(0.744)\end{array}$ & $\begin{array}{l}0.0230 \\
(0.775)\end{array}$ & $\begin{array}{l}0.0753 \\
(0.631)\end{array}$ & $\begin{array}{l}0.0765 \\
(0.624)\end{array}$ & $\begin{array}{l}0.1361 \\
(0.552)\end{array}$ & $\begin{array}{l}0.1400 \\
(0.545)\end{array}$ \\
\hline Not Hispanic or Latino & $\begin{array}{c}0.0825^{* * *} \\
(0.000)\end{array}$ & $\begin{array}{c}0.0941^{* * *} \\
(0.000)\end{array}$ & $\begin{array}{l}-0.0003 \\
(0.993)\end{array}$ & $\begin{array}{l}-0.0023 \\
(0.949)\end{array}$ & $\begin{array}{c}-0.0104 \\
(0.828)\end{array}$ & $\begin{array}{l}-0.0123 \\
(0.795)\end{array}$ & $\begin{array}{l}-0.0706 \\
(0.302)\end{array}$ & $\begin{array}{l}-0.0700 \\
(0.304)\end{array}$ \\
\hline IncomeRatioPrim_L & $\begin{array}{l}0.0305 \\
(0.763)\end{array}$ & $\begin{array}{l}0.1485 \\
(0.145)\end{array}$ & $\begin{array}{l}-1.2367 \\
(0.177)\end{array}$ & $\begin{array}{l}0.2511 \\
(0.841)\end{array}$ & $\begin{array}{l}-2.0000 \\
(0.585)\end{array}$ & $\begin{array}{l}-0.1194 \\
(0.978)\end{array}$ & $\begin{array}{c}-14.0361 \\
(0.348)\end{array}$ & $\begin{array}{c}-12.8680 \\
(0.407)\end{array}$ \\
\hline IncomeRatioPrim_R & $\begin{array}{l}0.0070^{*} \\
(0.065)\end{array}$ & $\begin{array}{c}0.1085^{* * 8} \\
(0.000)\end{array}$ & $\begin{array}{l}-0.3891 \\
(0.702)\end{array}$ & $\begin{array}{l}1.0627 \\
(0.430)\end{array}$ & $\begin{array}{l}2.9499 \\
(0.515)\end{array}$ & $\begin{array}{l}4.9946 \\
(0.305)\end{array}$ & $\begin{array}{l}11.8213 \\
(0.362)\end{array}$ & $\begin{array}{l}13.3020 \\
(0.341)\end{array}$ \\
\hline Observations & 103,758 & 103,758 & 8,448 & 8,448 & 3,349 & 3,349 & 1,721 & 1,721 \\
\hline R-squared & 0.066 & 0.067 & 0.103 & 0.103 & 0.148 & 0.148 & 0.200 & 0.200 \\
\hline
\end{tabular}

Table 4: Falsification Test results for the SAG at 57\%

(1) P-values are in parentheses; $* * *$ means $\mathrm{p}<0.01,{ }^{* *}$ means $\mathrm{p}<0.05$, and $*$ means $\mathrm{p}<0.1$.

(2) $\mathrm{SAG}=1$ if the loan is eligible for the SAG.

(3) IncomeRatioPrim $=$ IncomeRatio -0.60. IncomeRatioPrim_L $=$ IncomeRatioPrim*SAG. IncomeRatioPrim_R $=$ IncomeRatioPrim*(1-SAG).

(4) The baseline case of the dummy variable for race is American Indian or Alaska Native.

status of a loan. As a result, I impute the borrower's income and study the effect of the "low- and moderate-income goal (LMIG)," which is another mission goal mandated by Congress. Specifically, the goal requires that at least a certain percentage of mortgage loans purchased by GSEs should be for borrowers with incomes below $100 \%$ of the median income of its MSA (or nonmetropolitan county). ${ }^{23}$ Similar with the case of the SAG, I apply the RD designs and compare interest rates around the $100 \%$ income ratio cutoff.

The results for the LMIG with various specifications are presented in Table 6. Across all columns of Table 6, as expected, both the FICO score and the income level have significantly negative effects on the interest rate, and the LTV has a significantly positive effect. For example, a 1 point increase in the FICO score lowers the interest rate by about 0.06 basis point. However, again contrary to conventional wisdom, being eligible for the LMIG (and having a higher priority for the subsidized default insurance) has a statistically positive effect on the interest rate. The magnitude is 20-25 basis points, amounting to 3-4\% of the average interest rate in the corresponding sample.

${ }^{23}$ The percentage of the goal varies over time: it was $42 \%$ for $1997-2000,50 \%$ for $2001-2003$, etc. 


\begin{tabular}{|c|c|c|c|c|c|c|c|c|}
\hline Spread & $\begin{array}{c}\text { (1) } \\
\text { global }\end{array}$ & $\begin{array}{c}\text { (2) } \\
\text { global with } \\
\text { income }\end{array}$ & $\begin{array}{c}\text { (3) } \\
5 \% \text { with } \\
\text { MSA }\end{array}$ & $\begin{array}{c}4) \\
5 \% \text { with } \\
\text { MSA and } \\
\text { income }\end{array}$ & $\begin{array}{c}(5) \\
2 \% \text { with } \\
\text { MSA }\end{array}$ & $\begin{array}{c}(6) \\
2 \% \text { with } \\
\text { MSA and } \\
\text { income }\end{array}$ & $\begin{array}{c}(7) \\
1 \% \text { with } \\
\text { MSA }\end{array}$ & $\begin{array}{c}(8) \\
1 \% \text { with } \\
\text { MSA and } \\
\text { income }\end{array}$ \\
\hline $\mathrm{SAG}$ & $\begin{array}{l}-0.0456 * * * \\
(0.000)\end{array}$ & $\begin{array}{l}-0.0474 * * * \\
(0.000)\end{array}$ & $\begin{array}{l}-0.0152 \\
(0.675)\end{array}$ & $\begin{array}{r}-0.0154 \\
(0.672)\end{array}$ & $\begin{array}{r}-0.0021 \\
(0.970)\end{array}$ & $\begin{array}{l}0.0018 \\
(0.975)\end{array}$ & $\begin{array}{l}0.0379 \\
(0.743)\end{array}$ & $\begin{array}{l}0.0434 \\
(0.704)\end{array}$ \\
\hline Income & & $\begin{array}{l}-0.0019 * * * \\
(0.000)\end{array}$ & & $\begin{array}{l}0.0044 \\
(0.714)\end{array}$ & & $\begin{array}{r}-0.0261 \\
(0.189)\end{array}$ & & $\begin{array}{r}-0.0292 \\
(0.261)\end{array}$ \\
\hline Second-lien & $\begin{array}{l}2.4024^{* * * *} \\
(0.000)\end{array}$ & $\begin{array}{l}2.4134 * * * \\
(0.000)\end{array}$ & $\begin{array}{l}3.2483 * * * \\
(0.000)\end{array}$ & $\begin{array}{c}3.2497 * * * \\
(0.000)\end{array}$ & $\begin{array}{c}3.3783 * * * \\
(0.000)\end{array}$ & $\begin{array}{c}3.3669 * * * \\
(0.000)\end{array}$ & $\begin{array}{c}3.6571 * * * \\
(0.000)\end{array}$ & $\begin{array}{c}3.6552 * * * \\
(0.000)\end{array}$ \\
\hline Female & $\begin{array}{c}-0.0099 * \\
(0.077)\end{array}$ & $\begin{array}{c}-0.0103 * \\
(0.064)\end{array}$ & $\begin{array}{l}0.0063 \\
(0.765)\end{array}$ & $\begin{array}{l}0.0063 \\
(0.766)\end{array}$ & $\begin{array}{r}-0.0030 \\
(0.923)\end{array}$ & $\begin{array}{l}-0.0031 \\
(0.922)\end{array}$ & $\begin{array}{r}-0.0025 \\
(0.958)\end{array}$ & $\begin{array}{r}-0.0019 \\
(0.969)\end{array}$ \\
\hline Not Hispanic or Latino & $\begin{array}{l}0.0828^{* * * *} \\
(0.000)\end{array}$ & $\begin{array}{l}0.0945^{* * * *} \\
(0.000)\end{array}$ & $\begin{array}{r}-0.0106 \\
(0.687)\end{array}$ & $\begin{array}{r}-0.0104 \\
(0.693)\end{array}$ & $\begin{array}{r}-0.0227 \\
(0.597)\end{array}$ & $\begin{array}{l}-0.0239 \\
(0.578)\end{array}$ & $\begin{array}{r}-0.0273 \\
(0.600)\end{array}$ & $\begin{array}{r}-0.0257 \\
(0.623)\end{array}$ \\
\hline Asian & $\begin{array}{l}-0.1571^{* * * *} \\
(0.000)\end{array}$ & $\begin{array}{c}-0.1509 * * * \\
(0.000)\end{array}$ & $\begin{array}{l}0.1178 \\
(0.377)\end{array}$ & $\begin{array}{l}0.1173 \\
(0.378)\end{array}$ & $\begin{array}{l}0.1448 \\
(0.505)\end{array}$ & $\begin{array}{l}0.1416 \\
(0.515)\end{array}$ & $\begin{array}{r}-0.2065 \\
(0.690)\end{array}$ & $\begin{array}{r}-0.1960 \\
(0.704)\end{array}$ \\
\hline Black & $\begin{array}{l}0.2012^{* * *} \\
(0.000)\end{array}$ & $\begin{array}{l}0.2004^{* * *} \\
(0.000)\end{array}$ & $\begin{array}{l}0.3995 * * * \\
(0.000)\end{array}$ & $\begin{array}{c}0.3991^{* * *} \\
(0.000)\end{array}$ & $\begin{array}{c}0.4441 * * \\
(0.025)\end{array}$ & $\begin{array}{c}0.4425^{* *} \\
(0.024)\end{array}$ & $\begin{array}{l}0.0698 \\
(0.875)\end{array}$ & $\begin{array}{l}0.0766 \\
(0.863)\end{array}$ \\
\hline $\begin{array}{l}\text { Native Hawaiian or } \\
\text { Other Pacific Islander }\end{array}$ & $\begin{array}{r}-0.0299 \\
(0.531)\end{array}$ & $\begin{array}{r}-0.0307 \\
(0.520)\end{array}$ & $\begin{array}{l}0.2549 \\
(0.191)\end{array}$ & $\begin{array}{l}0.2539 \\
(0.194)\end{array}$ & $\begin{array}{l}0.4550 \\
(0.310)\end{array}$ & $\begin{array}{l}0.4541 \\
(0.308)\end{array}$ & $\begin{array}{r}-0.1355 \\
(0.859)\end{array}$ & $\begin{array}{r}-0.1282 \\
(0.867)\end{array}$ \\
\hline White & $\begin{array}{l}-0.0240 \\
(0.429)\end{array}$ & $\begin{array}{r}-0.0265 \\
(0.383)\end{array}$ & $\begin{array}{l}0.0878 \\
(0.374)\end{array}$ & $\begin{array}{l}0.0872 \\
(0.378)\end{array}$ & $\begin{array}{l}0.0991 \\
(0.584)\end{array}$ & $\begin{array}{l}0.0976 \\
(0.587)\end{array}$ & $\begin{array}{l}-0.2608 \\
(0.552)\end{array}$ & $\begin{array}{l}-0.2538 \\
(0.562)\end{array}$ \\
\hline IncomeRatioPrim_L & $\begin{array}{r}-0.0731 \\
(0.306)\end{array}$ & $\begin{array}{l}0.0458 \\
(0.526)\end{array}$ & $\begin{array}{l}0.7539 \\
(0.402)\end{array}$ & $\begin{array}{l}0.4872 \\
(0.708)\end{array}$ & $\begin{array}{l}1.0995 \\
(0.726)\end{array}$ & $\begin{array}{l}2.9879 \\
(0.371)\end{array}$ & $\begin{array}{l}-4.5741 \\
(0.791)\end{array}$ & $\begin{array}{l}-4.9940 \\
(0.768)\end{array}$ \\
\hline IncomeRatioPrim_R & $\begin{array}{l}0.0036 \\
(0.351)\end{array}$ & $\begin{array}{c}0.1057^{* * *} \\
(0.000)\end{array}$ & $\begin{array}{l}0.5898 \\
(0.542)\end{array}$ & $\begin{array}{l}0.3239 \\
(0.770)\end{array}$ & $\begin{array}{r}-0.4953 \\
(0.881)\end{array}$ & $\begin{array}{l}1.0779 \\
(0.749)\end{array}$ & $\begin{array}{c}13.7251 \\
(0.276)\end{array}$ & $\begin{array}{c}17.9379 \\
(0.162)\end{array}$ \\
\hline $\begin{array}{l}\text { Observations } \\
\text { R-squared }\end{array}$ & $\begin{array}{c}103,758 \\
0.066\end{array}$ & $\begin{array}{c}103,758 \\
0.067\end{array}$ & $\begin{array}{l}9,088 \\
0.117\end{array}$ & $\begin{array}{l}9,088 \\
0,117\end{array}$ & $\begin{array}{l}3,678 \\
0,163\end{array}$ & $\begin{array}{l}3,678 \\
0,164\end{array}$ & $\begin{array}{l}1,835 \\
0,205\end{array}$ & $\begin{array}{l}1,835 \\
0,206\end{array}$ \\
\hline
\end{tabular}

Table 5: Falsification Test results for the SAG at $63 \%$

(1) P-values are in parentheses; *** means $\mathrm{p}<0.01, * *$ means $\mathrm{p}<0.05$, and $*$ means $\mathrm{p}<0.1$.

(2) $\mathrm{SAG}=1$ if the loan is eligible for the SAG.

(3) IncomeRatioPrim $=$ IncomeRatio -0.60. IncomeRatioPrim_L $=$ IncomeRatioPrim*SAG. IncomeRatioPrim_R $=$ IncomeRatioPrim*(1-SAG).

(4) The baseline case of the dummy variable for race is American Indian or Alaska Native.

\subsection{Auxiliary evidence on mortgage default}

As auxiliary supporting evidence for the theoretical model (to be presented in subsequent sections), I also examine the effect of the subsidy on mortgage default rates of conforming loans. I do so by applying various duration or time-to-default models (including Exponential, Weibull, and Lognormal models) to the SFLL loan performance data set. I follow exactly the same data-cleaning procedure as the data set used to produce Table 6 (e.g., also study the period from 2004 to 2007), except that I use the monthly performance information of the mortgage loans. The ultimate sample contains 2,559,329 observations.

Specifically, I use the following empirical framework:

$$
S_{i}=\beta_{0}+\beta_{1} \text { Subsidy }_{i}+\beta_{2} \text { BorrowerChar }_{i}+\epsilon_{i}
$$

where $S_{i}$ is the survival time of loan $i$ (i.e., time to default, in number of months). Subsidy is the "subsidy propensity" of loan $i$, which is captured by the $L M I G_{i}$ dummy described above. Again, if $L M I G_{i}=1$, it indicates that loan $i$ is ex ante more likely to receive the subsidy and thus has a higher subsidy propensity. BorrowerChar ${ }_{i}$ is the vector of borrower characteristics of loan $i$, such as credit score and income. 


\begin{tabular}{|c|c|c|c|c|c|c|c|c|}
\hline Interest Rate & $\begin{array}{c}\text { (1) } \\
\text { global }\end{array}$ & $\begin{array}{c}\text { (2) } \\
\text { global with } \\
\text { income }\end{array}$ & $\begin{array}{l}\text { (3) } \\
5 \%\end{array}$ & $\begin{array}{c}\text { (4) } \\
5 \% \text { with } \\
\text { income }\end{array}$ & $\begin{array}{l}(5) \\
3 \%\end{array}$ & $\begin{array}{c}\text { (6) } \\
3 \% \text { with } \\
\text { income }\end{array}$ & $\begin{array}{l}(7) \\
2 \%\end{array}$ & $\begin{array}{c}\text { (8) } \\
2 \% \text { with } \\
\text { income }\end{array}$ \\
\hline LMIG & $\begin{array}{l}0.0020 \\
(0.913)\end{array}$ & $\begin{array}{l}0.0029 \\
(0.876)\end{array}$ & $\begin{array}{l}0.0979 \\
(0.182)\end{array}$ & $\begin{array}{l}0.1001 \\
(0.172)\end{array}$ & $\begin{array}{c}0.1984 * * \\
(0.037)\end{array}$ & $\begin{array}{c}0.1992 * * \\
(0.036)\end{array}$ & $\begin{array}{c}0.2562 * * \\
(0.037)\end{array}$ & $\begin{array}{c}0.2524 * * \\
(0.040)\end{array}$ \\
\hline $\mathrm{FICO}$ & $\begin{array}{c}-0.0005 * * * \\
(0.000)\end{array}$ & $\begin{array}{c}-0.0005 * * * \\
(0.000)\end{array}$ & $\begin{array}{c}-0.0005 * * \\
(0.022)\end{array}$ & $\begin{array}{c}-0.0005 * * \\
(0.028)\end{array}$ & $\begin{array}{c}-0.0008 * * * \\
(0.005)\end{array}$ & $\begin{array}{c}-0.0008 * * * \\
(0.006)\end{array}$ & $\begin{array}{c}-0.0006^{*} \\
(0.081)\end{array}$ & $\begin{array}{c}-0.0006^{*} \\
(0.084)\end{array}$ \\
\hline LTV & $\begin{array}{c}0.0043 * * * \\
(0.000)\end{array}$ & $\begin{array}{c}0.0043 * * * \\
(0.000)\end{array}$ & $\begin{array}{c}0.0059 * * * \\
(0.000)\end{array}$ & $\begin{array}{c}0.0057 * * * \\
(0.000)\end{array}$ & $\begin{array}{c}0.0061 * * * \\
(0.000)\end{array}$ & $\begin{array}{c}0.0060 * * * \\
(0.000)\end{array}$ & $\begin{array}{c}0.0071 * * * \\
(0.000)\end{array}$ & $\begin{array}{c}0.0070 * * * \\
(0.000)\end{array}$ \\
\hline Income & & $\begin{array}{c}-0.0024 * * * \\
(0.000)\end{array}$ & & $\begin{array}{c}-0.0025^{*} \\
(0.096)\end{array}$ & & $\begin{array}{l}-0.0016 \\
(0.431)\end{array}$ & & $\begin{array}{l}-0.0024 \\
(0.363)\end{array}$ \\
\hline MSA_college & $\begin{array}{c}-0.0030 * * * \\
(0.000)\end{array}$ & $\begin{array}{c}-0.0020 * * * * \\
(0.000)\end{array}$ & $\begin{array}{c}-0.0030 * \\
(0.090)\end{array}$ & $\begin{array}{r}-0.0011 \\
(0.615)\end{array}$ & $\begin{array}{c}-0.0048 * \\
(0.050)\end{array}$ & $\begin{array}{l}-0.0033 \\
(0.286)\end{array}$ & $\begin{array}{r}-0.0027 \\
(0.390)\end{array}$ & $\begin{array}{l}-0.0007 \\
(0.865)\end{array}$ \\
\hline IncomeRatioPrim_L & $\begin{array}{c}-0.2536 * * * \\
(0.006)\end{array}$ & $\begin{array}{r}-0.1219 \\
(0.200)\end{array}$ & $\begin{array}{l}8.6513 \\
(0.345)\end{array}$ & $\begin{array}{l}8.4932 \\
(0.354)\end{array}$ & $\begin{array}{l}11.0505 \\
(0.586)\end{array}$ & $\begin{array}{l}10.3582 \\
(0.610)\end{array}$ & $\begin{array}{c}63.4838 \\
(0.103)\end{array}$ & $\begin{array}{c}61.1125 \\
(0.117)\end{array}$ \\
\hline IncomeRatioPrim_R & $\begin{array}{l}0.2649 \\
(0.133)\end{array}$ & $\begin{array}{c}0.4023 * * \\
(0.024)\end{array}$ & $\begin{array}{l}2.4529 \\
(0.794)\end{array}$ & $\begin{array}{l}3.0107 \\
(0.749)\end{array}$ & $\begin{array}{c}38.3895^{*} \\
(0.054)\end{array}$ & $\begin{array}{c}39.0203^{*} \\
(0.051)\end{array}$ & $\begin{array}{l}18.2800 \\
(0.638)\end{array}$ & $\begin{array}{l}17.1127 \\
(0.660)\end{array}$ \\
\hline IncomeRatioPrim2_L & $\begin{array}{c}-0.7142 * * * \\
(0.002)\end{array}$ & $\begin{array}{c}-0.7224 * * * \\
(0.001)\end{array}$ & $\begin{array}{c}272.7786 \\
(0.524)\end{array}$ & $\begin{array}{c}260.8051 \\
(0.542)\end{array}$ & $\begin{array}{c}101.5716 \\
(0.948)\end{array}$ & $\begin{array}{c}45.2966 \\
(0.977)\end{array}$ & $\begin{array}{c}7,230.8168 \\
(0.109)\end{array}$ & $\begin{array}{c}6,954.7399 \\
(0.124)\end{array}$ \\
\hline IncomeRatioPrim2_R & $\begin{array}{r}-0.6407 \\
(0.210)\end{array}$ & $\begin{array}{l}-0.6852 \\
(0.180)\end{array}$ & $\begin{array}{c}-251.6613 \\
(0.578)\end{array}$ & $\begin{array}{c}-265.9723 \\
(0.556)\end{array}$ & $\begin{array}{c}-3,185.1832 * * \\
(0.046)\end{array}$ & $\begin{array}{c}-3,214.3421 * * \\
(0.044)\end{array}$ & $\begin{array}{c}146.1488 \\
(0.975)\end{array}$ & $\begin{array}{c}397.0764 \\
(0.932)\end{array}$ \\
\hline IncomeRatioPrim3_L & $\begin{array}{c}-0.8173 * * * \\
(0.000)\end{array}$ & $\begin{array}{c}-0.8182^{* * * *} \\
(0.000)\end{array}$ & $\begin{array}{c}2,547.9374 \\
(0.652)\end{array}$ & $\begin{array}{c}2,426.2178 \\
(0.667)\end{array}$ & $\begin{array}{c}-9,145.7807 \\
(0.789)\end{array}$ & $\begin{array}{c}-10,282.1672 \\
(0.764)\end{array}$ & $\begin{array}{c}243,913.5802 \\
(0.100)\end{array}$ & $\begin{array}{c}235,185.4578 \\
(0.114)\end{array}$ \\
\hline IncomeRatioPrim3_R & $\begin{array}{l}0.4564 \\
(0.250)\end{array}$ & $\begin{array}{l}0.5032 \\
(0.205)\end{array}$ & $\begin{array}{c}4,857.7864 \\
(0.423)\end{array}$ & $\begin{array}{c}4,997.9052 \\
(0.410)\end{array}$ & $\begin{array}{c}67,620.2224 * \\
(0.057)\end{array}$ & $\begin{array}{c}68,096.5327 * \\
(0.055)\end{array}$ & $\begin{array}{c}-71,979.5064 \\
(0.642)\end{array}$ & $\begin{array}{c}-81,964.9666 \\
(0.597)\end{array}$ \\
\hline $\begin{array}{l}\text { Observations } \\
\text { R-squared }\end{array}$ & $\begin{array}{c}47,961 \\
0.375\end{array}$ & $\begin{array}{c}47,961 \\
0.375\end{array}$ & $\begin{array}{l}1,343 \\
0.354\end{array}$ & $\begin{array}{l}1,343 \\
0.356\end{array}$ & $\begin{array}{c}830 \\
0.359\end{array}$ & $\begin{array}{c}830 \\
0.359\end{array}$ & $\begin{array}{c}566 \\
0.363\end{array}$ & $\begin{array}{c}566 \\
0.364\end{array}$ \\
\hline
\end{tabular}

Table 6: RD design results for the LMIG

(1) P-values are in parentheses; *** means $\mathrm{p}<0.01,{ }^{* *}$ means $\mathrm{p}<0.05$, and $*$ means $\mathrm{p}<0.1$.

(2) $\mathrm{LMIG}=1$ if the borrower satisfies the criterion of the "Low-and-Moderate-Income Goal," and 0 otherwise.

(3) IncomeRatio = borrower income/MSA median income. IncomeRatioPrim = IncomeRatio -1.

IncomeRatioPrim_L $=$ IncomeRatioPrim*LMIG. IncomeRatioPrim 2 _L $=$ IncomeRatioPrim $2^{*}$ LMIG, and so on.

Two points are worth noting regarding the empirical framework:

Firstly, I do not use a period-by-period Probit or Logistic model with the dependent variable being a dummy variable indicating whether loan $i$ defaults in month $t$. The reason is that, as Bajari, Chu, and Park (2011) point out, we essentially observe only one outcome for each loan, which is the time to default. The period-by-period Probit or Logistic model treats the status of the loan in each month as a separate observation, which articially deflates the standard errors. By contrast, the time-to-default framework used in this paper circumvents this problem by treating each loan as one observation.

Secondly, I do not include loan characteristics (such as interest rate and loan size) as additional regressors. I claim that this is a more appropriate specification than the empirical model with loan characteristics. To see this, suppose we do include loan characteristics and estimate the following equation (where LoanChar $_{i}$ is the vector of loan characteristics of loan $i$ ):

$$
S_{i}=\alpha_{0}+\alpha_{1} \text { Subsidy }_{i}+\alpha_{2} \text { LoanChar }_{i}+\alpha_{3} \text { BorrowerChar }_{i}+\eta_{i}
$$

The problem with Specification (2) is that in reality, loan characteristics are also endogenously chosen by the borrower, and thus we have to include the following equation in the estimation system:

$$
\text { LoanChar }_{i}=\gamma_{0}+\gamma_{1} \text { Subsidy }_{i}+\gamma_{2} \text { BorrowerChar }_{i}+u_{i}
$$


Plugging equation (3) into equation (2), we get the following after some rearrangements:

$$
S_{i}=\left(\alpha_{0}+\gamma_{0} \alpha_{2}\right)+\left(\alpha_{1}+\gamma_{1} \alpha_{2}\right) \text { Subsidy }_{i}+\left(\alpha_{3}+\gamma_{2} \alpha_{2}\right) \text { BorrowerChar }_{i}+\left(\eta_{i}+u_{i} \alpha_{2}\right)
$$

Equation (4) is equivalent to equation (1) that is used in the paper. In other words, equation (1) is the reduced form of the joint system consisting of equations (2) and (3), and thus captures the net effect of the subsidy on the time to default.

The results for the various duration models are presented in Table 7. Columns (2), (4) and (6) control for MSA fixed effects and use robust standard errors, so the interpretation is mainly based on these more reliable columns. Across these columns, as expected, a mortgage loan with a higher FICO score will have a longer time to default, i.e., a lower default risk, ceteris paribus. ${ }^{24}$ Importantly, five out of the six columns in Table 7 indicate that being eligible for the LMIG (and having a higher priority for the subsidized default insurance) has a statistically negative effect on the mortgage's time to default. Although the coefficient of LMIG in one specification of the Lognormal model (Column (6)) is insignificant, the reported Akaike information criteria suggest that the most reliable model is the Weibull model with MSA fixed effects and robust standard errors (Column (4)). These results suggest that the subsidy raises a conforming loan's default risk and makes the entire housing finance system more fragile. These results are consistent with the predictions in the theoretical model presented below.

\section{Benchmark model}

\subsection{Model setup}

There are two periods in the model: the contracting period $n=0$, and the default period $n=1$. There is a continuum of borrowers (agents). Each borrower is characterized by a private scalar type $\theta$. Denote the cumulative distribution function (cdf) of the type distribution by $F(\cdot)$, and the probability density function (pdf) by $f(\cdot)$, both defined on $[\underline{\theta}, \bar{\theta}]$ where $0 \leq \underline{\theta}<\bar{\theta}<+\infty$. There is a monopolistic bank (principal), who designs a menu of mortgage loan contracts consisting of a loan size $b(\theta)$ and a gross interest rate $R(\theta)$ for each $\theta$ at period 0 . Note that this model is different from the standard credit rationing model as in Stiglitz and Weiss (1981) in the sense that there is a continuum of interest rates instead of only one market interest rate that applies to all borrowers.

The type $\theta$ represents the unobserved quality of the borrower. Specifically, if a type- $\theta$ borrower repays the mortgage, he can keep his house and receive a monetary benefit $\theta$ due to his enhanced credit record. Hence, a borrower with a higher $\theta$ is less likely to default, and thus a higher $\theta$ represents a higher "quality index" or a lower "risk index" of the borrower from the bank's perspective. An alternative but equivalent interpretation is that $\theta$ represents the default cost: if the borrower defaults, his credit record will be damaged, and thus will incur a cost of $\theta$. Kawai, Onishi, and Uetake (2013) model the type of the borrower in a similar way.

At period 0 , each borrower receives a publicly observable vector $Z_{0}$, consisting of current income $y_{0}$, credit score $s$, housing demand $h_{0}$, a common current housing price $p_{0}$ (common to all borrowers, in terms of dollars per square feet), the distribution of future income $y_{1}$, and the distribution of common future housing price $p_{1}$ (cdf denoted by $G($.$) ). Based on the Z_{0}$ of all borrowers and

\footnotetext{
${ }^{24}$ The estimated effects of income in Columns (4) and (6) are insignificant and may seem to be less intuitive. However, this can be explained by the multicollinearity between FICO score and income. That is, most of the effect of the income variable is likely to have been captured by FICO score, which makes the income variable itself insignificant.
} 


\begin{tabular}{|c|c|c|c|c|c|c|}
\hline & $\begin{array}{c}\text { (1) } \\
\text { Exponential }\end{array}$ & $\begin{array}{c}(2) \\
\text { Exponential, } \\
\text { MSA \& } \\
\text { Robust } \\
\end{array}$ & $\begin{array}{c}\text { (3) } \\
\text { Weibull }\end{array}$ & $\begin{array}{c}\text { (4) } \\
\text { Weibull, } \\
\text { MSA \& } \\
\text { Robust } \\
\end{array}$ & $\begin{array}{c}\text { (5) } \\
\text { Lognormal }\end{array}$ & $\begin{array}{c}(6) \\
\text { Lognormal, } \\
\text { MSA \& } \\
\text { Robust } \\
\end{array}$ \\
\hline LMIG & $\begin{array}{c}-0.2526 * * * * \\
(0.000)\end{array}$ & $\begin{array}{c}-0.1546 * * * \\
(0.000)\end{array}$ & $\begin{array}{c}-0.0587 * * * * \\
(0.000)\end{array}$ & $\begin{array}{c}-0.0365^{* * * *} \\
(0.000)\end{array}$ & $\begin{array}{c}-0.0492 * * * * \\
(0.000)\end{array}$ & $\begin{array}{r}-0.0342 \\
(0.000)\end{array}$ \\
\hline fico & $\begin{array}{l}0.0123^{* * * *} \\
(0.000)\end{array}$ & $\begin{array}{l}0.0125 * * * \\
(0.000)\end{array}$ & $\begin{array}{c}0.0021 * * * \\
(0.000)\end{array}$ & $\begin{array}{c}0.0022 * * * \\
(0.000)\end{array}$ & $\begin{array}{c}0.0024 * * * \\
(0.000)\end{array}$ & $\begin{array}{c}0.002 \\
(0.000)\end{array}$ \\
\hline Income & $\begin{array}{c}-0.0039 * * * \\
(0.000)\end{array}$ & $\begin{array}{c}0.0020 * * * \\
(0.000)\end{array}$ & $\begin{array}{c}-0.0012^{* * * *} \\
(0.000)\end{array}$ & $\begin{array}{l}-0.0001 \\
(0.509)\end{array}$ & $\begin{array}{c}-0.0009 * * * \\
(0.000)\end{array}$ & $\begin{array}{l}-0.0007 \\
(0.000)\end{array}$ \\
\hline Constant & $\begin{array}{c}0.6237 * * * * \\
(0.000)\end{array}$ & $\begin{array}{c}0.3303^{* * *} \\
(0.025)\end{array}$ & $\begin{array}{c}3.7633^{* * * *} \\
(0.000)\end{array}$ & $\begin{array}{c}3.6541^{* * * *} \\
(0.000)\end{array}$ & $\begin{array}{c}3.7759 * * * \\
(0.000)\end{array}$ & $\begin{array}{l}3.6453 \\
(0.000)\end{array}$ \\
\hline Constant & & & & $\begin{array}{c}3.6541^{* * * *} * \\
(0.000)\end{array}$ & & \\
\hline Parameter & & & $\begin{array}{c}\ln (\mathrm{p}) \\
1.7344^{* * *} \\
(0.000)\end{array}$ & $\begin{array}{c}\ln (\mathrm{p}) \\
1.7288^{* * *} \\
(0.000)\end{array}$ & $\begin{array}{c}\ln (\text { sigma }) \\
-0.7343^{* * *} \\
(0.000)\end{array}$ & $\begin{array}{c}\ln (\text { sigma }) \\
-0.7021 \\
(0.000)\end{array}$ \\
\hline Observations & $2,559,329$ & $2,559,329$ & $2,559,329$ & $2,559,329$ & $2,559,329$ & $2,559,329$ \\
\hline $\begin{array}{c}\text { Degree of Freedom } \\
\text { Chi2 }\end{array}$ & $\begin{array}{c}3 \\
9186\end{array}$ & $\begin{array}{c}245 \\
19230\end{array}$ & $\begin{array}{c}3 \\
8418\end{array}$ & $\begin{array}{c}245 \\
34348\end{array}$ & $\begin{array}{c}3 \\
9053\end{array}$ & $\begin{array}{c}3 \\
9053\end{array}$ \\
\hline $\mathrm{AIC}$ & 198424.1 & 198604.5 & 146904.8 & 126821.5 & 2096724.6 & 1996872.4 \\
\hline
\end{tabular}

Table 7: Effects of subsidy on time to default

(1) P-values are in parentheses; ${ }^{* * *}$ means $\mathrm{p}<0.01,{ }^{* *}$ means $\mathrm{p}<0.05$, and ${ }^{*}$ means $\mathrm{p}<0.1$.

(2) $\mathrm{LMIG}=1$ if the borrower satisfies the criterion of the "Low-and-Moderate-Income Goal," and 0 otherwise.

(3) $\mathrm{AIC}=$ Akaike information criterion.

(4) Columns (2), (4) and (6) control for MSA fixed effects and use robust standard errors.

the type distribution $F($.$) , the bank optimally designs the menu of mortgage contracts at time 0$. Moreover, the bank has full commitment; it cannot change the contract terms once the contract menu is offered.

At period 1, each borrower receives a publicly observable vector $Z_{1}$, consisting of an income realization $y_{1}$ and a common housing price $p_{1}$. For simplicity, assume $y_{1}$ is sufficiently high so that no borrower will default due to the inability to repay, i.e., there is no "illiquidity default" in this model. Rather, this paper only considers the strategic default triggered by housing price shocks. ${ }^{25}$ Based on the realization of $p_{1}$, the borrower optimally chooses to default or repay. By contrast, due to the full commitment, the bank behaves mechanically at time 1: if the borrower repays, the bank collects the total repayment amount $R b \equiv T$; if the borrower defaults, the bank forecloses on the house and collects $\alpha_{f} p_{1} h_{0}$ instead of $T$, where $0<\alpha_{f}<1$ is the recovery ratio during the foreclosure process, i.e., $1-\alpha_{f}$ represents the liquidation cost.

${ }^{25}$ Elul et al. (2010), among others, discuss the modeling of the default decision using the "double trigger" framework: First, "illiquidity default," i.e., the borrower would like to repay, but is not able to because of the low income received in that period, see Gerardi, Shapiro, and Willen (2007) for example. Second, "strategic default," i.e., the borrower chooses to default even if he is able to repay. Evidence by Bhutta, Dokko, and Shan (2010) and Gerardi et al. (Forthcoming) indicates that the "illiquidity default" played a more important role in the recent crisis. Using survey data, Guiso, Sapienza, and Zingales (2013) find that the propensity of "strategic default" is affected by both pecuniary and non-pecuniary factors (such as views about fairness and morality), and that exposure to other people who strategically defaulted increases the propensity to default strategically. But Gerardi et al. (Forthcoming) emphasize the important interaction between the two sources of default. 
To focus on the screening process by the bank with a tractable model, two additional assumptions are made. First, all borrowers are assumed to have the same $Z_{0}$ and $Z_{1}$. It follows that the unobservable quality $\theta$ is the only factor driving the variation of the contracts, so the menu of bank's contracts can be written as $\{(b(\theta), R(b)) \mid \theta \in[\underline{\theta}, \bar{\theta}]\}$, with the understanding that all these contracts are conditional on the observable current income, credit score, etc.

This assumption also implies that the observables do not provide the bank with any extra information regarding the borrower's true quality $\theta$. To justify this simplifying assumption, notice that in reality, current income $y_{0}$ includes initial saving which is accumulated in the past over a long period of time, and housing demand $h_{0}$ can depend on, for example, the number of children. As a result, both $y_{0}$ and $h_{0}$ are somewhat exogenous, and can be uncorrelated with $\theta$. But it is easy to allow $y_{0}, s, h_{0}$ and $y_{1}$ to be correlated with the type $\theta$, in which case the bank will make lending decisions based on the posterior type distribution obtained from Bayes' rule. Note that although the bank's problem will be affected if we allow correlation between the observables and the type, the borrower's problem will not be affected, since the borrower is assumed to perfectly know his own type.

The second additional assumption is that $h_{0}$ is exogenous. Although it is easy to allow the correlation between the (exogenous) $h_{0}$ and $\theta$, it is not easy to endogenize $h_{0}$. To see this, note that $h_{0}$ is observable to the bank before making the lending decision. In case the equilibrium $h_{0}$ chosen by the borrower is strictly monotone in $\theta$, the bank can perfectly back out the underlying $\theta$, and thus the design of the mortgage contracts will become a degenerate problem.

\subsection{Borrower's problem}

\subsubsection{Borrower's problem: period 1}

At time $n=1$, the borrower faces a discrete-choice problem contingent on the housing price realization $p_{1}$, which is to choose a default dummy $d: \mathcal{P} \mapsto\{0,1\}$, where $\mathcal{P}=\left[0, p_{1}^{\max }\right]$ is the set of all possible realizations of housing price $p_{1}$. If the borrower defaults, he loses his house, and the only payoff he gets is his income $y_{1}$. If he repays, he loses the total scheduled repayment of $T \equiv R b$, but keeps the market value of the house $p_{1} h_{0}$. In addition, the non-defaulter receives a monetary benefit $\theta$, as well as his income realization $y_{1}$.

Note that it is more convenient to represent the bank's contract menu using the total scheduled repayment $T$ instead of the interest rate $R$. This is because it is the $T$ (rather than $R$ or $b$ alone) that matters for the borrower's default decision. Presented this way, the model suggests two interesting analogies. First, a two-period mortgage contract can be understood as a two-period zero-coupon bond. In period 0 , the bank makes an upfront payment $b$ (bond price or loan size) to buy the "bond" from the borrower. In return, the borrower promises to repay the scheduled amount $T$ (face value of the bond) to the bank in period 1 (although he can choose to default). The ratio of $T$ over $b$ is the gross interest rate $R$. Second, the mortgage contract can be understood as an employment contract between the firm owner and the worker. The $T$ is like the task level that the work needs to fulfill, and the $b$ is like the wage required by the worker to compensate for fulfilling the task. Fulfilling a task is costly to the worker, just as making a repayment is costly to the borrower. ${ }^{26}$

${ }^{26}$ As Segal (2012) points out, when characterizing the theoretical properties, it is more convenient to use a direct revelation contract (DRC) instead of a tariff. Therefore, henceforth I will represent the contract menu as $\{(b(\theta), T(\theta)) \mid \theta \in[\underline{\theta}, \bar{\theta}]\}$. 
Denoting the utility of a type- $\theta$ borrower by $U_{1}\left(p_{1}, T, \theta\right)$, his problem at $n=1$ can be written as:

$$
U_{1}\left(p_{1}, T, \theta\right)=\max \left\{y_{1}, p_{1} h_{0}+\theta-T+y_{1}\right\}
$$

Clearly, the borrower follows a threshold strategy at time 1: he defaults if and only if the housing price realization $p_{1}$ is less than or equal to a threshold

$$
\bar{p}_{1}(T, \theta) \equiv \frac{T-\theta}{h_{0}} .
$$

Moreover, the default threshold strictly increases in $T\left(\frac{\partial \bar{p}_{1}}{\partial T}=\frac{1}{h_{0}}>0\right)$ and decreases in $\theta\left(\frac{\partial \bar{p}_{1}}{\partial \theta}=\right.$ $\left.-\frac{1}{h_{0}}<0\right)$. The intuition is as follows: for a given borrower $\theta$, a higher scheduled repayment $T$ makes him more demanding (asking for a higher $p_{1}$ realization to make up the higher $T$ ) and thus more likely to default; for a given scheduled repayment $T$, a borrower of a higher type has a higher opportunity cost of default, and thus is less likely to default.

\subsubsection{Borrower's problem: period 0}

At time 0, the borrower has a two-stage decision problem. In the first stage, he decides whether to participate in the mortgage market (borrow from the bank and buy a house), or to stay outside (rent a house in both periods using his income endowments). A type- $\theta$ borrower will participate if and only if his expected lifetime utility from participating, denoted by $U(\theta)$, is larger than or equal to that of his outside option, $y_{0}+E_{0} y_{1} \cdot{ }^{27}$ In the second stage, conditional on participation, the borrower optimally chooses the mortgage contract $(b(\theta), T(\theta)$ ) (equivalently, choosing which type to report) to maximize his life time utility:

$$
U(\theta)=\max _{\tau \in \Theta}\left[v\left(h_{0}\right)+y_{0}-\left(p_{0} h_{0}-b(\tau)\right)\right]+\beta E_{0} U_{1}\left(p_{1}, T(\tau), \theta\right)
$$

where the expression in the bracket is the borrower's utility at period 0 (the utility from living in the house $v\left(h_{0}\right)$, plus the utility from consumption which equals the current income $y_{0}$ minus the down payment $\left.p_{0} h_{0}-b\right)$; the set of all possible types is denoted by $\Theta$, and the expected utility is equal to

$$
\begin{aligned}
E_{0} U_{1}\left(p_{1}, T, \theta\right) & =\int_{0}^{\bar{p}_{1}(T, \theta)} y_{1} g\left(p_{1}\right) d p_{1}+\int_{\bar{p}_{1}(T, \theta)}^{p_{1}^{\max }}\left(p_{1} h_{0}+\theta-T+y_{1}\right) g\left(p_{1}\right) d p_{1} \\
& =E_{0} y_{1}+\int_{\bar{p}_{1}(T, \theta)}^{p_{1}^{\text {max }}}\left(p_{1} h_{0}+\theta-T\right) g\left(p_{1}\right) d p_{1} \\
& \equiv E_{0} y_{1}+\frac{1}{\beta} W(T, \theta) .
\end{aligned}
$$

Since $v\left(h_{0}\right)+y_{0}-p_{0} h_{0}+\beta E_{0} y_{1}$ is a constant which does not affect the maximization problem, henceforth I will ignore it. ${ }^{28}$ Then the above problem is equivalent to

$$
U(\theta)=\max _{\tau \in \Theta} b(\tau)+W(T(\tau), \theta)
$$

\footnotetext{
${ }^{27}$ Assume that the rental prices in both period 0 and period 1 are such that the money-metric utility to the borrower from living in a rental house exactly equals the amount of income he spends to rent the house. Hence, the value of his outside option equals $y_{0}+E_{0} y_{1}$.

${ }^{28}$ The constant $v\left(h_{0}\right)+y_{0}-p_{0} h_{0}+\beta E_{0} y_{1}$ is clearly relevant for the borrower's participation decision, i.e., whether to borrow a mortgage and buy a house, or to rent a house and receive a reservation utility. Hence, strictly speaking, we should keep this constant and another constant (the reservation utility) throughout the analysis. It turns out that these two constants do not affect the equilibrium, so I ignore both of them for brevity.
} 
where $W(T, \theta)$ is defined as above. This formula shows that by taking a mortgage contract, the borrower receives two assets: first, an upfront consumption flow with a value of $b$; second, a continuation value $W(T, \theta)$.

Below are some remarks on the borrower's problem. First, I assume that the borrower cannot adjust the housing size over time. Hence, the housing size in period 1 remains $h_{0}$. Second, for simplicity, I assume the borrower cannot save for consumption purposes, so the borrower has to spend all of their income in each period. This assumption is not innocuous, but does not seem too unrealistic either, because the mortgage balance is much larger than the flow saving in each period.

\subsection{Bank's problem without subsidy}

When faced with a borrower of type $\theta$, the bank has two decisions to make. First, it optimally decides to approve or reject the borrower. Second, conditional on approval, it optimally designs the loan contract $(b(\theta), T(\theta))$ for the borrower.

As for the bank's first decision, consider the following threshold rejection strategy: for some $\theta_{0} \in(0, \bar{\theta})$, the bank approves the type- $\theta$ borrower if and only if $\theta \geq \theta_{0}$. Note that although the bank does not observe the type, it can still "choose" $\theta_{0}$ to exclude borrowers. This is because the bank is able to design the menu of contracts to affect which $\theta_{0}$ will be just indifferent between taking the mortgage contract and staying outside. An alternative way to see this is that due to the incentive compatibility constraints, the bank behaves as if it can observe the true types of all borrowers; the bank sorts borrowers according to $\theta$, and optimally decides the lowest type $\theta_{0}$ to lend to. These arguments establish why such a threshold rejection strategy can be implemented. The optimality condition for choosing $\theta_{0}$ will be discussed later. Maskin and Riley (1984), among others, have considered the same threshold exclusion strategy.

As for the bank's second decision, it designs a menu of loan sizes and scheduled repayments $\left\{(b(\theta), T(\theta)) \mid \theta \in\left[\theta_{0}, \bar{\theta}\right]\right\}$ to maximize its total expected profit from all borrowers. Specifically:

$$
\begin{aligned}
& \Pi \equiv \max _{(b(.), T(.))} \int_{\theta_{0}}^{\bar{\theta}}[-b(\theta)+\Omega(T(\theta), \theta, 0)] f(\theta) d \theta \\
& \text { subject to : } \quad U(\theta) \geq 0, \quad \forall \theta \in\left[\theta_{0}, \bar{\theta}\right] \quad(I R) \\
& b(\theta)+W(T(\theta), \theta) \geq b(\tau)+W\left((T(\tau), \theta), \quad \forall \theta, \tau \in\left[\theta_{0}, \bar{\theta}\right]\right.
\end{aligned}
$$

where (IR) is the individual rationality constraint; (IC) is the incentive compatibility constraint; $\Omega(T, \theta, \omega)=\frac{1}{R_{f}}\left\{\int_{0}^{\bar{p}_{1}(T, \theta)}\left[\alpha_{f} p_{1} h_{0}+\omega\left(T-\alpha_{f} p_{1} h_{0}\right)\right] g\left(p_{1}\right) d p_{1}+\int_{\bar{p}_{1}(T, \theta)}^{p_{\max }} T g\left(p_{1}\right) d p_{1}\right\}$ is the expected revenue from a type- $\theta$ borrower. Specifically, $R_{f}$ is the (gross) risk-free interest rate, $\alpha_{f}$ is again the fraction of the housing value recovered by the bank in case of a default, and $0 \leq \omega \leq 1$ is the fraction of subsidy on the bank's unrecovered loss. When $p_{1}$ is below $\bar{p}_{1}(T, \theta)$, in which case type $\theta$ defaults, the bank receives $\alpha_{f} p_{1} h_{0}$ from the foreclosed house and $\omega\left(T-\alpha_{f} p_{1} h_{0}\right)$ from the government in case the subsidy program exists and the loan is eligible for the subsidy (see next section). When $p_{1}$ is above $\bar{p}_{1}(T, \theta)$, in which case type $\theta$ does not default, the bank simply collects $T$.

Note that I model the subsidy mechanism as a free but partial insurance (i.e., the bank can only recover part of the loss), instead of a costly but full insurance as in reality. In terms of the net present value, the subsidy mechanism in my model is equivalent to that in reality, but such an abstraction allows me to avoid modelling the mortgage default insurance market, which significantly simplifies the analysis. 
It turns out that the specific expression of the $\Omega(T, \theta, \omega)$ function does not matter for the results, so I do not use a specific functional form for the rest of the paper. Instead, I just specify the following assumptions on $\Omega(T, \theta, \omega)$ :

$$
\Omega_{T}(T, \theta, \omega)>0, \Omega_{\omega}(T, \theta, \omega)>0, \Omega_{T \omega}(T, \theta, \omega)>0, \quad \forall T \in \mathcal{R}^{+}, \forall \theta \in\left[\theta_{0}, \bar{\theta}\right] \text { and } \forall \omega \in[0,1]
$$

For the functional form of $\Omega$ specified above, these assumptions are clearly satisfied. More generally, these are not restrictive assumptions, given the features of the subsidy program described in the introduction.

Note that the bank's funding cost of making a loan of size $b(\theta)$ is simply $b(\theta)$. I assume such a simple one-dollar-to-one-dollar funding cost function because the bank is assumed to borrow funds at the risk-free rate from the international financial market, which has unlimited fund supply. Hence, to lend one dollar, the bank just needs to borrow one dollar from the international financial market. This seems to be an innocuous assumption, especially before the financial crisis when the internatial financial market had sufficient confidence in U.S. banks. Moreover, I assume that the bank's administrative cost is zero, and that the bank's total cost only consists of the funding cost.

\subsection{Characterization of the optimal contracts}

\subsubsection{Single-Crossing Property (SCP)}

Since the SCP is crucial to simplify the bank's problem (6), this subsection provides a discussion of this property.

The marginal utility of the borrower from taking a contract with an additional dollar of scheduled repayment $T$ is

$$
W_{T}(T, \theta)=-\left\{\beta\left[1-G\left(\bar{p}_{1}\right)\right] \times 1+\beta g\left(\bar{p}_{1}\right) \frac{\partial \bar{p}_{1}}{\partial T} \times\left(\bar{p}_{1} h_{0}+\theta-T\right)\right\}
$$

The negative sign indicates that $T$ decreases the utility of the borrower, which is intuitive. To highlight this negative relationship, I refer to $-W(T, \theta)$ as the "disutility" and $-W_{T}(T, \theta) \equiv$ $\left|W_{T}(T, \theta)\right|$ as the "marginal disutility." Equation (8) illustrates that the marginal disutility from one extra dollar of $T$ consists of two effects:

First, in the case of a good housing price realization where borrower $\theta$ decides to repay, which occurs with probability $1-G\left(\bar{p}_{1}\right)$, he will need to pay the extra dollar, which constitutes a marginal disutility of $\beta\left[1-G\left(\bar{p}_{1}\right)\right] \times 1$ to the borrower. I refer to this effect as the "repayment balance effect."

Second, the extra dollar of $T$ makes the borrower more demanding (increasing his default threshold $\bar{p}_{1}$ ) and raises his default probability by $\frac{\partial G\left(\bar{p}_{1}\right)}{\partial T}=g\left(\bar{p}_{1}\right) \frac{\partial \bar{p}_{1}}{\partial T}$. If default does occur, the borrower will lose his house (losing $\left.\bar{p}_{1} h_{0}\right)$ and damage his credit record (losing $\theta$ ), although he can avoid paying $T$. Therefore, the higher default probability due to the one extra dollar of $T$ brings a disutility of $\beta\left[g\left(\bar{p}_{1}\right) \frac{\partial \bar{p}_{1}}{\partial T} \times\left(\bar{p}_{1} h_{0}+\theta-T\right)\right]$ to the borrower. I refer to this effect as the "default threshold effect."

Importantly, due to the inability to commit, the borrower still has a chance to make a default decision in period 1. Moreover, the optimality condition of this decision implies that at the threshold housing price $\bar{p}_{1}$, the borrower is indifferent between repayment and default, so $\bar{p}_{1} h_{0}+$ $\theta-T=0$. Therefore, the "default threshold effect" turns out to be 0 , and the only marginal disutility of increasing $T$ by one dollar is the "repayment balance effect," i.e.,

$$
W_{T}(T, \theta)=-\beta\left[1-G\left(\bar{p}_{1}\right)\right] \times 1
$$


which is the repayment probability multiplied by the marginal payment, discounted by $\beta$.

It then follows that

$$
W_{T \theta}(T, \theta)=-\beta \frac{\partial\left[1-G\left(\bar{p}_{1}\right)\right]}{\partial \theta}, \quad \forall \theta \in[\underline{\theta}, \bar{\theta}]
$$

By Lemma 1, we have $\frac{\partial\left[1-G\left(\bar{p}_{1}\right)\right]}{\partial \theta}>0$, i.e., the repayment probability $1-G\left(\bar{p}_{1}\right)$ is strictly higher for a borrower of a higher quality $\theta$; but the marginal repayment $(\$ 1)$ is independent of $\theta$. Therefore, $W_{T \theta}(T, \theta)<0$ for all $\underline{\theta} \leq \theta \leq \bar{\theta}$. Hence, we have the following lemma:

LEMMA 1: The borrower's preference satisfies:

(i) $W_{T}(T, \theta)<0$ in $\underline{\theta} \leq \theta \leq \bar{\theta}$, so the borrower will strictly suffer more in period 1 from taking a contract with a larger $T$ in period 0 .

(ii) $W_{T \theta}<0$ in $\underline{\theta} \leq \theta \leq \bar{\theta}$, i.e., it has the SCP in the entire domain. Hence, the optimal $T(\theta)$ is strictly decreasing in $\underline{\theta} \leq \theta \leq \bar{\theta}$.

Parts (i) and (ii) of this lemma are both intuitive: a borrower of a higher quality understands that for the same scheduled repayment $T$, he will be more likely to repay (to avoid his higher default cost). Because the marginal disutility of slightly increasing $T$ equals the repayment probability multiplied by the constant marginal payment (discounted by $\beta$ ), the higher-quality borrower finds it more costly to take a contract with a slightly higher $T$ compared with a lower-quality borrower, i.e., $\frac{\partial\left|W_{T}(T, \theta)\right|}{\partial \theta}=-W_{T \theta}(T, \theta)>0$. Therefore, the higher-quality borrower wants to take a lower $T$ in the first place, compared with a lower-quality borrower (all else being equal). Moreover, when designing the optimal contracts, the bank has to respect this. ${ }^{29}$

\subsubsection{Optimal contracts}

It turns out that under the SCP, we can replace the principal's global IC constraints by local IC constraints, which are also referred to as ICFOC. ${ }^{30}$ In addition, by the strict monotonicity of the information rent $U(\theta)$, it suffices to impose the IR on type $\theta_{0}$ alone. Moreover, the bank will adjust the contract menu to completely extract $\theta_{0}$ 's information rent, so $\theta_{0}$ 's IR must be binding at the optimum. Hence, the bank's problem (6) can be simplified to

$$
\begin{aligned}
& \Pi \equiv \max _{(T(.), b(.))} \int_{\theta_{0}}^{\bar{\theta}}[-b(\theta)+\Omega(T(\theta), \theta, 0)] f(\theta) d \theta \\
& \text { subject to : } \quad U\left(\theta_{0}\right)=b\left(\theta_{0}\right)+W\left(T_{0}, \theta_{0}\right)=0 \quad(I R) \\
& U(\theta)=U\left(\theta_{0}\right)+\int_{\theta_{0}}^{\theta} W_{\tau}(T(\tau), \tau) d \tau, \quad \forall \theta \in\left[\theta_{0}, \bar{\theta}\right] \quad(I C F O C)
\end{aligned}
$$

Moreover, to simplify the solution of the model as well as to understand the results intuitively, we can reformulate the contract design problem. It is natural to think about the contract menu offered by the bank as specifying for each loan size $b$ an interest rate $R$, or effectively a scheduled repayment burden ("tariff") $T=R b$. But this is equivalent to specifying instead a loan size $b$ for each scheduled repayment burden $T$. That is, instead of $(b, R(b))$ or $(b, T(b))$, we will view the

${ }^{29}$ The strict monotonicity of $T$ follows from Edlin and Shannon (1998). Edlin and Shannon (1998) also require the differentiability of the tariff function, which is $b(T)$ in this paper. It can be seen later that $b(T)$ is indeed differentiable.

${ }^{30}$ The ICFOC is the same as the borrower's first-order condition (FOC) $b^{\prime}(T)=-W_{T}(T, \theta)$ (treating $T$ as the allocation and $b$ as the transfer, as explained later). For more details, see Mirrlees (1971) and Tirole (1994, Page $15)$. 
contract menu as pairs $(T, b(T))$, treating $T$ as the allocation and $b(T)$ as the upfront payment (tariff) to compensate the borrower for taking a particular repayment burden $T$. Doing so will significantly simplify the solution procedure, since it transforms the original utility function that is nonlinear in the tariff to one that is quasi-linear in the newly-defined tariff (recall that the utility function $u(T, b, \theta)=b+W(T, \theta))$.

Using the reformulated model, we can obtain the optimal contracts following the standard procedure, which is to eliminate the transfer and then solve the relaxed pointwise maximization problem. Through the following two propositions, this subsection characterizes the benchmark model's optimal contracts obtained this way.

PROPOSITION 1: Assume that the following second-order condition (SOC) holds: ${ }^{31}$

$$
W_{T T}(T, \theta)+\Omega_{T T}(T, \theta, 0)-\frac{1-F(\theta)}{f(\theta)} W_{\theta T T}(T, \theta)<0, \quad \forall T \in \mathcal{R}^{+} \text {and } \forall \theta \in\left[\theta_{0}, \bar{\theta}\right]
$$

Then conditional on the rejection threshold $\theta_{0} \in(\underline{\theta}, \bar{\theta})$, the optimal contracts can be solved in the following order:

(i) the optimal scheduled repayment $T(\theta)$ to a borrower of type $\theta$ is the solution to the following functional equation:

$$
-W_{T}(T, \theta)=\Omega_{T}(T, \theta, 0)+\frac{1-F(\theta)}{f(\theta)}\left[-W_{\theta T}(T, \theta)\right], \quad \forall \theta \in\left[\theta_{0}, \bar{\theta}\right]
$$

where $W_{T}(T, \theta)=-\beta\left[1-G\left(\bar{p}_{1}\right)\right] \times 1<0, \Omega_{T}(T, \theta, 0)>0$ is the bank's marginal revenue under zero subsidy, and $W_{\theta T}=W_{T \theta}=-\beta g\left(\bar{p}_{1}\right) \frac{1}{h_{0}}<0$.

(ii) the associated information rent $U(\theta)$ is given by

$$
U(\theta)=U\left(\theta_{0}\right)+\int_{\theta_{0}}^{\theta} W_{\tau}(T(\tau), \tau) d \tau=\int_{\theta_{0}}^{\theta} W_{\tau}(T(\tau), \tau) d \tau, \quad \forall \theta \in\left[\theta_{0}, \bar{\theta}\right]
$$

where $W_{\tau}(T, \tau)=\frac{\partial U(\tau)}{\partial \tau}=\beta\left[1-G\left(\bar{p}_{1}(T, \tau)\right)\right] \times 1>0$ is the information rent to a borrower of type $\tau$.

(iii) the optimal loan size $b(\theta)$ is given by

$$
b(\theta)=U(\theta)-W(T, \theta), \quad \forall \theta \in\left[\theta_{0}, \bar{\theta}\right]
$$

(iv) the optimal interest rate $R(\theta)$ is given by

$$
R(\theta)=\frac{T(\theta)}{b(\theta)}, \quad \forall \theta \in\left[\theta_{0}, \bar{\theta}\right]
$$

PROOF: see Appendix A.

Q.E.D.

Equation (10) is the bank's optimality condition of choosing the scheduled repayment $T(\theta)$ for a type- $\theta$ contract. Following the reformulation explained above, we can interpret equation (10) as follows. On the one hand, when increasing the scheduled repayment $T(\theta)$ for type- $\theta$ borrowers by

${ }^{31}$ The SOC is to ensure the solution to the FOC is a maxima rather than a minima, so that the analysis of optimal contracts is meaningful. It turns out under reasonable parametrizations of the $\Omega$ function, this SOC holds. 
one dollar, the bank has to pay a larger upfront amount $b$ in order to convince them to take the contract. This constitutes the bank's marginal cost of increasing $T$. Mathematically, this marginal cost equals $b^{\prime}(T)$. Note that following the reformulation, the borrower's optimality condition becomes $-W_{T}(T, \theta)=b^{\prime}(T)$, so the left-hand side (LHS) of equation (10) captures the bank's marginal cost of increasing $T(\theta)$ by one dollar.

On the other hand, the bank's marginal benefit of increasing the scheduled repayment $T(\theta)$ by one dollar consists of two parts, both captured by the right-hand side (RHS) of equation (10). First, doing so can directly increase the bank's expected revenue from a type- $\theta$ borrower by $\Omega_{T}(T, \theta, 0)$. Second, by increasing the scheduled repayment $T(\theta)$ for type $\theta$, the bank makes type- $\theta$ 's contract less attractive to all borrowers of types higher than $\theta$, so higher types will have a lower incentive to take type- $\theta$ 's contract. As a result, the bank can save some information rents: the marginal saving from each borrower of higher types (in absolute value) is $\left|\frac{\partial W_{\theta}(T, \theta)}{\partial T}\right|=-W_{\theta T}(T, \theta)$ (note that $\left.W_{\theta T}(T, \theta)<0\right)$, and there are $\frac{1-F(\theta)}{f(\theta)}$ such borrowers (relative to the mass of type- $\theta$ borrowers).

As for the optimal choice of the rejection threshold $\theta_{0}$, we have the following proposition:

PROPOSITION 2: The optimal rejection threshold $\theta_{0} \in(\underline{\theta}, \bar{\theta})$ is determined by

$$
\left[\Omega\left(T_{0}, \theta_{0}, 0\right)+W\left(T_{0}, \theta_{0}\right)\right] f\left(\theta_{0}\right)=W_{\theta}\left(T_{0}, \theta_{0}\right)\left[1-F\left(\theta_{0}\right)\right]
$$

where $T_{0}=T\left(\theta_{0}\right)$ is given by equation (10).

The LHS of equation (13) captures the bank's marginal benefit of decreasing the rejection threshold $\theta_{0}$. Decreasing $\theta_{0}$ allows the bank to expand its customer base and to earn a higher profit. Specifically, the bank can earn $\Omega\left(T_{0}, \theta_{0}, \omega\right)-b\left(T_{0}\right)$ from each borrower of type $\theta_{0}$, and there are $f\left(\theta_{0}\right)$ of them. Note that the bank will always adjust the contract terms such that $\theta_{0}$ earns zero information rent, i.e., $U\left(\theta_{0}\right)=b\left(\theta_{0}\right)+W\left(T_{0}, \theta_{0}\right)=0$, so $W\left(T_{0}, \theta_{0}\right)=-b\left(\theta_{0}\right)$ and thus $\left[\Omega\left(T_{0}, \theta_{0}, 0\right)+W\left(T_{0}, \theta_{0}\right)\right] f\left(\theta_{0}\right)$ is indeed the increase in the (total) profit from all type- $\theta_{0}$ borrowers.

The RHS of equation (13) captures the bank's marginal cost of decreasing the rejection threshold $\theta_{0}$. As $\theta_{0}$ becomes lower, all higher types (i.e., existing customers) will have more contracts to mimic, so the bank has to give up more information rents to them to satisfy the IC. Specifically, the bank has to give up $W_{\theta}\left(T_{0}, \theta_{0}\right)>0$ to each borrower of type $\theta>\theta_{0}$, and there are $1-F\left(\theta_{0}\right)$ of such borrowers.

\subsubsection{Properties of the optimal contracts}

This subsection characterizes some properties of the optimal contracts through two propositions.

PROPOSITION 3: Under the optimal contracts with no subsidy, the loan size (leverage ratio) $b(\theta)$ is continuous and strictly decreasing in $\theta$ for $\theta_{0} \leq \theta \leq \bar{\theta}$. That is, a higher-quality borrower is strictly less leveraged.

The mathematical proof of this proposition is provided in Appendix B. Below is an intuitive understanding. On the one hand, we can establish that the optimal $b-T$ schedule designed by the bank must be strictly increasing. Suppose not. First, consider the case where it is strictly decreasing, as in Figure 5. Suppose further that $(T, b(T))$ is the optimal contract of a particular borrower. However, if the borrower instead chooses a contract with a strictly lower $T$, e.g., contract $\left(T^{\prime}, b\left(T^{\prime}\right)\right)$, then he can get a strictly larger upfront payment $b\left(T^{\prime}\right)$ in period 0 . Moreover, by Part (i) of Lemma 1, the borrower will suffer strictly less in period 1 from taking a contract with a strictly lower $T$ in period 0 , so the borrower will find it strictly better off to deviate to $\left(T^{\prime}, b\left(T^{\prime}\right)\right)$. Hence, $(T, b(T))$ cannot be optimal, which is a contradiction. Similar arguments apply to the 
case where $b$ is flat over some range of $T$. Therefore, the optimal $b$ - $T$ schedule must be strictly increasing.

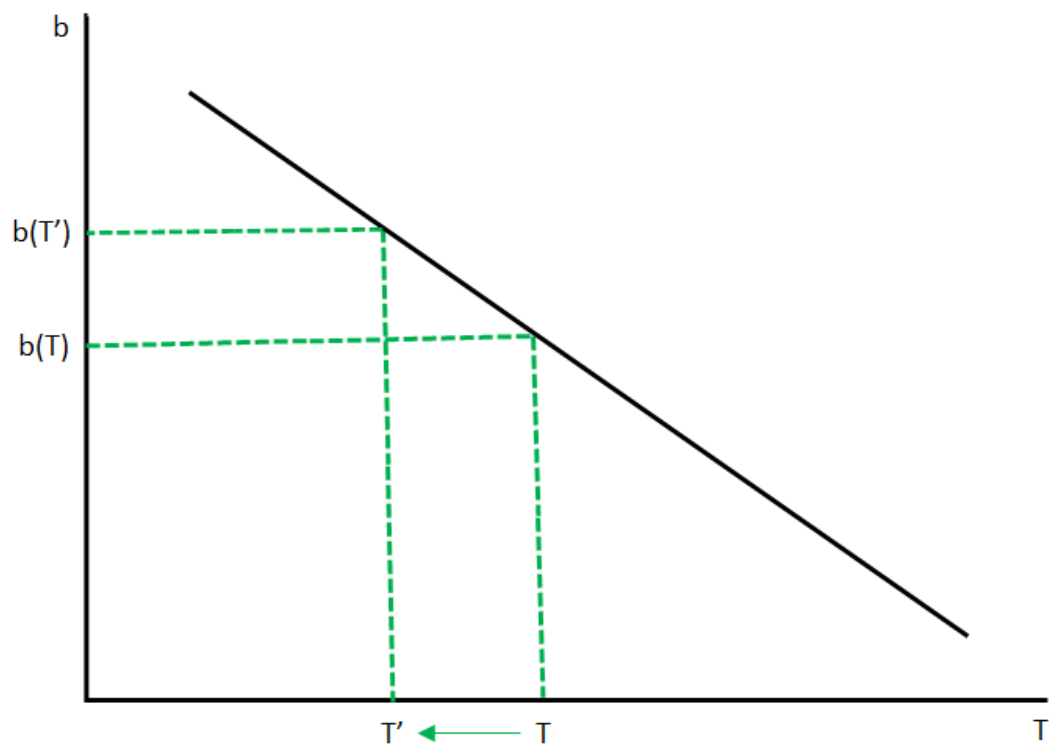

Figure 5: A proposed b-T schedule without subsidy.

On the other hand, Part (ii) of Lemma 1 states that borrower of a higher quality is more averse to default and will pick a contract with a strictly lower scheduled repayment $T(\theta)$ at period 0 . Combining with the previous argument, it follows that the optimal loan size $b(\theta)$ strictly decreases in $\theta$. Since the model is conditional on the initial housing expenditure $p_{0} h_{0}$, the loan size $b(\theta)$ is equivalent to the leverage ratio $\frac{b}{p_{0} h_{0}}$, so the leverage ratio also strictly decreases in borrower's quality $\theta$. This prediction is consistent with the finance literature. The continuity of $b(\theta)$ is clear, since there is no structural change in the incentives of the bank if there is no subsidy.

So far, I have examined the property of the loan size or leverage ratio of the optimal contracts. To examine the interest rate, the following lemma is needed:

LEMMA 2: Under the optimal contracts, the elasticity of the loan size $b$ with respect to the scheduled repayment $T$ is strictly less than 1. Hence, as the optimal scheduled repayment $T$ (face value or task) increases, the bank only needs to increase the optimal loan size $b$ (bond price or wage) at an increasingly slower rate.

PROOF: see Appendix C.

Q.E.D.

The intuition is as follows. As the borrower moves to a contract with a higher scheduled repayment (face value) $T$, he understands that he will be more demanding and less likely to repay in period 1. Recall that the borrower's marginal disutility of taking an extra dollar of $T$ equals his repayment probability, which is decreasing in $T$, multiplied by the marginal repayment, which is always $\beta \times 1$ regardless of the level of $T$. Hence, the borrower's marginal disutility will be lower as $T$ becomes higher. To satisfy the IR and IC constraints as well as to maximize its profit, the bank only needs to compensate the borrower by a smaller increase in $b$ (purchasing price) as he moves to a higher $T$.

Based on this lemma, we have the following proposition: 
PROPOSITION 4: Under the optimal contracts with no subsidy, the interest rate $R(\theta)$ is continuous and strictly decreasing in $\theta$ for $\theta_{0} \leq \theta \leq \bar{\theta}$. That is, a higher-quality borrower pays a strictly lower interest rate $R$.

PROOF: see Appendix D.

This prediction is also consistent with the finance literature. Note that this proposition does not require the optimal $R(\theta)$ to be differentiable or continuous, and thus allows for a discontinuous $R(\theta)$ function. The next section will use this property.

The intuition is as follows. By the SCP in Lemma 1, the optimal contract designed for a lowerquality borrower will have a higher scheduled repayment $T$ (face value), since he is less likely to pay back and thus suffers less than a higher quality. By Proposition 3, it should also have a higher loan amount $b$ (bond price) to compensate for the higher face value $T$, otherwise other types will want to mimic. However, according to Lemma 2, a higher $T$ leads to a lower repayment probability and thus a lower marginal disutility, so the bank only has to increase the upfront compensation $b$ (loan amount or bond price) by a smaller percentage than $T$, so the average "compensation per face value" (received by the borrower) $\frac{b}{T}$ is lower for a lower-quality borrower, i.e., the interest rate (paid by the borrower) $\frac{T}{b}$ is higher for a lower-quality borrower than that for a higher quality.

Combining Propositions 3 and 4, we immediately get the following corollary:

COROLLARY 1: Under the optimal contracts with no subsidy, the $R$-b schedule designed by the bank is continuous and upward sloping.

Figure 6 shows the optimal $R$ - $b$ schedule. Note that this does not contradict the downward sloping schedule observed in data as in Figure 2, because Figure 2 plots the absolute loan amount whereas the $b$ in my model is actually the leverage ratio. More generally, Figure 2 is the pooled plot for all borrowers with different observable characteristics, whereas my model is conditional on these characteristics. ${ }^{32}$ In addition, the usual argument for the downward sloping schedule is that a larger loan size tends to split the bank's loan-specific fixed cost more, so that the per-unit cost of providing the loan becomes smaller, hence a lower interest rate. Since my model does not have the fixed cost, the only present effect is the one explained above, which corresponds to an upward sloping schedule.

An important implication of the previous two propositions and Corollary 1 is that borrowers of higher quality will self-select into contracts with lower interest rate by taking a lower loan size (leverage ratio). Hence, even if the subsidy is present, it is still possible that the observed lower interest rate for conforming loans (than jumbo loans) is due to the higher borrower quality itself and the IC constraints associated with the asymmetric information, rather than due to the subsidy. The next section shows that this is indeed the case.

\section{Model with subsidy}

\subsection{Setup and solution procedure for optimal contracts}

Under the subsidy, the borrower's problem remains exactly the same as the benchmark model. The bank's problem is also similar to that in the benchmark model, with the only difference being the bank's expected revenue function. Importantly, because only loans of size less than or equal to the CLL are eligible for the subsidy, the bank's expected revenue function becomes a split function.

${ }^{32}$ Due to data restrictions, I cannot create a version of Figure 2 that controls for observable borrower characteristics. 


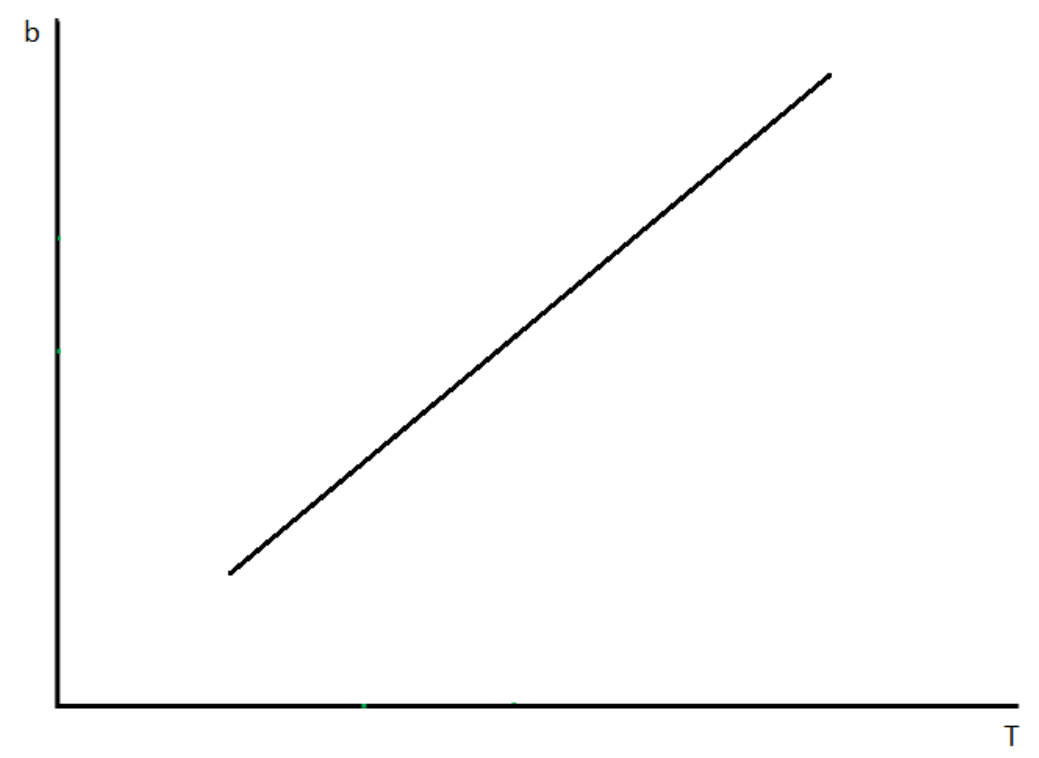

Figure 6: Optimal R-b schedule without subsidy.

Specifically, it remains to be $\Omega(T, \theta, 0)$ if $b(\theta)>C L L$ (jumbo loans), and jumps to $\Omega(T, \theta, \omega)$ if $b(\theta) \leq C L L$ (conforming loans), where $0 \leq \omega \leq 1$ is the subsidy parameter. In case a conforming loan defaults, the government subsidizes the bank by $\omega$ fraction of the loss. Again, the specific expression of the $\Omega(T, \theta, \omega)$ function does not matter for the results of this paper, so I do not specify its functional form here. The restrictions on $\Omega(T, \theta, \omega)$ are the same as those in the benchmark model.

Note that the discontinuity caused by the subsidy program makes the bank's objective function to be non-differentiable at $b=C L L$. Consequently, the standard maximization techniques are not applicable and thus it is not easy to solve for the general strategy of the bank. Therefore, in this paper I consider a particular strategy of the bank, in which the bank adopts a threshold strategy not only for the loan approval decision (as in the benchmark model), but also for the loan size decision.

Specifically, I guess that there exist two cutoff types $\theta_{1}, \theta_{2} \in\left(\theta_{0}, \bar{\theta}\right)$, such that the bank finds it optimal to lend an amount strictly above $C L L$ to all types in $\left(\theta_{0}, \theta_{1}\right)$ ("jumbo group"), exactly equal to $C L L$ to all types in $\left[\theta_{1}, \theta_{2}\right]$ ("CLL group"), and strictly below $C L L$ to all types in $\left(\theta_{2}, \bar{\theta}\right]$ ("strictly conforming group"). ${ }^{33}$ Moreover, borrowers in each group also find it optimal to accept such loan sizes designed by the bank. Since I also consider a threshold strategy of the bank for the approval decision, the bank will lend 0 to all types in $\left[\underline{\theta}, \theta_{0}\right]$ ("rejected group"). See Figure 7.

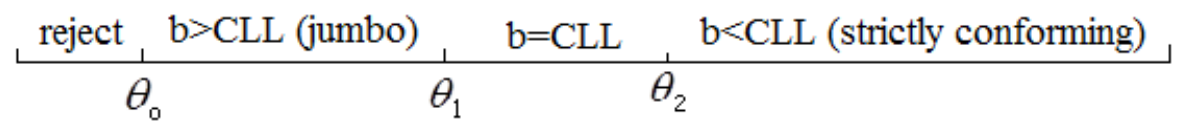

Figure 7: Threshold strategy.

\footnotetext{
${ }^{33}$ If we treat $T$ as the tariff and $\mathrm{b}$ as the quantity, then the bunching is consistent with the mechanism design literature, such as Topkis (1998) and Edlin and Shannon (1998). That is, the kink of the tariff at one quantity level $(b=C L L)$ translates into the bunching of the optimal quantity at the same level.
} 
Since the benchmark model shows that we have the strict monotonicity of $T(\theta)$ and $b(\theta)$ in $\theta$, such a threshold strategy is plausible in the case with the subsidy. Under the threshold strategy, the bank's objective function becomes continuous and differentiable in each group, so the bank's problem can be substantially simplified. Note that the problem for the CLL group is degenerate, because the bank cannot distinguish borrowers in this group and thus only needs to choose one interest rate level (equivalently, one scheduled repayment level) for all borrowers in $\left[\theta_{1}, \theta_{2}\right]$. Denote the common interest rate level and the scheduled repayment level of the CLL group by $R_{C L L}$ and $T_{C L L}$, respectively.

Moreover, similar arguments with Proposition 3 show that $b$ is strictly increasing in $T$ in the entire domain of $T$, otherwise all borrowers would strictly prefer contracts with (lower $T$, higher $b$ ). Hence, it is as if the subsidy program is implemented in terms of $T$, i.e., the loan is eligible for the subsidy if its $T \leq T_{C L L}$ and ineligible if $T>T_{C L L}$.

The borrower's preference still satisfies the SCP, so we can again replace the principal's global IC constraints by local IC constraints (ICFOC), and thus the bank's problems for the strictly conforming group and the jumbo group under the subsidy are similar to that in the benchmark model, i.e., problem (9). ${ }^{34}$ The main difference is that now the bank not only needs the "no within-group deviation conditions (ICFOC)," but also additional IC constraints to ensure there are no "across-group deviations," i.e., borrowers in one group do not have incentives to mimic any other groups. It turns out that under the menu of the optimal contracts with subsidy, borrower's information rent $U(\theta)$ is continous and strictly increasing in $\theta$. Hence, to ensure "no across-group deviations," it suffices to impose the following "no across-group downward deviation conditions:" the strictly conforming group does not want to mimic the CLL group; the CLL group does not want to mimic the jumbo group; and the jumbo group does not want to mimic the rejection group.

To summarize, under the subsidy, the menu of optimal contracts can be solved in two steps. First, conditional on the three cutoff types $\left(\theta_{0}, \theta_{1}, \theta_{2}\right)$ and the scheduled repayment of the CLL group $\left(T_{C L L}\right)$, the bank designs a menu of contracts $(b(\theta), T(\theta))$ for the strictly conforming group and the jumbo group, respectively, subject to "no within-group deviation conditions" (ICFOC) and "no across-group downward deviation conditions." Second, the bank chooses $\theta_{0}, \theta_{1}, \theta_{2}$ and $T_{C L L}$ to maximize the total profits obtained from all groups.

The optimal contracts with subsidy can be obtained using a similar procedure as in Proposition 1 when there is no subsidy. ${ }^{35}$ Moreover, the properties of the optimal contracts, as well as the intuition, are also similar to those without subsidy. In particular, the optimal interest rate $R(\theta)$ with subsidy is still strictly decreasing in $\theta$ over the population of all approved borrowers, $\left[\theta_{0}, \bar{\theta}\right]$, although it is no longer continuous. For brevity, I do not provide the full characterization of the optimal contracts; rather, I only focus on the effect of the subsidy on the optimal interest rate.

\subsection{Positive analysis of subsidy for the strictly conforming group}

Let a variable with a superscript $Y$ and $N$ be the object with and without subsidy, respectively. We have the following lemma:

LEMMA 4: The introduction of the subsidy program strictly increases the equilibrium scheduled repayment for the same borrower quality in the entire strictly conforming group, i.e., $T^{Y}(\theta)>$

\footnotetext{
${ }^{34}$ I will present the characterization of the model with subsidy by treating the contract as a DRC rather than a tariff.

${ }^{35}$ We can use the optimal control techniques as in Kirk (2004, Pages 188-189) to derive the necessary conditions for the Hamiltonian.
} 
$T^{N}(\theta)$ for any given $\theta$ in $\left(\theta_{2}, \bar{\theta}\right]$. Moreover, it strictly increases the aggregate default rate in this group.

PROOF: see Appendix E.

The intuition is as follows. Because all loans in this group are conforming, the bank can claim a subsidy from the government if the loan defaults. Hence, the subsidy directly raises the bank's marginal revenue (MR) of increasing the scheduled repayment $T$ for a given borrower type, which equals $\Omega_{T}(T, \theta, \omega)+\frac{1-F(\theta)}{f(\theta)}\left[-W_{\theta T}(T, \theta)\right]$. However, the subsidy does not directly affect the marginal cost (MC), which is the extra upfront loan amount paid to the borrower, $b^{\prime}(T)$. This is because borrower's FOC implies that the MC, $b^{\prime}(T)$, is just the borrower's marginal disutility $\left|W_{T}(T, \theta)\right|$, which is entirely determined by the borrower's preference rather than the subsidy. Therefore, the bank will increase $T$ to intersect the uniformly higher MR curve with the fixed MC curve.

Note that for the same borrower, a higher repayment burden will result in a higher default risk. By the Law of Large Numbers, it follows that the subsidy will result in a higher aggregate default rate. This has an important financial stability implication, which will be discussed again later.

Based on Lemmas 3 and 4, we can establish the following proposition.

PROPOSITION 5: The introduction of the subsidy program strictly increases the equilibrium interest rate for the same borrower quality in the entire strictly conforming group, i.e., $R^{Y}(\theta)>$ $R^{N}(\theta)$ for any given $\theta$ in $\left(\theta_{2}, \bar{\theta}\right]$.

PROOF: see Appendix F.

This proposition illustrates the key ideas in this paper. In contrast to the literature, this proposition states that the mortgage subsidy program (done through the subsidized default insurance by GSEs) does not lower the interest rate even for loans that are eligible for the subsidy. On the contrary, the subsidy has actually raised the interest rate for the same borrower who borrows an amount strictly below the CLL when the subsidy is present.

The intuition can be best understood in three steps:

Step 1: bank's moral hazard. The subsidy increases the bank's marginal revenue while keeping the marginal cost unchanged, so it is optimal for the bank to expand business by increasing the scheduled repayment $T$ (and the loan size/household leverage $b$ ) for all types, as long as the loans are still conforming. In other words, to take advantage of the underpriced mortgage insurance, the bank will optimally want to take excessive risk. To this end, it intentionally generating more risk through offering a higher future repayment burden $T$ for each borrower.

Step 2: borrower's "opportunistic" behavior. As $T$ increases, the borrower understands that he will be less likely to repay in period 1 and thus suffer less, so his marginal disutility becomes lower. As a result, the borrower is also willing to accept the higher $T$.

Step 3: bank's rent extraction behavior. To satisfy the IR and IC constraints as well as to maximize its profit, the bank only needs to compensate the borrower by a smaller percentage increase in the upfront payment $b$, effectively charging a higher $R \equiv \frac{T}{b}$ after the subsidy is introduced. All these behaviors are optimal from the individuals' own perspectives (both the bank and the borrower are trying to take advantage of the subsidy mechanism), but they will result in a higher system-wide default rate, as discussed earlier in the paper.

Although these arguments are made in terms of $T$ and $b$, we can state them equivalently in terms of $R$ and $b$. Specifically, although the bank understands that a higher $R$ (accompanied by a higher $b$ ) will lead to a higher default probability, the default insurance subsidy provides the bank with a safety net, which induces the following asymmetric payoff structure to the bank: if the borrower does not default at the higher interest rate $R$, the bank can get a higher profit from 
the higher interest payment; but even if the borrower does default at the higher $R$, the bank does not have to assume all the loss due to the default insurance subsidy program. Hence, the bank will optimally choose to raise $R$.

Note that the bank also has to design a higher $b$ for the higher $R$ in order to satisfy the borrower's participation constraint. This is stated in the following proposition:

PROPOSITION 6: The introduction of the subsidy program increases the leverage ratios of all borrowers in the strictly conforming group. That is, $b^{Y}(\theta)>b^{N}(\theta)$ for any given $\theta$ in $\left(\theta_{2}, \bar{\theta}\right]$.

PROOF: see Appendix G.

Q.E.D.

This proposition has an important implication on financial stability. It implies that the subsidy raises the leverage for the same borrower, which is consistent with the literature (e.g., Elenev, Landvoigt, and Van Nieuwerburgh (2015)). The higher leverage makes the household more susceptible to adverse macroeconomic shocks, increases the (aggregate) default rate, and ultimately undermines financial stability. Note that although the system is protected by the government guarantee, a higher aggregate default rate still tends to weaken financial stability given the various inefficiencies (e.g., fire sale) associated with a higher default rate.

\subsection{Normative analysis of subsidy for the strictly conforming group}

One may argue that since the subsidy increases the loan sizes of borrowers in the strictly conforming group, and since the borrowers are allowed to default more frequently under the subsidy, their welfare may still be higher under the subsidy. Regarding these arguments, we have the following proposition:

PROPOSITION \%: The introduction of the subsidy program decreases the welfare of all borrowers in the strictly conforming group. That is, $U^{Y}(\theta)<U^{N}(\theta)$ for any given $\theta$ in $\left(\theta_{2}, \bar{\theta}\right]$.

PROOF: see Appendix H.

The intuition is as follows. After the subsidy is introduced, the bank is less worried about default, so it lends more aggressively by increasing the scheduled repayment of the mortgage, which is just the face value of the bond if we treat the mortgage contract as a zero-coupon bond explained earlier. This in turn makes the borrower more likely to default, so the marginal disutility from the repayment becomes lower. Therefore, the bank only needs to give up a lower amount of information rent to incentivize borrowers. Up to now, the intuition is exactly the same as the reason why the subsidy increases interest rate. But information rent is the only surplus to consumers in this model, so the consumer welfare will be lower with a higher subsidy.

These arguments show that under asymmetric information, the presence of subsidy enables the bank to extract more information rent from the borrowers. Without the subsidy, the borrower's marginal disutility is relatively high, and the bank needs to give up more information rent to incentivize borrowers to report their types truthfully. With the subsidy, the borrowers can default more frequently (and the bank tolerates that), which lowers the borrower's marginal disutility and thus the borrower only demand for less information rent from the bank.

\subsection{Jumbo-conforming spread}

So far, this paper has answered the two research questions posed in the introduction. To check if the results are simply due to the possibly unrealistic assumptions of the model, this subsection 
examines whether the model can generate the positive jumbo-conforming interest rate spread observed in data. On this, we have the following proposition:

PROPOSITION 8: The interaction between the subsidy program and asymmetric information generates a positive jumbo-conforming spread in the equilibrium interest rates. That is, $\lim _{\theta \uparrow \theta_{1}} R^{Y}(\theta)>R^{Y}\left(\theta_{1}\right) \equiv R_{C L L}$.

The proof, provided in Appendix I, is similar to that of Proposition 4, which states that the equilibrium interest rate $R(\theta)$ without the subsidy is continuous and strictly decreasing in the entire domain $\left[\theta_{0}, \bar{\theta}\right] .{ }^{36}$ But the main intuition of Proposition 8 is still similar to that of Proposition 4 . Specifically, to ensure that no borrower in the entire $C L L$ group wants to mimic someone in the jumbo group, the bank needs to ensure type $\theta_{1}$ (the lowest type in the $C L L$ group) is indifferent between taking his own contract $\left(T_{C L L}, C L L\right)$ and the contract designed for an arbitrarily lower type $\theta_{1}^{-} \equiv \theta_{1}-\epsilon$ (the "highest" type in the jumbo group), $\left(T_{1}^{-}, b_{1}^{-}\right)$. In addition, borrower's SCP implies that the optimal $T_{1}^{-}$designed for the lower quality $\theta_{1}^{-}$has a higher scheduled repayment (face value or task). The higher $T$ needs to be compensated by a higher $b$ (bond price or wage), but again because the marginal disutility of $T$ becomes lower at a higher level of $T$, the bank only has to increase the wage compensation by a smaller percentage than the task, so the average "wage per task" $\frac{b}{T}$ is lower for $\theta_{1}^{-}$, i.e., the interest rate $\frac{T}{b}$ is higher. As for the discontinuous jump, it stems from the bank's discontinuous adjustment of $T(\theta)$ at $\theta_{1}$ to account for the subsidy.

Importantly, this proposition implies that the observed jumbo-conforming spread is simply a result of the incentive compatibility constraints associated with asymmetric information in my model (despite the model's unconventional results on interest rates), rather than an indication that the subsidy has lowered the interest rates of conforming loans.

\subsection{Effects of subsidy on interest rate: summary}

The effects of the subsidy on all groups are summarized in Figure 8 and Figure 9. Note that the $\theta_{0}$ with subsidy is equal to that without subsidy, hence the $R(\theta)$ plots with and without subsidy start from the same point. ${ }^{37}$ Also, we do not need to distinguish between $\theta_{2}^{Y}$ and $\theta_{2}^{N}$ because there is no bunching when the subsidy is absent. Similarly for $\theta_{1}^{Y}$ and $\theta_{1}^{N}$.

\footnotetext{
${ }^{36}$ There are two differences: first, we need to ensure there is no across-group deviations; second, we need to deal with the discontinuity of $T(\theta)$ at $\theta_{1}$ introduced by the subsidy, so we cannot directly use the elasticity argument as in Lemma 2.

${ }^{37}$ This reflects the fact that my paper focuses on the intensive margin rather than the extensive margin. The proof of this is provided in Appendix J. The intuition is as follows: $b$ and $\theta$ are inversely related in this model, so all loans in the neighborhood around $\theta_{0}$ are jumbo loans and are ineligible for the subsidy. Therefore, when the bank makes the decision of decreasing or increasing $\theta_{0}$ by $\epsilon$, the bank cannot get the subsidy from loans in the neighborhood of $\theta_{0}$ anyway, so the introduction of the subsidy has no effect on the bank's optimality condition for choosing $\theta_{0}$, hence no effect on the equilibrium $\theta_{0}$. Appendix $\mathrm{J}$ also shows that the subsidy increases both the loan size (household leverage) $b$ and interest rate $R$ in the jumbo group (for approved borrowers).
} 


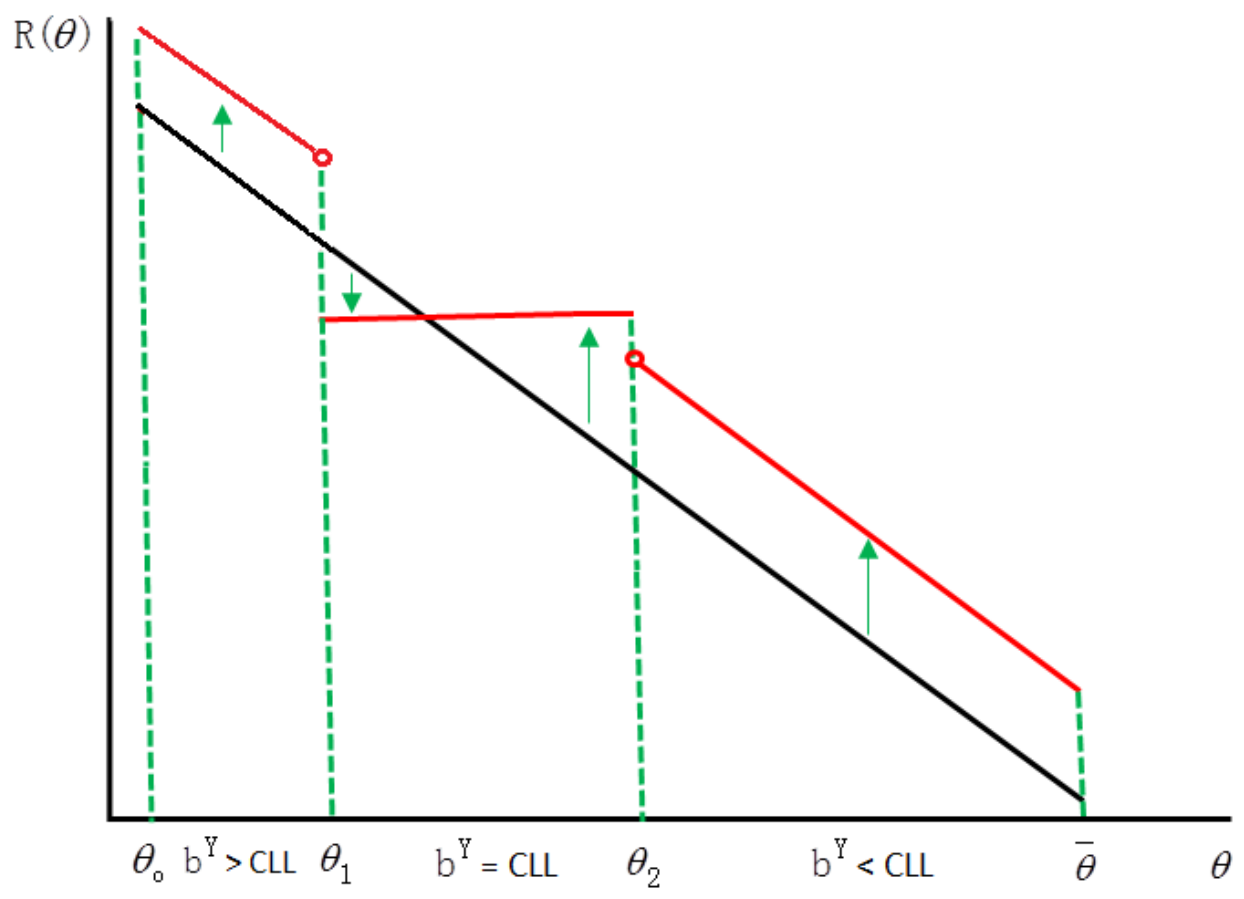

Figure 8: Optimal $R(\theta)$ schedule with and without subsidy.

$b$ is the loan size, $R$ is the gross interest rate, and $\theta$ is the unobservable quality index of the borrower. The superscript $Y$ and $N$ means with and without subsidy, respectively. The straight line on the bottom is the equilibrium in the counterfactual case without subsidy.

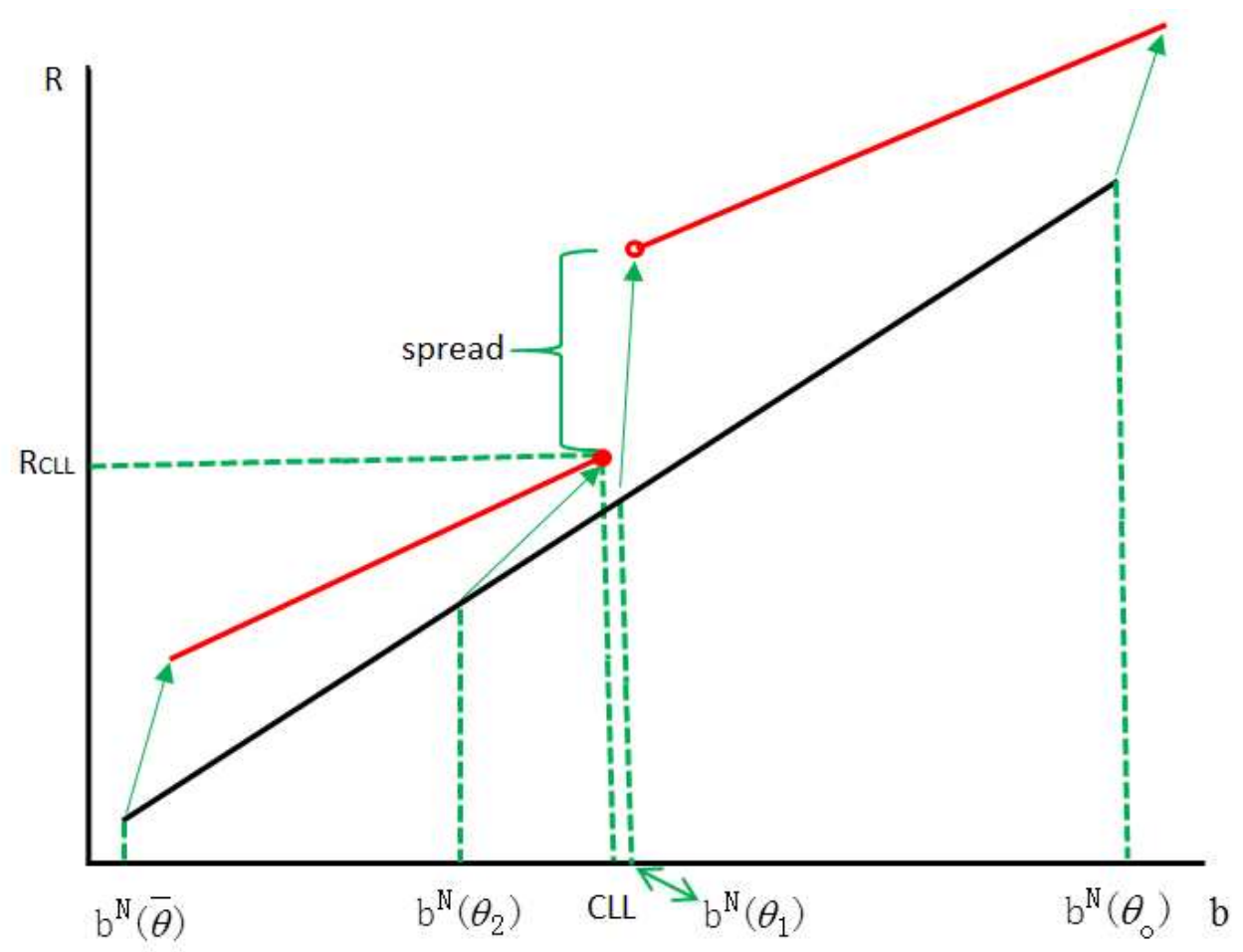

Figure 9: Optimal R-b schedule with and without subsidy.

$b$ is the loan size, $R$ is the gross interest rate, and $\theta$ is the unobservable quality index of the borrower. The superscript $Y$ and $N$ means with and without subsidy, respectively. The straight line on the bottom is the equilibrium in the counterfactual case without subsidy. 
As indicated by the northeast arrow in the left bottom of Figure 9, the introduction of the subsidy increases both the loan size and the interest rate for any given borrower quality $\theta$ until a cutoff type $\theta_{2}$ (the "strictly conforming group"). Borrowers who would borrow loans of sizes around CLL in the absence of the subsidy all "bunch" to borrow the same amount CLL at the same interest rate after the subsidy is introduced. And borrowers who would borrow an amount sufficiently larger than CLL in the absence of the subsidy are also affected in a similar way as the strictly conforming group, that is, both their loan amounts and interest rates are higher under the subsidy. Importantly, under the optimal contracts with subsidy, borrowers' incentive compatibility constraints imply that loans just above the CLL should still have higher interest rates than loans just below the CLL, otherwise type $\theta_{1}$ will deviate from his own contract and take instead the contract with a loan size just above the CLL, because doing so allows him to take a strictly larger loan size at a strictly lower interest rate. Hence, the observed jumbo-conforming spread is not necessarily an indication that the subsidy benefits conforming borrowers via interest rate reductions.

\section{Conclusion}

In this paper, I evaluate the effectiveness of the government subsidy done through the mortgage default insurance by the GSEs. I do so both empirically and theoretically. On the empirical front, I show that the supporting evidence for the conventional wisdom is subject to an endogeneity problem: the subsidy policy is implemented in terms of the loan size, which is endogenously chosen by the borrower and thus is affected by the subsidy policy. To circumvent this problem, I use the variation in interest rates generated by a mandate issued by U.S. Congress, the "special affordable goal" targeted at relatively poor borrowers. Since this mandate is implemented in terms of borrowers' incomes, which are unlikely to be manipulated by borrowers of GSE-insured loans, my empirical strategy provides a relatively clean way to identify the causal effect of the subsidy on interest rates. Using this strategy, I find that among the conforming loans, those with a discontinuously higher ex ante probability to receive the subsidy also have discontinuously higher interest rates, which implies that the subsidy has raised mortgage interest rates of conforming loans. Using various time-to-default models, I also show that the subsidy raises mortgage default rates, which serves as auxiliary supporting evidence for my model's predictions.

On the theoretical front, I propose a monopolistic screening model with asymmetric information to explain my seemingly counterintuitive empirical result, as well as to shed light on the welfare implications of the subsidy. My model illustrates that the bank's moral hazard problem is the key channel through which the subsidy has raised mortgage interest rates for conforming borrowers. Importantly, exactly because the subsidy allows the bank to more aggressively "exploit" borrowers by charging higher interest rates, the welfare of borrowers will be lower after the subsidy is introduced. This is true even if we do not consider the fact that borrowers have to pay higher taxes to finance the subsidy. In addition, consistent with conventional wisdom and my auxiliary empirical result, the model predicts that the subsidy induces borrowers to default more frequently, which threatens the financial stability.

There are two avenues for future research. On the empirical front, future work can apply the empirical strategies used in this paper to more detailed data so as to mitigate the measurement error problem. On the theoretical front, future work can extend the model to an oligopolistic case to explicitly examine the impacts of the subsidy under competition. 


\section{Appendices}

\section{Appendix A: Proof of Proposition 1}

PROOF: The proof is standard, once we reformulate the contract menu as $(T, b(T))$ instead of $(b, T(b))$, as explained in the text. The specific proof is as follows.

First, eliminate the transfer from borrower's problem as $b=-W(T, \theta)+U(\theta)$.

Second, simplify the bank's problem to a pointwise problem. Plugging $b$ into bank's objective function in problem (9), we can rewrite the bank's problem as

$$
\max _{(T(\cdot), b(.))} \int_{\theta_{0}}^{\bar{\theta}}[W(T(\theta), \theta)-U(\theta)+\Omega(T(\theta), \theta, 0)] f(\theta) d \theta
$$

subject to the same IR and ICFOC as in problem (9).

For the second term, use integration by parts:

$$
\begin{aligned}
\int_{\theta_{0}}^{\bar{\theta}} U(\theta) f(\theta) d \theta & =\int_{\theta_{0}}^{\bar{\theta}} U(\theta) d F(\theta) \\
& =\left.U(\theta) F(\theta)\right|_{\theta_{0}} ^{\bar{\theta}}-\int_{\theta_{0}}^{\bar{\theta}} F(\theta) U^{\prime}(\theta) d \theta \\
& =U(\bar{\theta})-\int_{\theta_{0}}^{\bar{\theta}} F(\theta) W_{\theta}(T(\theta), \theta) d \theta,
\end{aligned}
$$

where the last equality uses the differential version of the ICFOC.

Evaluate the ICFOC at $\theta=\bar{\theta}$, and we have $U(\bar{\theta})=\int_{\theta_{0}}^{\bar{\theta}} W_{\tau}(T(\tau), \tau) d \tau$. Hence:

$$
\begin{aligned}
\int_{\theta_{0}}^{\bar{\theta}} U(\theta) f(\theta) d \theta & =\int_{\theta_{0}}^{\bar{\theta}} W_{\tau}(T(\tau), \tau) d \tau-\int_{\theta_{0}}^{\bar{\theta}} F(\theta) W_{\theta}(T(\theta), \theta) d \theta \\
& =\int_{\theta_{0}}^{\bar{\theta}} W_{\theta}(T(\theta), \theta) d \theta-\int_{\theta_{0}}^{\bar{\theta}} F(\theta) W_{\theta}(T(\theta), \theta) d \theta \\
& =\int_{\theta_{0}}^{\bar{\theta}}[1-F(\theta)] W_{\theta}(T(\theta), \theta) d \theta \\
& =\int_{\theta_{0}}^{\bar{\theta}} \frac{1-F(\theta)}{f(\theta)} W_{\theta}(T(\theta), \theta) f(\theta) d \theta
\end{aligned}
$$

Plugging into the bank's objective function, we can simplify the bank's problem as choosing one function $T($.$) instead of two functions (T(),. b()$.$) :$

$$
\max _{T(.)} \int_{\theta_{0}}^{\bar{\theta}}\left[W(T(\theta), \theta)+\Omega(T(\theta), \theta, 0)-\frac{1-F(\theta)}{f(\theta)} W_{\theta}(T(\theta), \theta)\right] f(\theta) d \theta
$$

This problem is equivalent to the following pointwise maximization problem:

$$
\max _{T(.)} W(T(\theta), \theta)+\Omega(T(\theta), \theta, 0)-\frac{1-F(\theta)}{f(\theta)} W_{\theta}(T(\theta), \theta)
$$


The above simplified objective function has the standard interpretation: $W(T(\theta), \theta)+\Omega(T(\theta), \theta, 0)$ represents the social surplus of offering a type- $\theta$ contract in case of perfect information. However, the presence of information asymmetry requires the bank to give up a certain amount of information rent to the borrower: $W_{\theta}(T(\theta), \theta)$ is the amount the bank has to give up to each of the types higher than $\theta$, and there are $\frac{1-F(\theta)}{f(\theta)}$ of such types (relative to type- $\theta$ borrowers).

The third step is to take the derivative with respect to $T(\theta)$. Hence, we have

$$
W_{T}(T, \theta)+\Omega_{T}(T, \theta, 0)-\frac{1-F(\theta)}{f(\theta)} W_{\theta T}(T, \theta)=0,
$$

which is the rearranged version of equation (10) in Proposition 1. To ensure the above FOC corresponds to a maxima rather than a minima, we need the SOC as specified in Proposition 1.

Once we solve for $T(\theta)$ from equation (10), we can then plug into the ICFOC to get the equilibrium information rent $U(\theta)$, as given by equation (11) in Proposition 1. Finally, we can use the defintion of $U(\theta)$ to get $b(\theta)=-W[T(\theta), \theta]+U(\theta)$, and then $R(\theta)=\frac{T(\theta)}{b(\theta)}$.

Q.E.D.

\section{Appendix B: Proof of Proposition 3}

PROOF: Proposition 1 shows that the optimal compensation

$$
b(\theta)=-W(T(\theta), \theta)+U(\theta)=-W(T(\theta), \theta)+\int_{\theta_{0}}^{\theta} W_{\tau}(T(\tau), \tau) d \tau
$$

SO

$$
b^{\prime}(\theta)=-W_{T}(T(\theta), \theta) T^{\prime}(\theta)-W_{\theta}(T(\theta), \theta)+W_{\theta}(T(\theta), \theta)=-W_{T}(T(\theta), \theta) T^{\prime}(\theta)
$$

Using $W_{T}(T(\theta), \theta)<0$ and $T^{\prime}(\theta)<0$, we have $b^{\prime}(\theta)<0$.

Q.E.D.

\section{Appendix C: Proof of Lemma 2}

PROOF:

Want to show

$$
\frac{T}{b(T)} \frac{d b(T)}{d T}<1
$$
or

Since $\frac{d b(T)}{d T}=-W_{T}(T, \theta)$ by the FOC of the borrower, it sufficies to show $\frac{T}{b(T)}\left[-W_{T}(T, \theta)\right]<1$,

$$
b(T)>-T W_{T}(T, \theta)
$$

Rewrite $b(T)$ as $b(T)=b(0)+\int_{0}^{T}\left[\frac{d b(x)}{d x}\right] d x$. Using $b(0)=0$ and the borrower's FOC $\frac{d b(x)}{d x}=$ $-W_{T}(x, \theta)$, we have

$$
b(T)=0+\int_{0}^{T}\left[-W_{T}(x, \theta)\right] d x=-[W(T, \theta)-W(0, \theta)]
$$

Using (17), we can rewrite (16) as

$$
-[W(T, \theta)-W(0, \theta)]>-T W_{T}(T, \theta)
$$


Or,

$$
\frac{W(T, \theta)-W(0, \theta)}{T-0}<W_{T}(T, \theta)
$$

Note that the LHS of (18) is the slope of the secant line between two points $(T, W(T, \theta))$ and $(0, W(0, \theta))$, and the RHS is the slope of the tangent line passing through the point $(T, W(T, \theta))$.

Recall that $W_{T}(T, \theta)=-\beta\left[1-G\left(\bar{p}_{1}\right)\right]<0$, so

$$
W_{T T}(T, \theta)=\beta g\left(\bar{p}_{1}\right) \frac{1}{h_{0}}>0
$$

This establishes that for any given $\theta \in[\underline{\theta}, \bar{\theta}], W(T, \theta)$ is a strictly decreasing and strictly convex function in $T \in[0,+\infty)$. By the mathematical property of such a function, (18) holds (illustrated in Figure 10), and thus (15) holds.

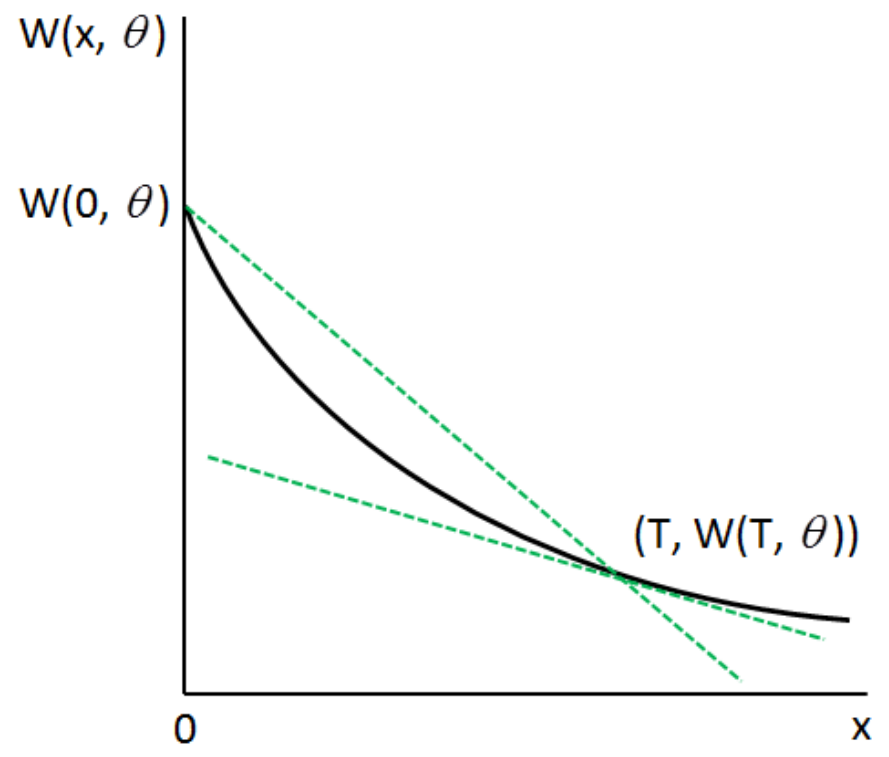

Figure 10: Strict convexity of $W$ function.

Hence, the elasticity of $b$ with respect to $T$ is strictly less than 1 for any optimal contract. Q.E.D.

\section{Appendix D: Proof of Proposition 4}

PROOF: The continuity of $R(\theta)$ is clear.

To show the strict monotonicity of $R(\theta)$, it is equivalent to showing

$$
R\left(\theta^{-}\right) \equiv \frac{T^{-}}{b^{-}}>R(\theta) \equiv \frac{T}{b}, \quad \forall \theta_{0}<\theta \leq \bar{\theta}
$$

or

$$
\frac{b^{-}}{b}<\frac{T^{-}}{T}
$$

where $\theta^{-} \equiv \theta-\epsilon$ for any $\epsilon>0, T^{-} \equiv T\left(\theta^{-}\right), b^{-} \equiv b\left(\theta^{-}\right), T \equiv T(\theta)$ and $b \equiv b(\theta)$. 
By the indifference condition (i.e., the incentive compatibility condition) of type $\theta: W(T, \theta)+$ $b=W\left(T^{-}, \theta\right)+b^{-}$, or,

$$
b^{-}=b-\left[W\left(T^{-}, \theta\right)-W(T, \theta)\right]
$$

The intuition of equation (20) is that the compensation for type $\theta-\epsilon, b^{-}$, should be larger than that for type $\theta$ by the difference in the two types' disutilities from their "tasks."

Plugging equation (20) into (19), (19) becomes

$$
\frac{b-\left[W\left(T^{-}, \theta\right)-W(T, \theta)\right]}{b}<\frac{T^{-}}{T}
$$

Subtract 1 from both sides:

$$
-\frac{W\left(T^{-}, \theta\right)-W(T, \theta)}{b}<\frac{T^{-}-T}{T}
$$

Since $T^{-}-T>0$ by the SCP, (19) becomes

$$
-\frac{W\left(T^{-}, \theta\right)-W(T, \theta)}{T^{-}-T}<\frac{b}{T}
$$

As in the proof of Lemma 2, we can rewrite $b$ as

$$
b(T)=0+\int_{0}^{T}\left[-W_{T}(x, \theta)\right] d x=-[W(T, \theta)-W(0, \theta)]
$$

Plugging into (21), we get

$$
-\frac{W\left(T^{-}, \theta\right)-W(T, \theta)}{T^{-}-T}<-\frac{W(T, \theta)-W(0, \theta)}{T-0}
$$

The LHS of (22) is the absolute value of the slope of the secant line between two points $\left(T^{-}, W\left(T^{-}, \theta\right)\right)$ and $(T, W(T, \theta))$ which are very close to each other; the RHS is the absolute value of the slope of the secant line between two points $(T, W(T, \theta))$ and $(0, W(0, \theta))$. Since $W(T, \theta)$ is strictly decreasing and strictly convex in $T$ (see the proof of Lemma 2), (22) and thus (19) hold.

Q.E.D.

\section{Appendix E: Proof of Lemma 4}

PROOF:

For any given $\theta \in\left(\theta_{2}, \bar{\theta}\right]$ (in the strictly conforming group), the bank will choose $T(\theta)$ according to:

$$
-W_{T}(T, \theta)=\Omega_{T}(T, \theta, \omega)+\frac{1-F(\theta)}{f(\theta)}\left[-W_{\theta T}(T, \theta)\right]
$$

Taking total derivatives with respect to $\omega$ on both sides for a given $\theta$ :

$$
-W_{T T}(T, \theta) \frac{d T}{d \omega}=\Omega_{T T}(T, \theta, \omega) \frac{d T}{d \omega}+\Omega_{T \omega}(T, \theta, \omega)+\frac{1-F(\theta)}{f(\theta)}\left[-W_{\theta T T}(T, \theta)\right] \frac{d T}{d \omega}
$$

Hence,

$$
\frac{d T}{d \omega}=\frac{\Omega_{T \omega}(T, \theta, \omega)}{-W_{T T}(T, \theta)-\Omega_{T T}(T, \theta, \omega)+\frac{1-F(\theta)}{f(\theta)} W_{\theta T T}(T, \theta)}
$$


By Assumption (7) in the text, we have $\Omega_{T \omega}(T, \theta, \omega)>0$, which is not a restrictive assumption because it is the key feature of the subsidy program considered in the paper.

That the denominator of $\frac{d T}{d \omega}$ being positive is just the SOC of the bank when designing the optimal contract. To make the analysis of optimal contracts meaningful, it is assumed to be satisfied, as in Proposition 1. Hence, $\frac{d T}{d \omega}>0$.

Q.E.D.

\section{Appendix F: Proof of Proposition 5}

It suffices to show $\frac{d R(\theta)}{d \omega}>0$ for all $0 \leq \omega \leq 1$. Using the definition of $R$, we have $\frac{d R(\theta)}{d \omega}=\frac{d\left[\frac{T(\theta)}{b(\theta)}\right]}{d \omega}=$ $\frac{1}{b^{2}}\left(\frac{d T}{d \omega} b-T \frac{d b}{d \omega}\right)=\frac{1}{b} \frac{d T}{d \omega}\left(1-\frac{T}{b} \frac{d b}{d T}\right)$. By Lemma 2, $1-\frac{T}{b} \frac{d b}{d T}>0$. And by Lemma $4, \frac{d T}{d \omega}>0$. Hence, $\frac{d R(\theta)}{d \omega}>0$ for all $\theta_{2}<\theta \leq \bar{\theta}$ and all $0 \leq \omega \leq 1$.

Q.E.D.

\section{Appendix G: Proof of Proposition 6}

It suffices to show $\frac{d b(\theta)}{d \omega}>0$ for all $0 \leq \omega \leq 1$. Firstly, we can decompose $\frac{d b}{d \omega}$ as $\frac{d b}{d \omega}=\frac{d b}{d T} \frac{d T}{d \omega}$. Secondly, note that $\frac{d b}{d T}=-W_{T}(T, \theta)>0$, and $\frac{d T}{d \omega}>0$ (by Proposition 5), we have $\frac{d b}{d \omega}>0$. Q.E.D.

\section{Appendix H: Proof of Proposition 7}

The welfare of type $\theta$ in the strictly conforming group is just the information rent $U(\theta)$, which is given by

$$
U(\theta)=U\left(\theta_{0}\right)+\int_{\theta_{0}}^{\theta} W_{\tau}(T(\tau), \tau) d \tau=\int_{\theta_{0}}^{\theta} W_{\tau}(T(\tau), \tau) d \tau, \quad \forall \theta \in\left(\theta_{2}, \bar{\theta}\right]
$$

where $W_{\tau}(T, \tau)=\frac{\partial U(\tau)}{\partial \tau}=\beta\left[1-G\left(\bar{p}_{1}(T, \tau)\right)\right] \times 1>0$ is the information rent to a borrower of type $\tau$.

Note that although the presence of the subsidy introduces a discontinuity to the schedule of $T(),. b($.$) and R($.$) , we can still use the above formula for the information rent. The reason is$ that the schdule of $U($.$) is still continuous in \theta$ despite the presence of the subsidy. This is in turn because the bank will always re-design the contract menu to eliminate any discontinuous jump in $U($.$) in order to extract the consumer rents as much as possible. In other words, the standard$ "smooth pasting" argument applies.

Using $\frac{d \theta_{0}}{d \omega}=0$ (see Appendix J), we have

$$
\frac{d U(\theta)}{d \omega}=\int_{\theta_{0}}^{\theta} W_{\tau T}(T(\tau), \tau) \frac{d T(\tau)}{d \omega} d \tau, \quad \forall \theta \in\left(\theta_{2}, \bar{\theta}\right]
$$

Since $W_{\tau T}(T(\tau), \tau)<0$ and $\frac{d T(\tau)}{d \omega}>0$, we have $\frac{d U(\theta)}{d \omega}<0, \quad \forall \theta \in\left(\theta_{2}, \bar{\theta}\right]$

\section{Appendix I: Proof of Proposition 8}

PROOF: The proof is analogous to that of Proposition 4 as in Appendix D. We only need to replace $\theta$ by $\theta_{1}, \theta^{-}$by $\theta_{1}^{-}$; accordingly, replace $T$ by $T_{C L L}$ and $b$ by $C L L$.

Q.E.D. 


\section{Appendix J: Effect of subsidy for jumbo group}

First, we can show that $T\left(\theta_{1}-\epsilon\right)$ (where $\epsilon>0$ is an arbitrarily small number) must increase as the subsidy is introduced. This can be established by the incentive compatibility condition of $\theta_{1}-\epsilon$ between his own contract $\left(b\left(\theta_{1}-\epsilon\right), T\left(\theta_{1}-\epsilon\right)\right)$ and $\theta_{1}^{\prime} s$ contract $\left(C L L, T_{C L L}\right)$.

Second, by the continuity and monotonicity of $T(\theta)$ in $\left[\theta_{0}, \theta_{1}\right)$, we can establish that

$$
T^{Y}(\theta)>T^{N}(\theta), \quad \forall\left[\theta_{0}, \theta_{1}\right) .
$$

Third, by the monotonicity of $b(T)$ schedule, we have

$$
b^{Y}(\theta)>b^{N}(\theta), \quad \forall\left[\theta_{0}, \theta_{1}\right) .
$$

Moreover, by Lemma 2, $T$ must increase faster than $b$, so we have

$$
R^{Y}(\theta)>R^{N}(\theta), \quad \forall\left[\theta_{0}, \theta_{1}\right) .
$$

The rest of this appendix is devoted to the discussion of $\theta_{0}$. Since the bank is monopolistic and is very likely to earn a positive total profit in equilibrium, we should pin down the lending threshold $\theta_{0}$ by using the FOC with respect to $\theta_{0}$, rather than the zero-profit condition of the bank (in terms of its total profit). Note that the reason why there is an FOC with respect to $\theta_{0}$ is that the bank still needs to choose the value of $\theta_{0}$ subject to all borrowers' IRs and ICs, including both within-group and across-group ICs.

Specifically, under the subsidy, the FOC for $\theta_{0}$ is

$$
\left[\Omega\left(T_{0}, \theta_{0}, 0\right)+W\left(T_{0}, \theta_{0}\right)\right] f\left(\theta_{0}\right)=W_{\theta}\left(T_{0}, \theta_{0}\right)\left[1-F\left(\theta_{0}\right)\right]
$$

where the LHS is again the marginal benefit through expanding the customer base by marginally decreasing $\theta_{0}$ : the bank obtains a profit of $\Omega\left(T_{0}, \theta_{0}, 0\right)-b\left(T_{0}\right)=\Omega\left(T_{0}, \theta_{0}, 0\right)+W\left(T_{0}, \theta_{0}\right)$ from each $\theta_{0}$ (using $U\left(\theta_{0}\right)=b\left(T_{0}\right)+W\left(T_{0}, \theta_{0}\right)=0$ ), and there are $f\left(\theta_{0}\right)$ of them. The RHS is the marginal cost of decreasing $\theta_{0}$ : a lower $\theta_{0}$ means all higher types will have more contracts to mimic, so the bank has to give up more information rents to all existing customers to ensure incentive compatibility.

Importantly, it is $\Omega\left(T_{0}, \theta_{0}, 0\right)$ rather than $\Omega\left(T_{0}, \theta_{0}, \omega\right)$ that enters equation (23). This is because all loans of types in the neighborhood of $\theta_{0}$ are of size larger than the CLL, and thus ineligible for the subsidy. When the bank makes the decision of decreasing or increasing $\theta_{0}$ by $\epsilon$, the bank cannot get any subsidy from loans in the neighborhood of $\theta_{0}$, so the subsidy does not affect the optimality condition of choosing $\theta_{0}$, equation (23). 


\section{References}

[1] Acharya, V., M. Richardson, S. Van Nieuwerburgh, and L. J. White (2011): "Guaranteed To Fail: Freddie, Fannie, and the Debacle of U.S. Mortgage Finance," Princeton University Press.

[2] Acharya, V., and T. Yorulmazer (2007): "Too Many to Fail - An Analysis of Time-inconsistency in Bank Closure Policies," Journal of Financial Intermediation, 16, 1-31.

[3] Adelino, M., A. Schoar, and F. Severino (2014): "Credit Supply and House Prices: Evidence from Mortgage Market Segmentation," NBER Working Paper, No. 17832.

[4] Ambrose, B. W., R. Buttimer, and T. Thibodeau (2001): "A New Spin on the Jumbo/Conforming Loan Rate Differential," Journal of Real Estate Finance and Economics, 23, 309-35.

[5] Ambrose, B. W., J. Conklin, and J. Yoshida (2016): "Credit Rationing, Income Exaggeration, and Adverse Selection in the Mortgage Market," Journal of Finance, 71, 2637-2686.

[6] Ambrose, B., M. LaCour-Little, and A. Sanders (2004): "The Effect of Conforming Loan Status on Mortgage Yield Spreads: A Loan Level Analysis," Real Estate Economics, 32, 541-69.

[7] Anzoategui, D., M. Chivakul, and W. Maliszewski (2015): "Financial Distortions in China: A General Equilibrium Approach," IMF Working Paper, No. 15/274.

[8] Avery, R., K. Brevoort, and G. Canner (2007): "Opportunities and Issues in Using HMDA Data," Journal of Real Estate Research, 29(4), 351-380.

[9] Bajari, P., S. Chu, and M. Park (2011): "An Empirical Model of Subprime Mortgage Default From 2000 to 2007," NBER Working Paper.

[10] Bhutta, N. (2012): "GSE Activity and Mortgage Supply in Lower-Income and Minority Neighborhoods: The Effect of the Affordable Housing Goals." Journal of Real Estate Finan Econ, 45, 238-261.

[11] Bhutta, N., J. Dokko, and H. Shan (2010): "The Depth of Negative Equity and Mortgage Default Decisions," Finance and Economics Discussion Series, Federal Reserve Board.

[12] Bubb, R., and A. Kaufman (2014): "Securitization and Moral Hazard: Evidence from Credit Score Cutoff Rules," Journal of Monetary Economics, 63, 1-18.

[13] Burgess, G., S. M. Sherlund, and W. Passmore (2005): "The Effect of Housing Government-Sponsored Enterprises on Mortgage Rates," Real Estate Economics, 33 (3), 427-463.

[14] Chambers, M., C. Garriga, and D. E. Schlagenhauf (2009): "Housing Policy and the Progressivity of Income Taxation," Journal of Monetary Economics, 56(8), 1116-1134.

[15] Cotterman, R. F., and J. E. Pearce (1996). Studies on Privatizing Fannie Mae and Freddie Mac, Chapter The Effects of the Federal National Mortgage Association and the Federal Home Loan Mortgage Corporation on Conventional Fixed-Rate Mortgage Yields, pp. 97-168. U.S. Department of Housing and Urban Development, Office of Policy Development and Research.

[16] DeFusco, A. A., and A. Paciorek (2014): "The Interest Rate Elasticity of Mortgage Demand: Evidence from Bunching at the Conforming Loan Limit," Finance and Economics Discussion Series, Federal Reserve Board.

[17] Edlin, A., and C. Shannon (1998): "Strict Monotonicity in Comparative Statics," Journal of Economic Theory, (81), 201-19.

[18] Elenev, V., T. Landvoigt, and S. Van Nieuwerburgh (2015): "Phasing out the GSEs," Working Paper, NYU Stern.

[19] Elul, R., N. S. Souleles, S. Chomsisengphet, D. Glennon, and R. Hunt (2010): "What Triggers Mortgage Default?" American Economic Review: Papers 83 Proceedings, 100, 490-494.

[20] Farhi, E., and J. Tirole (2012): "Collective Moral Hazard, Maturity Mismatch, and Systemic Bailouts," American Economic Review, 102(1): 60-93.

[21] Floetotto, M., Michael K., and J. Stroebel (2016): "Government Intervention in the Housing Market: Who Wins, Who Loses?" Journal of Monetary Economics, 80 (C), 106-123.

[22] Frame, W. S., L. D. Wall, and L. J. White (2013): "The Devil's in the Tail: Residential Mortgage Finance and the U.S. Treasury," Journal of Applied Finance, 23, 61-83.

[23] Fuster, A., and J. Vickery (2015): "Securitization and the Fixed-Rate Mortgage," Review of Financial Studies, 28 (1): 176-211.

[24] Gerardi, K., K. F. Herkenho, L. E. Ohanian, and P. S. Willen (Forthcoming): "Unemployment, Negative Equity, and Strategic Default," Review of Financial Studies.

[25] Gerardi, K., A. H. Shapiro, and P. Willen (2007): "Subprime Outcomes: Risky Mortgages, Homeownership Experiences, and Foreclosure," Working Paper No. 07-15, Federal Reserve Bank of Boston.

[26] Gervais, M. (2002): "Housing Taxation and Capital Accumulation," Journal of Monetary Economics, 49(7), 1461-1489. 
[27] Guiso, L., P. Sapienza, and L. Zingales (2013): "The Determinants of Attitudes Toward Strategic Default on Mortgages," Journal of Finance, 68 (4), 1473-1515.

[28] Guttentag, J. (2010): "The Mortgage Encyclopedia," 2nd edition, McGraw-Hill Companies, Inc.

[29] Imbens, G., and Lemieux, T. (2008): "Regression Discontinuity Designs: A Guide to Practice," Journal of Econometrics, 142(2), 615-635.

[30] Jeske, K., D. Krueger, and K. Mitman (2013): "Housing, Mortgage Bailout Guarantees and the Macro Economy," Journal of Monetary Economics, 60 (8).

[31] Jiang, W., A. A. Nelson, and E. Vytlacil (2014): "Liar's Loan? Effects of Origination Channel and Information Falsification on Mortgage Delinquency," Review of Economics and Statistics, 96, 1-18.

[32] K., Kei, K. Onishi, and K. Uetake (2013): "Signaling in Online Credit Markets," Working Paper.

[33] Kaufman, A. (2014): "The Influence of Fannie and Freddie on Mortgage Loan Terms," Real Estate Economics, $42(2), 472-496$.

[34] Keys, B. J., T. Mukherjee, A. Seru, and V. Vig (2010): "Did Securitization Lead to Lax Screening? Evidence from Subprime Loans," Quarterly Journal of Economics, 125 (1), 307-362.

[35] Keys, B. J., A. Seru, and V. Vig (2012): "Lender Screening and the Role of Securitization: Evidence from Prime and Subprime Mortgage Markets," Review of Financial Studies, 25 (7), 2071-2108.

[36] Kim, M., D. Kligera, and B. Vale (2003): "Estimating Switching Costs: the Case of Banking," Journal of Financial Intermediation, 12 (1), 25-56.

[37] Kirk, D. E. (2004): Optimal Control Theory: An Introduction, Prentice-Hall.

[38] LaCour-Little, M., and J. Yang (2013): "Taking the Lie out of Liar Loans: The Effect of Reduced Documentation on the Performance and Pricing of Alt-A and Subprime Mortgages," Journal of Real Estate Research, $35,507-553$.

[39] Lee, D. S., and T. Lemieux (2010): "Regression Discontinuity Designs in Economics." Journal of Economic Literature, 48(2): 281-355.

[40] Lucas, D., and R. McDonald (2010): "Valuing Government Guarantees: Fannie and Freddie Revisited," In Measuring and Managing Federal Financial Risk, edited by Deborah Lucas., Chicago: University of Chicago Press.

[41] Maskin, E. and J. Riley (1984): "Monopoly with Incomplete Information," Rand Journal of Economics, 15, 171-196.

[42] Mayer, C., and P. Karen (2009): "Subprime Mortgages: What, Where, and to Whom?" In Housing Markets and the Economy: Risk, Regulation, and Policy: Essays in honor of Karl E. Case.

[43] McKenzie, J. (2002): "A Reconsideration of the Jumbo/Non-jumbo Mortgage Rate Differential," Journal of Real Estate Finance and Economics, 25, 197-214.

[44] Mian, A., and A. Sufi (Forthcoming): "Fraudulent Income Overstatement on Mortgage Applications During the Credit Expansion of 2002 to 2005," Review of Financial Studies.

[45] Mirrlees, J. A. (1971): "An Exploration in the Theory of Optimum Income Taxation," Review of Economic Studies, 38 (2), 175-208.

[46] Moulton, S. (2014): "Did Affordable Housing Mandates Cause the Subprime Mortgage Crisis?" Journal of Housing Economics, 24, 21-38.

[47] Naranjo, A., and A. Toevs (2002): "The Effects of Purchases of Mortgages and Securitization by Government Sponsored Enterprises on Mortgage Yield Spreads and Volatility," Journal of Real Estate Finance and Economics, 25, 173-96.

[48] Passmore, W. (2005): "The GSE Implicit Subsidy and the Value of Government Ambiguity," Real Estate Economics, 33 (3), 465-486.

[49] Passmore, W., R. Sparks, and J. Ingpen (2002): "GSEs, Mortgage Rates, and the Long-Run Effects of Mortgage Securitization," Journal of Real Estate Finance and Economics, 25, 215-42.

[50] Piskorski, T., and A. Tchistyi (2010): "Optimal Mortgage Design," Review of Financial Studies, 23 (3), 98-140.

[51] Poterba, J., and T. Sinai (2011): "Revenue Costs and Incentive Effects of the Mortgage Interest Deduction for Owner-Occupied Housing," National Tax Journal, 64 (2, Part 2), 531-564.

[52] Poterba, J., and T. Sinai (2008): Tax Expenditures for Owner-Occupied Housing: Deductions for Property Taxes and Mortgage Interest and the Exclusion of Imputed Rental Income," American Economic Review: Papers \& Proceedings, 98 (2), 84-89.

[53] Segal, I. (2012): "Lecture Notes in Contract Theory," Stanford University.

[54] Sharpe, S. A. (1990): "Asymmetric Information, Bank Lending and Implicit Contracts: A Stylized Model of Customer Relationships," Journal of Finance, 45 (4), 1069-1087. 
[55] Sherlund, S. M. (2008): "The Jumbo-Conforming Spread: A Semiparametric Approach," Finance and Economics Discussion Series, Federal Reserve Board.

[56] Sommer, K., and P. Sullivan (2013): "Implications of U.S. Tax Policy for House Prices, Rents and Homeownership," Working Paper, Federal Reserve Board of Governors.

[57] Stiglitz, J. E., and A. Weiss (1981): "Credit Rationing in Markets with Imperfect Information," American Economic Review, 71 (3), 393-410.

[58] Tirole, J. (1994): "The Theory of Industrial Organization," MIT Press.

[59] Topkis, D. (1998): "Supermodularity and Complementarity," Princeton University Press. 